Ann. Abeille, I963, 6 (2), 85-I59.

\title{
LES LAVANDES ET L'APICULTURE DANS LE SUD-EST DE LA FRANCE
}

\author{
E. BARBIER
}

Station expérimentale d'Agrumiculture, Centre de Recherches agronomiques d'Algérie, Boufarite

\section{SOMMAIRE}

\section{I. - Botanique Des lavandes}

A. - Le genre Lavandula, principalement en France

B. - Lavandes et Lavandins

I) Ressemblances

2) Différences
a) Hampe florale
b) Bractées et bractéoles
c) Pollen
d) Essences

\section{II. - BIologie DES LAVANDES ET LAVANDINS}
A. - Développement végétatif
1) Technique
2) Allongement des hampes
3) Évolition du poids des hampes
B. - Évolution florale
I) Apparition des fleurs sur l'épi
2) Rythme journalier de la foraison
3) Époque et intensité de la floraison
4) Durée de vie de la corolle

III. - VALEUR APICOLE, PRINCIPALEMENT DES LAVANDINS
A. - Le nectar
I) Étude de la sécrétion nectarifère
2) Le nectar récolté par les abeilles
3) Composition chimique des nectars
B. - Les miels de Lavandin
I) Richesse en pollen et spectre pollinique
2) Couleur
3) Pente de la courbe de neutralisation des acides libres
4) Composition chimique
5) Teneur en eau


IV. - PROBL ĖMES POSÉS PAR LE BUTINAGE DES ABEIL LAVANDES ET LAVANDINS

A. - Les abeilles et la production des essences

1) Réaction des lavandins au butinage

2) Réaction d'une lavande vraie au butinage

B. - Activité des abeilles et densité des ruches

I) Évaluation de la production mellifère d'un lavandin

2) Intensité du butinage

\section{Conclusion}




\section{CHAPITRE I}

\section{BOTANIQUE DES LAVANDES}

\section{A. - Le genre Lavandula, principalement en France}

Dans le monde, le genre Lavandula est représenté par un nombre assez restreint d'espèces. L'Index Kewensis et ses suppléments en énumèrent 29, mais il est possible que certaines ne soient que des sous-espèces ou même des formes végétatives d'espèces bien définies. La répartition du genre Lavandula est limitée à 1'hémisphère nord et plus particulièrement aux régions à climat sec et chaud de type méditerranéen.

Actuellement, le genre est bien représenté dans l'ouest du Bassin méditerranéen : Italie, France, péninsule Ibérique et surtout Afrique du Nord. Vers l'est on en trouve en Grèce, Syrie, Palestine, Figypte et jusqu'aux Indes.

Mais il est probable qu'aux époques anciennes les lavandes couvraient tout le nord du continent africain. En effet, des lavandes existent en Érythrée, en Somalie et aux confins soudano-égyptiens ; deux espèces, Lavandula coronopifolia PorRET et Lavandula antineae MAIRE (MAIRE, I933) peuplent le Hoggar, et enfin plusieurs lavandes se trouvent dans les îles Canaries et du Cap-Vert.

Les différentes espèces ont été groupées par CHAYTOR (citée par GA'T'TEFOSSE, I939) en 5 sections dont deux seulement intéressent la France.

$\left.I^{\circ}\right)$ Section Stoechas avec Lavandula Stoechas L. et, çà et là, L. dentata L., en culture dans les jardins du Midi,

$2^{\circ}$ ) Section Spica avec Lavandula latifolia viLL, et L. vera D. C, sans oublier leurs hybrides désignés sous le nom de "Lavandin ".

\section{I. - Iavandula Stoechas L.}

Appelée en français lavande maritime et en provençal Keirelet ou Kairelet, cette lavande croît abondamment sur les terrains siliceux des régions méditerranéennes.

On la trouve principalement dans les massifs des Maures, du Tanneron et de 1'Estérel, sur les collines entre Cannes et Golfe-Juan, dans les Cévennes, les Corbières et jusqu'en Dordogne; mais elle se développe aussi dans les terrains dolomitiques privés de calcaire en arrière d'Antibes où elle a été signalée par DrouineAu et GUINOCHE:T (I944), et où nous avons pu constater que son abondance en certains points lui confère même un léger intérêt apicole.

Elle est également abondante dans les îles d'Hyères ou îles Stoechades d'où viendrait son nom. 
DiOscorides cité par le Dr T. B. (I926) n’écrivait-il pas : «Le Stoechas (Stica) croîst auprès des Gaules en certaines îles étant vis-à-vis de Marseille, qui sont ainsi nommées stoechas et dont cette herbe aprins le nom. "A moins que ce nom ne vienne tout simplement de l'alignement des fleurs sur l'épi. L.e Dr T. B. (I926) donne comme définition $\mathrm{du}$ mot Stoechades : vient du grec stoichades et signifie " rangées en lignes".

Par ailleurs la lavande maritime n'est pas limitée au territoire français. Elle existe dans tout le Bassin méditerranéen, en Espagne, en Algérie et notamment en Grèce ; aussi est-il probable que cette lavande était connue des Grecs bien avant qu'ils ne se lancent dans des expéditions maritimes relativement lointaines. Ces remarques permettent de penser que le nom de Stoechas pourrait provenir de l'alignement des fleurs et non pas de la présence de cette lavande dans les îles Stoechades ; c'est d'ailleurs 1'opinion de Fournier (I946).

Lavandula Stoechas se distingue facilement des autres lavandes de la flore française grâce à ses rameaux courts, feuillés sur toute leur longueur jusqu'à l'épi.

Les feuilles opposées, petites et étroites, sont couvertes sur leurs deux faces d'un duvet de poils ramifiés au milieu desquels apparaissent, surtout sur la face inférieure, des cellules à essence.

L'épi lui-même est court; il mesure 20 à $30 \mathrm{~mm}$ et est constitué par des bractées colorées en violet à l'aisselle desquelles se développent les fleurs.

Les corolles, d'un violet foncé, sont alignées sur quatre rangs qui donnent à l'épi une forme quadrangulaire bien caractéristique.

L'épi est surmonté par quatre bractées très développées et colorées en bleuviolet d'un bel effet, ce qui les fait prendre au premier abord pour les fleurs véritables.

Dans 1'Estérel la floraison de cette plante se situe de la mi-février à la fin mai. Elle est activement butinée par les abeilles et on retrouve son pollen dans les miels récoltés sur le littoral provençal entre Hyères et Antibes.

En France, la production de miel par cette plante reste exceptionelle. BARBIER et PANGaUd (I96I) donnent les caractéristiques physicochimiques et la composition pollinique de " miels unifloraux " de lavande maritime. Signalons encore que sa cristallisation est souvent assez grossière.

Par contre cette plante est si abondante en Espagne que son miel y est assez courant.

Du point de vue parfum, Lavandula Stoechas aurait été utilisée par les Grecs et plus tard par les Romains; mais l'essence qu'on peut en extraire a une odeur très forte et désagréable. IGoLEN (I944) la qualifie de grossière et de camphrée. Elle n'est pas utilisée en parfumerie actuellement et son extraction n'est pas pratiquée.

Sur les feuilles, on trouve comme chez les autres espèces, des cellules à essence en petit nombre; leur diamètre avoisine $37 \mu$. Ces cellules sont très rares sur la corolle oì elles mestrent jusqu'à $75 \mu$. Mais, contrairement à ce qui existe chez Lavandula vera $\mathrm{D}$. C. et Lavandula latifolia VILL., les cellules à essence sont rares sur le calice.

C'est dans cette particularité anatomique qu'il faut voir la cause essentielle des très faibles rendements signalés pour cette plante (IGOLEN, I944), rendements que nous avons nous-mêmes retrouvés au cours de distillations effectuées sur des plantes récoltées dans le massif du Tanneron (Alpes-Maritimes). 


\section{2 - LaVANDUla Latifolia Vil.L.}

Cette lavande a pour synonyme L. Spica L. (en partie), L. Spica D. C. ; elle est appelée en français grande lavande ou lavande mâle. La plante étant hermaphro dite, ce terme indique ici le développement et non pas le sexe, mais c'est sous le nom de Spic ou d'Aspic que cette lavande est le plus souvent désignée.

C'est un sous-arbrisseau à souche ramifiée; ses feuilles sont larges et couvertes d'un duvet blanchâtre plus ou moins abondant; les hampes florales, longues de 50 à $70 \mathrm{~cm}$, feuillées principalement à la base, portent à l'extrémité un épi floral peu fourni accompagné de deux épis secondaires qui prennent naissance à quelque distance en dessous de l'épi principal.

Les épillets prennent naissance à l'aiselle d'une bractée très étroite accompagnée de bractéoles linéaires.

Les fleurs, assez semblables à celles des lavandes vraies, sont plus petites 'et d'un bleu-violet assez variable; elles apparaissent tardivement par rapport à celles de la lavande vraie. C'est ainsi que dans les Basses-Alpes, près de Riez, alors que Lavandula zera $\mathrm{D}$. C. commence à fleurir dès le $\mathrm{I} 7$ juin (en $\mathrm{I}_{95} 8$ ) les premières fleurs de l'Aspic n'apparaissent qu'à partir de fin juillet.

L'Aspic est une plante robuste, peu exigeante et adaptée aux terrains calcaires ; ses racines profondes lui permettent de résister à la sécheresse et l'amertume de ses feuilles la protège de la dent des moutons et des chèvres, aussi reste-t-elle longtemps en place (LAMOTHE, I926).

Par contre, sensible au froid, cette plante ne dépasse pas les limites de l'olivier et du chêne-vert depuis le niveau de la mer jusque vers $600 \mathrm{~m}$ d'altitude. On la trouve en France en bordure de la Méditerranée, entre les frontières d'Italie et d'Iispagne ; occupant une étroite bande de terrain dans les Alpes-Maritimes entre Menton et Grasse, son aire s'élargit dans le département du Var et des Basses-Alpes et remonte la vallée du Rhône, mais c'est dans le Languedoc que l'Aspic couvre de vastes étendues en bordure des Cévennes, des Causes, de la montagne Noire et des Corbières.

Selon les régions on a signalé différentes variétés de Lavandula latifolia VILI. : variété tomentosa aux feuilles très duveteuses, localisée aux Alpes-Maritimes, variété erigens particulière à 1'Hérault, variété inclinans à épis longs, aigus et retournés à l'extrémité, dans les Bouches. du-Rhône,

variété intermpta dont l'épi est interrompu à la base, mais cette forme d'épi est assez commune chez Lavandula vera D. C. et chez les lavandins, variété lanata enfin, en Eispagne.

Sans pour cela définir des variétés, PAULET (I96I) en cultivant de nombreux échantillons provenant des divers départements méditerranéens, remarque la grande diversité de forme des épis, de taille des plantes, de couleur des fleurs et de parfum.

Il constate aussi que les plantes cultivées acquièrent un plus grand développement que celui atteint dans la garrigue. Nous verrons plus loin ces mêmes différences pour la lavande vraie.

On retrouve Lavandula latifolia viL.. en Afrique du Nord, mais en Espagne elle est si abondante que ce pays est le principal producteur d'essence d'Aspic.

Fin France, l'extraction de cette essence était localisée au Languedoc, mais elle 
est actuellement presque abandonnée car son prix de revient élevé ne permet pas de lutter avec celui des essences d'Espagne, ni avec celui des essences de lavandin, ces dernières étant d'ailleurs de qualité nettement supérieure.

L'extraction de l'essence d'Aspic se pratique comme celle de lavande vraie, mais les rendements sont très faibles. LAMOTHE (I926) cite 0,45 p. Ioo et nous avons obtenu dans les conditions les plus favorables $0,30 \mathrm{p}$. roo par rapport au poids vert ou 0,56 p. Ioo par rapport au poids sec, pour des coupes réalisées dans les BassesAlpes dans une "spiqueraie " naturelle où les plantes avaient un développement assez médiocre.

De couleur jaune pâle, l'essence d'Aspic a une densité comprise entre 0,904 et 0,922 . Elle est soluble dans $\mathrm{r}, 2$ à 2,5 volumes d'alcool à $70^{\circ}$. Son odeur rappelle celle de la lavande vraie mais elle est plus forte et camphrée. Sa composition est d'ailleurs caractérisée par la présence, en quantité notable, de bornéol et de camphre et d'une faible proportion d'esters qui varie de 4 à II p. Ioo. N'étant pas employée en parfumerie, elle était réservée à des préparations médicinales vétérinaires et à la savonnerie où elle est maintenant remplacée par l'essence de lavandin.

\section{3. - Lavandula Vera D. C.}

Synonymes : Lavandula Spica L. (en partie) = Lavandula officinalis CHAIX = Lavandula angustofolia MIL $=$ Lavandula vulgaris LAMARK. En français elle est appelée lavande vraie ou lavande fine.

C'est un sous-arbrisseau à souche ramifiée et en général moins développée que celle de l'espèce précédente.

Les feuilles sont étroites, linéaires, roulées sur les bords et couvertes de poils ramifiés; à leur face intérieure on peut remarquer des cellules à essence bien développées.

Les hampes florales sont fines et d'un développement médiocre (20 à $40 \mathrm{~cm}$ ), fetillées principalement à leur partie inférieure. Ellles sont terminées par un épi allongé et simple. Celui-ci est constitué par un nombre variable d'épillets qui prennent naissance à la base d'une bractée large et enveloppante accompagnée de bractéoles linéaires très petites, les premiers étant parfois bifides et souvent ailés, les épillets étant plus ou moins distants les uns des autres et plus ou moins fournis en calices.

Ces particularités donnent à l'épi de lavande une allure très variable et on connaît des lavandes à épis courts, longs, gros, fins, pointus et même échevelés.

I a corolle, soudée en tube, étale à l'extérieur du calice deux lèvres; la supérieure a deux lobes et l'inférieure en a trois. Sa couleur est bleu lavande pâle à foncé parfois teinté de rose, et il existe çà et là des individus à fleurs blanches.

Le calice, tubulaire et plus ou moins renflé, porte à son sommet cinq dents. Sur toute sa longueur il est plissé par treize sillons dont la crête est recouverte par des poils ramifiés, plus ou moins nombreux, dirigés vers l'extérieur et de couleur blanchâtre à violette plus ou moins intense. Sous les poils ramifiés qui constituent une sorte de manchon et dirigés vers le creux des sillons, on peut remarquer des cellules à essence très développées.

Ajoutons à cela qu'il existe des individus à port plus ou moins remontant, à précocité variable et que d'autre part, comme nous le verrons plus loin, chaque plant semble bien avoir une essence particulière, tant pour sa composition chimique 
et ses caractéristiques physiques que pour son parfum et que cette essence est produite en plus ou moins grande abondance; on aura alors une idée de la multiplicité extraordinaire des caractères individuels pouvant se trouver dans l'espèce.

'Toutefois, en examinant le développement des lavandes, deux grandes divisions peuvent être faites et JORDAx a voulu voir deux sous-espèces qu'il a désignées sous les noms de Lavandula fragrans à rameaux grêles, à épis courts, à forme ramassée et de Lavandula delphinensis à rameaux plus puissants, à épis plus longs et plus fournis.

Les essences fournies par ces deux sous-espèces étant d'ailleurs très différentes, celle de Lavandula fragrans serait plus fine et plus odorante alors que celle de Lavandula delphinensis serait plus riche en esters.

Mais FONIARD (I922) a montré que la division de l'espèce en deux sous-espèces était factice; les caractères fragrans sont ceux de toute lavande poussant en lieux secs et très ensoleillés c'est-à-dire à 1' " adret " ou face sud du relief, alors que les caractères delphinensis sont ceux que prennent les lavandes poussant dans des lieux moins ensoleillés et surtout plus humides, ces conditions écologiques se trouvent réunies à l' "ubac " c'est-à-dire à la face nord du relief.

Lavandula pyrenaica BENTH a été signalée dans les Pyrénées commme espèce particulière.

En culture, les lavandes prennent la forme delphinensis grâce à un sol profond et aux soins culturaux qui ont pour conséquence une augmentation des réserves hydriques mises à la disposition des plantes.

C'est ainsi que dans la collection d'étude constituée à Nice avec diverses "variétés " de lavandes cultivées : "Maillette ", "Matheronne ", "Verte " et de lavandes satuvages récoltées en divers lieux : Castillon, Lambruisse, Digne dans les BassesAlpes, Plan du Caujuers dans le haut Var, plateau de Caussols, col de Bleine, col de Braus, La Brigue dans les Alpes-Maritimes, nous avons pu remarquer comme l'avait fait FONDARD (I922) que les lavandes sauvages qui appartenaient à la forme fragrans prenaient en culture un développement important et acquéraient ainsi les caractères delphinensis.

Nous avons pu remarquer aussi que toutes les lavandes en collection conservaient leurs caractères individuels : couleur de la corolle, pilosité des feuilles et du calice, etc. Par ailleurs, chacune atteignait un développement particulier et possédait des épis ayant une forme spéciale.

En somme, l'espèce se présente comme une population hautement hétérogène. L'aspect d'un champ de lavandes cultivées, dont la plantation a été faite avec les plants sauvages récoltés dans la montagne voisine, donne bien un aperçu de la richesse considérable du patrimoine génétique des lavandes. Toutes les formes, les développements, les pilosités, les couleurs des corolles, les précocités se trouvent réunies et pourtant cet échantillonnage n'intéresse qu'une partie forcément très réduite des formes que 1'on peut rencontrer dans l'aire d'extension de l'espèce.

Dans la pratique, certains plants considérés comme intéressants du point de vue de leur rendement ont fait l'objet d'une multiplication par voie végétative et c'est ainsi que le bouturage a permis la création de véritables "clones " ou " cultivars" d'une parfaite homogénéité comme la "Maillette ", la "Matheronne ", la "Verte ", etc. dont on verra par ailleurs l'intérêt pour aborder l'étude des rendements et de l'évolution des caractéristiques des essences de lavande. Mais la mise en culture de ces 
"variété " a été plus ou moins heureuse. Celle de la "Matheronne " notamment a été particulièrement catastrophique pour les producteurs qui se sont intéressés à elle puisque son essence n'étant plus acceptée par les parfumeurs les plantations, ont dî être arrachées bien avant qu'elles n'aient atteint leur limite d'âge.

A l'état spontané, Lavandula vera $\mathrm{D}$. C. est commune à tout le Bassin méditerranéen, mais c'est surtout en France et principalement en Provence qu'elle couvre de vastes surfaces en bordure des Alpes.

On la trouve en grande abondance sur les terrains calcaires du Jurassique et du Crétacé entre 500 et I $500 \mathrm{~m}$ d'altitude mais, en dehors de ces limites, elle existe encore vers I 800 à $2000 \mathrm{~m}$ et elle a été signalée à moins de $400 \mathrm{~m}$; ajoutons qu'en culture elle végète très bien à Nice au voisinage de la mer.

A l'ouest du Rhône on retrouve encore cette lavande en bordure du Massif central notamment dans les Causses et également dans les Pyrénées.

\section{4. - LES LAVANDINS}

Alors que les plantes énumérées ci-dessus représentent des espèces au sens botanique du mot, les lavandins, au contraire, constituent un groupe d'individus sensiblement différents les uns des autres et ressemblant d'après GiraUd (I927) tantôt à Lavandula latifolia VIL L et tantôt à Lavandula vera D. C., mais ces individus ont pour caractère commun un développement nettement plus important que celui de chacune de ces espèces.

\section{a) Historique}

Les coupeurs de lavande et les distillateurs connaissaient bien ces individus qu'ils désignaient par les noms de grosse lavande, grande lavande, lavande bâtarde ou lavandins, et ils avaient remarqué que ces plantes apparaissaient dans les populations de lavande fine poussant à faible altitude.

Les essences obtenues à partir des lavandes récoltées dans ces lieux avaient, en même temps qu'un rendement élevé, des caractéristiques différentes de celles provenant de lavandes récoltées plus haut en montagne et leur parfum particulier se rapprochait de celui des essences d'Aspic ; ce qui faisait dire qu'à basse altitude, la lavande dégénérait ou "s'aspiquait".

On doit à BrRkenstock (cité par IGOLEN, I944) d'avoir démontré que ce phénomène était dû̀ à la présence des lavandins.

\section{b) Origine et formation}

Ces plantes avaient été reconnues çà et là par des botanistes et décrites comme étant des hybrides; certaines avaient été désignées sous les noms de :

\begin{tabular}{|c|c|}
\hline Lavandula Spica latifolia ... & Ar,BERT, I 875 \\
\hline Lavandula Burnati & BRIQUET \\
\hline Lavandula hortensis.... & Abbé Hy, I 888 \\
\hline Lavandula aurigerana & MAII \\
\hline Lavandula Latifolia pyrenaica & SENNEN, I 897. \\
\hline
\end{tabular}


Le caractère hybride des lavandins est donc reconnu par les botanistes et on les trouve dans les flores courantes sous les dénominations de Lavandula Burnati BRIQUET $=$ Lavandula latifolia $\times$ officinalis CHATANIER $=$ Lavandula hybrida Reverchon; mais on doit au Service agricole des Établissements ChIRIs (I926) d'en avoir fait pour la première fois la démonstration expérimentale en fécondant des fleurs de Lavandula latifolia viLr, préalablement castrées avec du pollen de Lavandula vera D. C.

Sur les fleurs pollinisées six graines furent récoltées et le semis donna naissance à deux individus qui furent reconnus comme étant des lavandins.

Dans la nature, l'hybridation des deux espèces, aux aires de végétation et aux époques de floraison différentes, est rendue possible grâce aux particularités suivantes :

$\left.I^{\circ}\right)$ La différence entre les altitudes auxquelles se développent les deux espèces n'est pas aussi tranchée qu'on pourrait le croire ; Lavandula latifolia viL, s'élève jusqu'à 600 à $800 \mathrm{~m}$ en certains points et Lavandula vera D. C. descend souvent à moins de $400 \mathrm{~m}$, si bien qu'il y a des zones où végètent en mélange les deux espèces et c'est précisément là qu'apparaissent les lavandins.

$2^{\circ}$ ) Les époques de floraison précédemment indiquées sont valables pour des floraisons normales, dont les débuts sont séparés par trente à quarante jours, mais la floraison de Lavandula vera I). C. se prolonge pendant plus d'un mois (dans nos relevés, du $I_{7}$ juin à fin juillet). De plus, des pluies tardives au printemps favorisent une floraison plus échelonnée grâce à des épis de deuxième pousse dont les fleurs plus tardives augmentent la possibilité de production de pollen.

Il faut compter également sur des types à floraison très tardive ou sur des végétaux ayant subit un retard anormal de végétation. C'est ainsi que des plantes, dont les hampes avaient été coupées au moment où apparaissaient les premières fleurs, ont donné une seconde pousse dont les fleurs sont écloses à partir du 23 août, soit un mois après l'apparition des fleurs de 1'Aspic.

I)ans la pratique, des résultats voisins ou moins extrêmes peuvent être obtenus par traumatisme ou encore par l'intermédiaire de jeunes plants provenant de semis dont la floraison tardive correspond à peu près à celle de l'aspic.

$3^{\circ}$ ) La pollinisation croisée, responsable de l'hybridation entre les deux espèces, est toujours possible grâce aux nombreux insectes qui butinent les fleurs sans faire de discrimination botanique; les deux espèces leur fournissent d'ailleurs nectar et pollen.

Au sujet de cette pollinisation, Humber' (IgIg) indique qu'elle serait provoquée probablement par les insectes ou encore par le vent, mais cette dernière hypothèse ne peut être retenue en raison de la couche de matières "graisseuses " qui agglutine le pollen. Cette particularité fait que la pollinisation des lavandes exige une intervention extérieure et, compte tenu de la présence du nectar, cette pollinisation est obligatoirement entomophile.

Dans une expérimentation relatée par ailleurs (BARBIER, I962) il a été constaté que les lavandes vraies de la "variété " "Matheronne " produisent dans les conditions normales de très nombreuses graines (Io p. IOo du poids sec de la récolte) alors que les plantes protégées de la visite des insectes pollinisateurs ne produisent pas de graines.

De leur côté, GATTEFosse E'T LAMOTHE (I9I7) pensent que l'hybridation serait due aux abeilles. Or il suffit d'avoir vu avec quelle assiduité les abeilles butinent 


\section{Planche I}

\section{Lavandula latifolia VILL $\times$ I600}

Préparation :

Échantillon $n^{0} 7$ I 6 récolté en août 1956 près du col du Pilon au nord de Grasse (A.-M.).

Explication des vues :

Exine : vues I et 2 : Aspect du réticulum aux deux niveaux extrêmes des columelles, vue 3 : plage polaire;

Aperture : vue 5 ;

Coupes optiques:

vue 4 : coupe équatoriale et épaisseur de l'exine, vue $6:$ coupe polaire.

\section{Description du pollen et dimensions :}

Forme : Pollen hexacolpé - en vue polaire, forme subrégulière hexagonale — en vue équatoriale forme ovalaire;

Dimensions : $\mathrm{P}=26 \mu-\mathrm{E}_{\mathrm{I}}=36 \mu-\mathrm{E}_{2}=35,5 \mu$;

Apertures : six colpus à bords bien délimités par l'ectexine, de largeur maximum à l'équateur $\varepsilon=5,7 \mu$

Fxine : Épaisseur totale $=2,5 \mu-$ Endexine mince $0,5 \mu-$ Ectexine $0,5 \mu$ de hauteur, Columelles se rejoignant à leur partie supérieure en formant un réticulum dense apparemment uni ; à leur partie inférieure pieds minces et séparés;

$b \mathrm{I}=b 2=\mathrm{I}, 5 \mu-t=7,5 \mu$;

Plage polaire: sensiblement régulière

$$
t_{2}=14,2 \mu-t_{3}=15,6 \mu \text {. }
$$

Aspect : Coloration ocre jaune. Le grain non dégraissé porte des gouttelettes de liant pollinique de couleur jaune,

Protoplasme non granuleux;

Taux de pollens avortés : 2,3 p. Io0. 

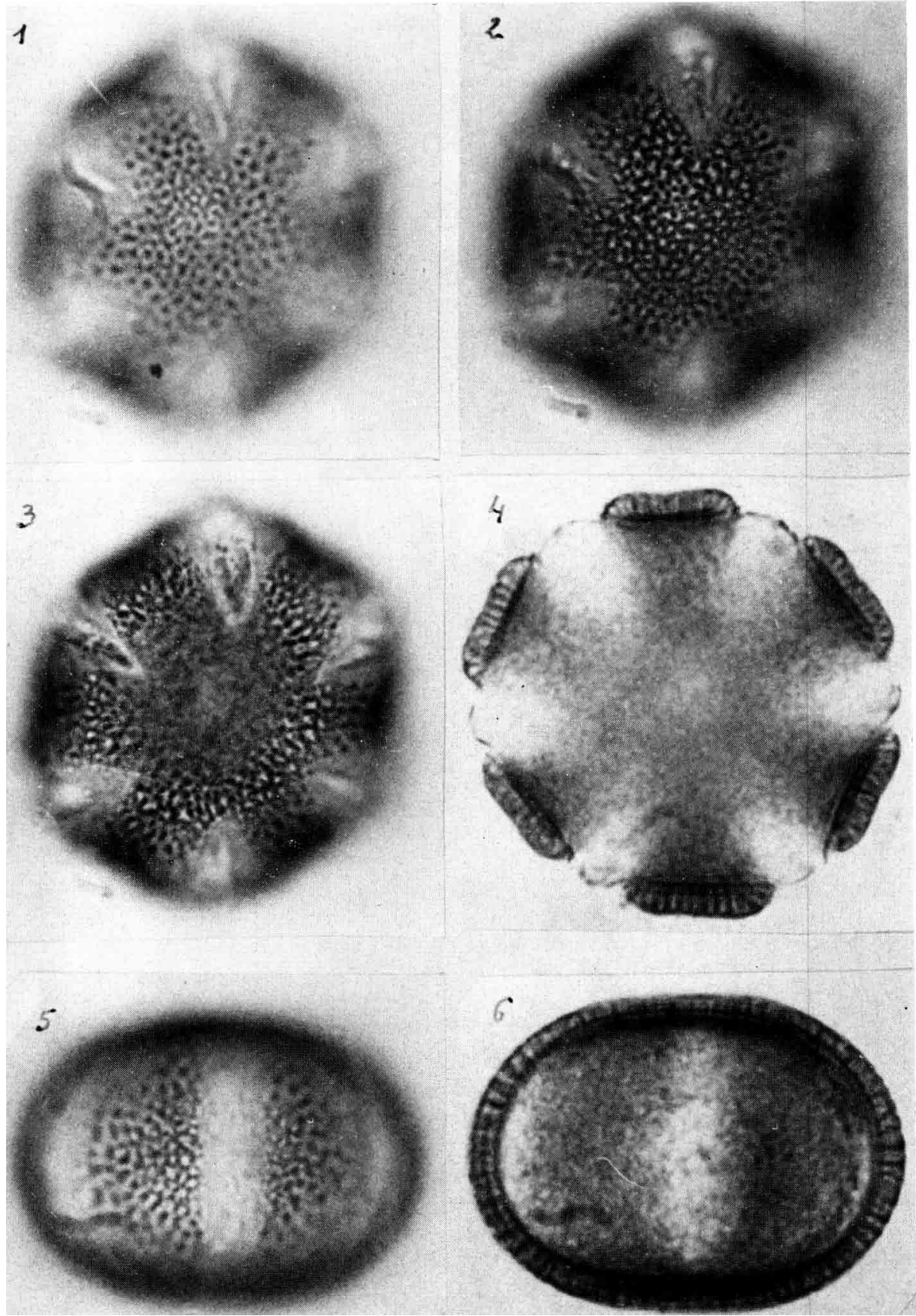


\section{Planche II}

Variété " Matheronne ».

\section{Lavandula vera D. C. $\times$ I 600}

\section{Préparation :}

Échantillon $n^{\circ} 800$ récolté en juillet 1958 dans une culture près de Puimoisson (B.-A.).

Explication des vues :

Exinc : Vues I et $2:$ Aspect du pseudo-réticulum aux deux niveaux extrêmes des columelles, Vue 3 : plage polaire;

Aperture: vue 5 ;

Coupes optiques': vue $4:$ Coupe équatoriale et épaisseur de l'exine, Vue 6 : coupe polaire.

\section{Description du pollen et dimensions :}

Forme : Pollen hexacolpé - en vue polaire forme hexagonale allongée - en vue équatoriale forme ovalaire;

Dimensions : $\mathrm{P}=26 \mu$. $-\mathrm{E}_{\mathrm{I}}=34 \mu-\mathrm{E}_{2} 32 \mu$;

Apertures: Six colpus à bords bien délimités par l'ectexine de largeur maximum à l'éruateur, $\varepsilon=6 \mu$ :

Exine : Épaisseur totale $2,5 \mu$. Endexine mince $0,5 \mu$. Ectexine $0,5 \mu$ portant des columelles de $1,5 \mu$ de hauteur. Columelles volumineuses non réunies à leur partie supérieure ne formant pas un réticulum uni, à leur partic inférieure pieds gros et très nettement séparés.

$b_{\mathrm{I}}=b_{2}=\mathrm{I} \mathrm{I} \mu-t=8,5 \mu$

Plage polaire : sensiblement régulière: $t_{2}=\mathrm{I} 7 \mu-t_{3}=\mathrm{I} 7,5 \mu$

Aspect : Coloration ocre jaune. Le grain non dégraissé porte des gouttelettes de liant pollinique de couleur jaune,

Protoplasme non granuleux;

Taux de pollens avortés : 2 p. 100. 

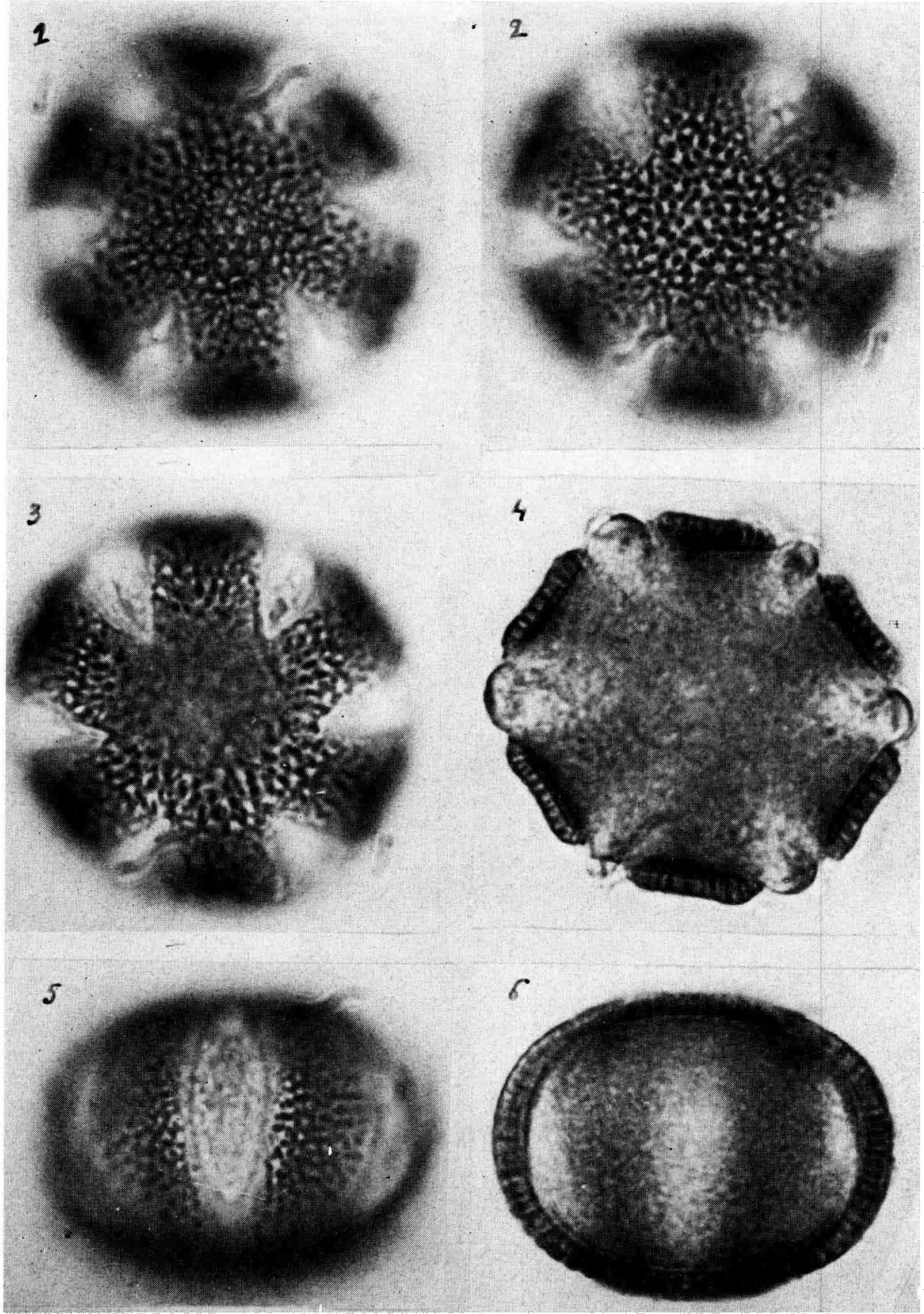

PlANCIE II. Lavanlula vera D. C. variéte "Matheronne" 
Préparation :

Échantillon no 26 récolté en mars I954. Massif de l'Estérel (A.-M.).

Explication des vues :

Exine : Vues I et 2 : Aspect de l'ornementation de l'exine aux deux niveaux extrêmes, Vue 3 : plage polaire;

Aperture : vue 5;

Coupes optiques: Vue 4 : coupe équatoriale et épaisseur de l'exine, Vue 6 : coupe polaire.

\section{Description du pollen et dimensions :}

Forme : Pollen hexacolpé - en vue polaire, forme hexagonale très régulière - en vue équatoriale forme ovalaire ;

Dimensions : $\mathrm{P}=28 \mu$. $-\mathrm{E}_{\mathrm{I}}=\mathrm{E}_{2}=35 \mu$;

Apertures : Six colpus à bords bien délimités par l'ectexine de largeur maximum à l'équateur, $\varepsilon=6,5 \mu$;

Exine : épaisseur totale 1,7 . Lndexine et ectexine confuses. Exine finement perforée; $b_{\mathrm{I}}=\mathrm{I} \mathrm{I} \mu-b_{2}=\mathrm{I} 2,5 \mu-t-\mathrm{I} 2,5 \mu$.

Plage polaire : très régulière et large. $t_{2}=t_{3}=24,5 \mu$

Aspect : Coloration ocre jaune. Le grain non dégraissé porte des gouttelettes de liant pollinique de couleur jaune. - Protoplasme non granuleux;

Taux de pollens avortés : I p. Ioo. 

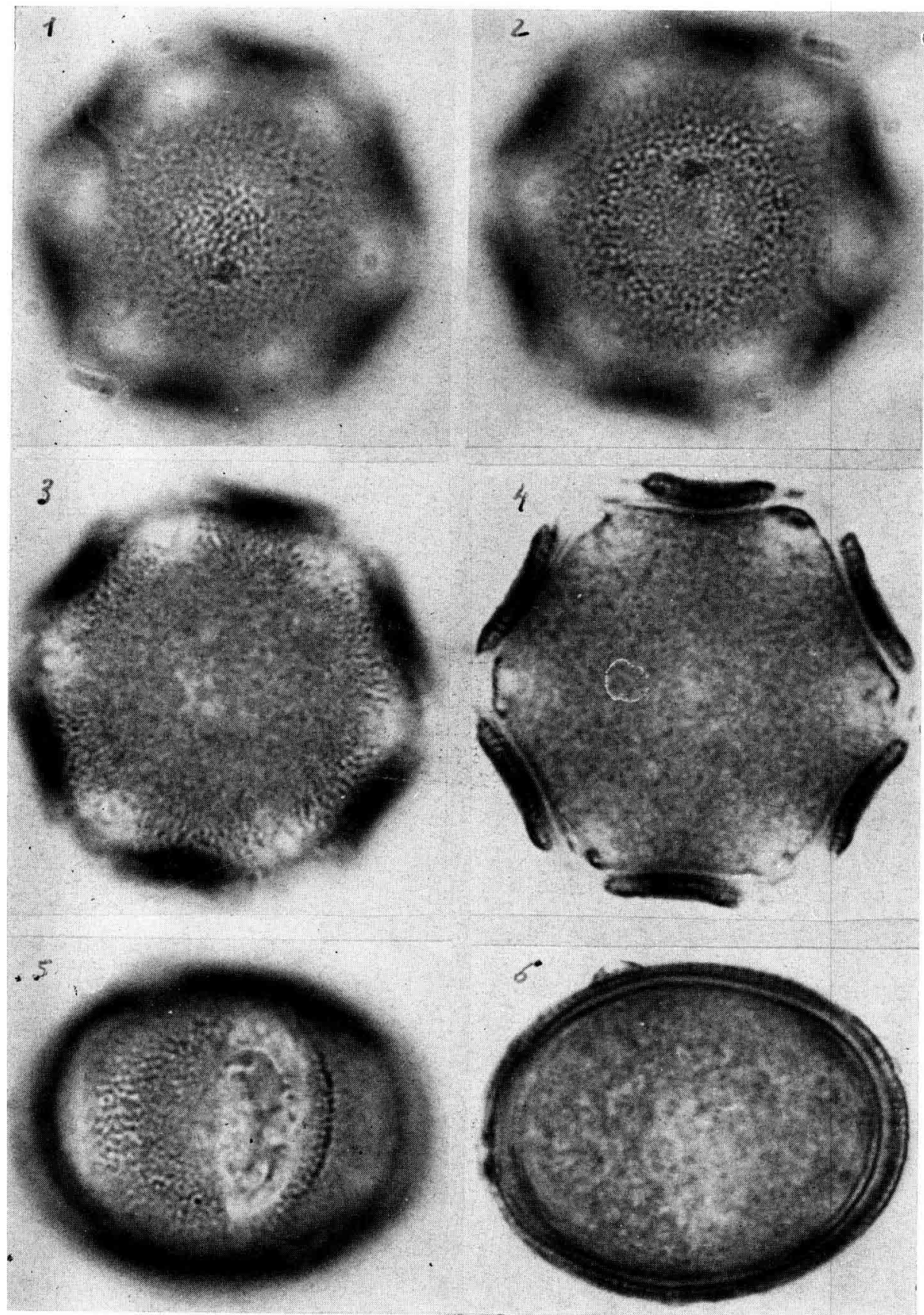

Plancue irf. Lamandula stoechas L. 


\title{
Planche IV
}

\section{Fréparation :}

\author{
Lavandula dentala L. $\times$ I 600
}

Échantillon $n^{\circ} 659$ récolté en octobre 1955 dans un jardin à Nice, (A.-1I.).

\section{Explication des vues :}

Exine : Vues I et $2:$ Aspect de l'ornementation de l'exine aux deux niveaux extrê nes, Vue 2 : plage polaire;

Aperture : vuc 4 ;

Coupes optiques: Vue $3:$ coupe équatoriale et épaisseur de l'exine, Vue 5 : coupe polaire.

\section{Description du pollen et dimensions :}

Forme : Pollen hexacolpé — en vue polaire, forme hexagonale allongée - en vue éfuatoriale forme ovalaire ;

Dimensions $: \mathrm{P}=28,5 \mu .-\mathrm{E}_{\mathrm{I}}=39,5 \mu .-\mathrm{I}_{2}=35 \mu$,

Apcrtures: Six colpus a bords bien délimités par l'ectexine de largeur maximum à l'équateur, $\varepsilon=8 \mu$

Exine : épaisseur totale $=2 \mu$. lindexine et ectexine confuses. Ixine finement perforée ; $b_{\mathrm{I}}=\mathrm{I} 2 \mu-b_{2}=\mathrm{I} 3 \mu-t=5 \mu$;

Plage polaire : irrégulière et petite,

$$
12=13 \mu-13=15 \mu \text {. }
$$

Aspect : Coloration ocre jaune. Le grain non dégraissé porte des gouttelettes de liant pollinique de couleur jaune,

Protoplasme non granuleux ;

Taux de pollens avortés : 5,5 p. 100. 

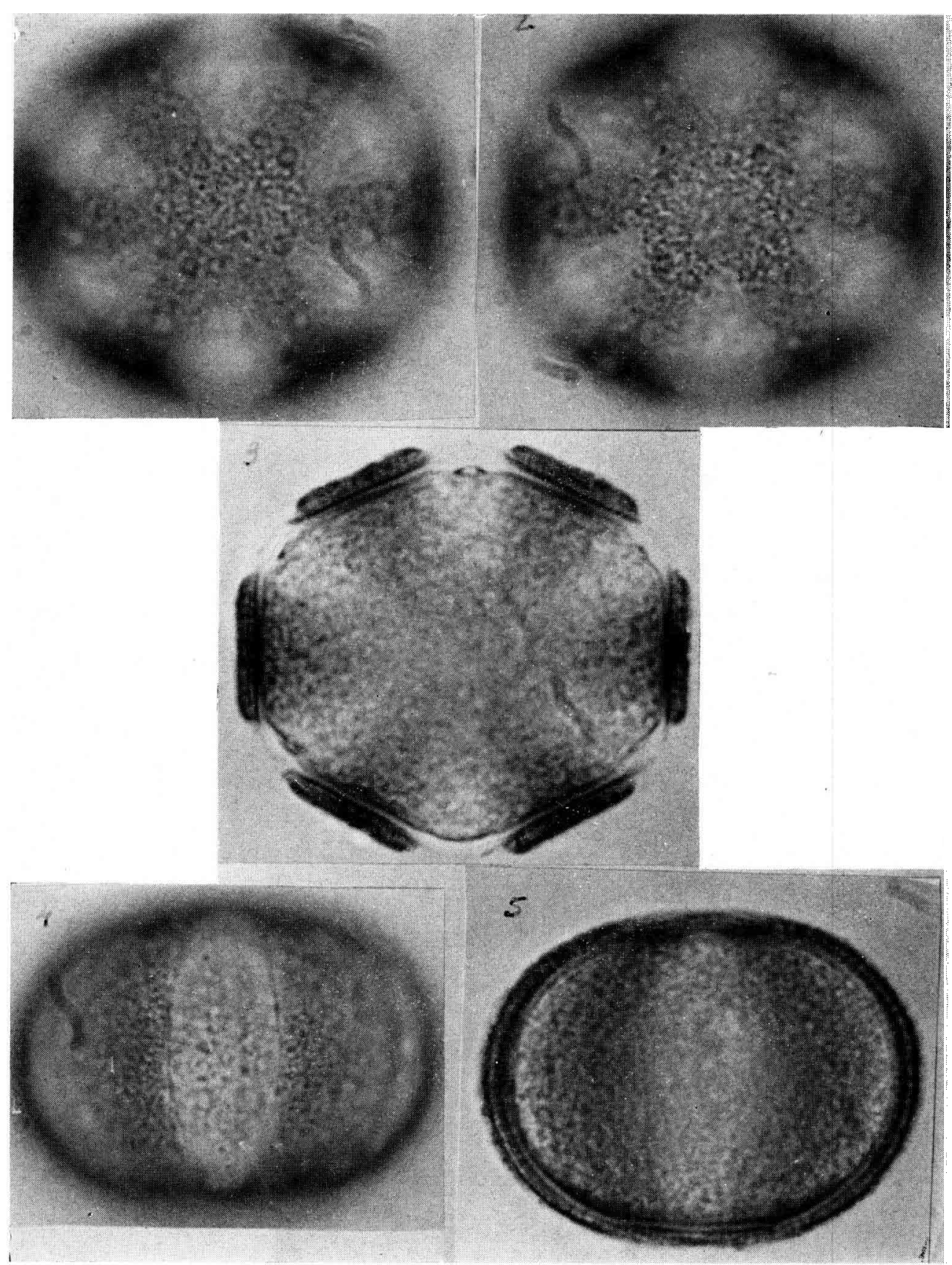

Playche Iv. Iarandula dentala $\mathrm{L}$. 
Lavandin Super A : Planche $V \times$ I 600

Lavandin Abrial: Planche VI $\times$ I 600

\section{Préparations :}

Échantillons Super A no $805-$ Abrial no 8 I I récoltés en culture à Nice (A.-M.) en août $195^{8}$.

\section{Explication des vues:}

Exine : Vue I : Ornementation de l'exine rappelant celle de Lavandula vera I. C. ;

Aperture : vue 4 (Super A) sillon germinatif fermé;

Coupes optiques: vue 2 : coupe équatoriale et épaisseur de l'exine, Vue 3 : coupe polaire.

\section{Description du pollen et dimensions :}

Forme : Pollen hexacolpé - en vue polaire forme subcirculaire - en vue équatoriale forme circulaire parfois en "fuseau " ou en " tonneau ";

Dimensions : assez variables

$$
\mathrm{P}=30 \dot{a} 34 \mu . \mathrm{E}=30 \text { à } 33 \mu \text {; }
$$

Apertures : Six colpus à bords bien délimités mais le plus souvent fermés. Si le pollen est de forme normale, il ressemble à celui de Lavandula vera D. C.;

Exine : voir Lavandula vera D. C.

Plage polaire : si pollen normal voir Lavandula vera $\mathrm{D}$. C. ;

Aspect : Coloration ocre jaune. Le grain non dégraissé porte des gouttelettes de liant pollinique de couleur jaune,

Protoplasmes non granuleux (sur pollen normal)

Taux de pollens avortés : Super A : 92 p. гоo-Abrial 93,6 p. Ioo.

\section{Remarques:}

Sur 12 clones de lavandin examinés, II possèdent des pollens semblables à ceux présentés aux planches $V$ et VI. Ce sont les lavandins suivants : Super $A$ - Abrial - Lavandin Blanc Lavandin Bleu - Maïme - A A $58-83^{8}-836-268-$ I 34 - et "Lavande" A 58.

Seul le lavandin Super $Z$ possède un pollen différent dans nos préparations. Son exine mince présente une ornementation presque invisible sans columelles apparentes. 


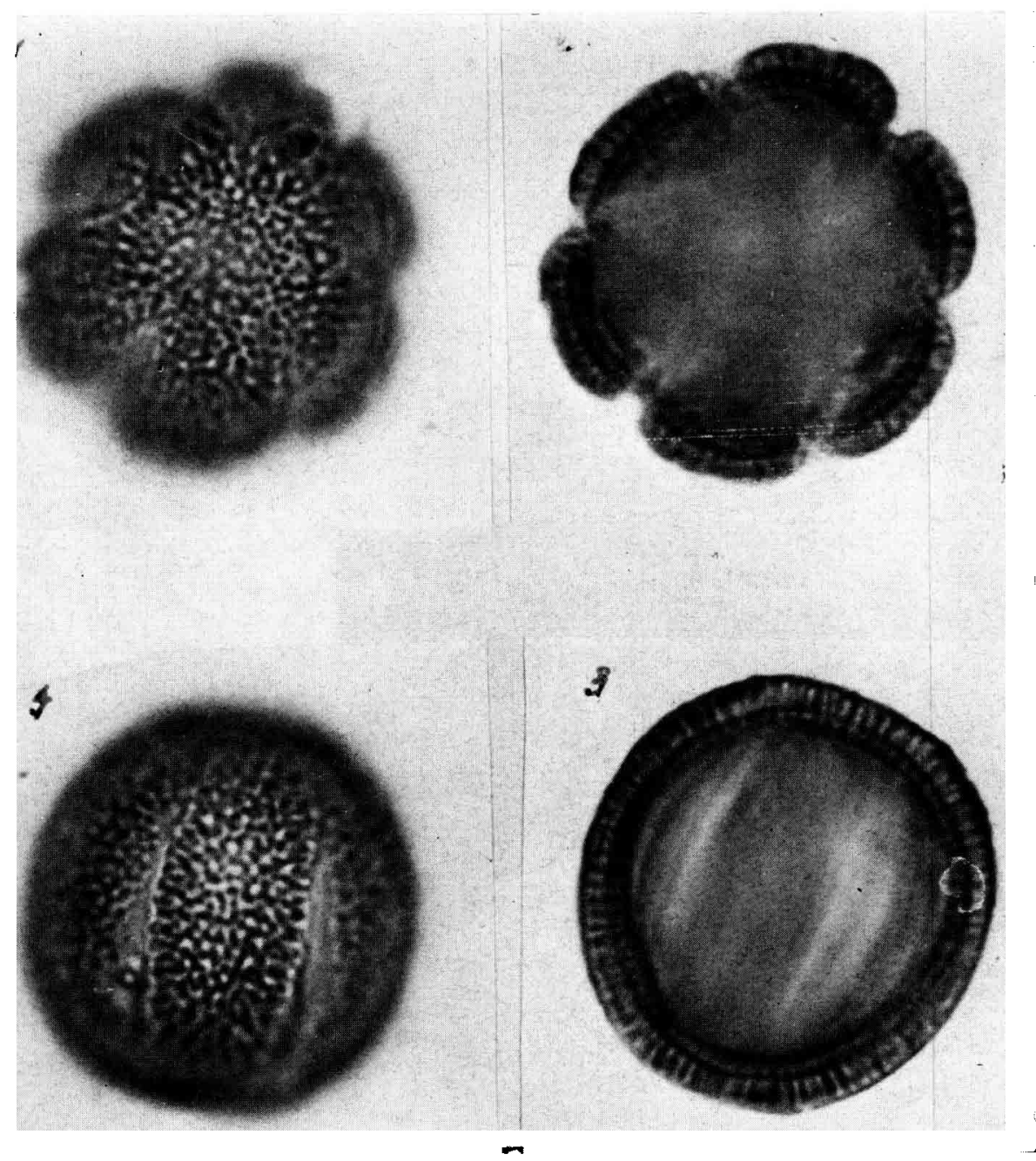

I'J.sulle v. Lavandin "siuger 1 " 


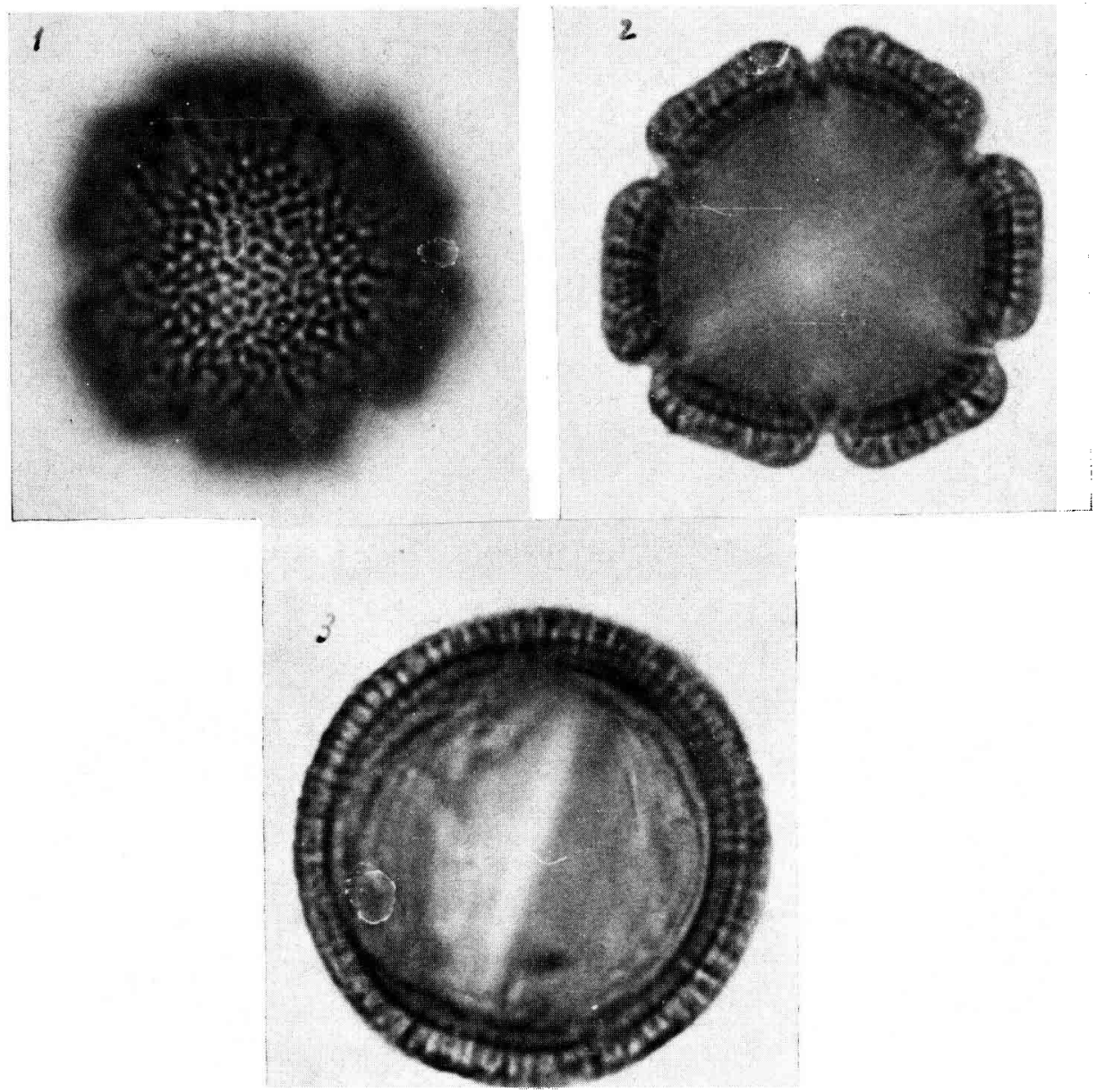

P'LANCIE vi. Lavandin "Abrial" 
les lavandes, pour être convaincu du rôle prépondérant de cet insecte dans la pollinisation croisée des lavandes et, par voie de conséquence, dans l'apparition des lavandins.

Le sens du croisement semble bien être celui du transport du pollen de Lavandula vera $\mathrm{D}$. C., sur le stigmate de Lavandula latifolia VILL; c'est d'ailleurs dans ce sens que l'hybridation expérimentale, réalisée aux Établissements CHIRIs, a été faite. Le semis des graines récoltées sur 1'Aspic poussant à proximité de Lavandula vera $\mathrm{D}$. C. donne très souvent des lavandins.

Par contre le croisement en sens inverse (pollen de Lavandula latifolia vis. sur stigmate de Lavandula vera D. C.), s'il n'est pas considéré comme impossible, n'a jamais donné de résultats et le semis des graines de lavande vraie n'a jamais donné de lavandins (CHIRIS, I926).

\section{5. - Le Pollen Dans le GenRe Lavandula}

Le grain de pollen, dans ses dimensions, sa forme et l'ornementation de ses enveloppes, est caractéristique du genre et souvent de l'espèce à laquelle appartient la plante qui lui a donné naissance.

VAN CAMPO (I946), pour les Abiétinées, WAGENITZ (I955), pour le genre Centaurea par exemple, ont montré tout l'intérêt de l'examen du pollen pout la détermination et la phylogénie des plantes.

En ce qui concerne le genre Lavandula nous avons pu constater que si pour les quelques espèces examinées la forme générale est assez voisine, l'ornementation de l'exine permet de distinguer deux groupes bien distincts.

Le premier avec Lavandula vera D. C. et Lavandula latifolia VIL, chez lesquels l'exine porte une ornementation grossière.

Le second avec Lavandula stoechas $\mathrm{L}_{\text {. }}$ et Lavandula dentata $\mathrm{L}_{\text {. }}$ chez lesquels l'exine porte une ornementation beaucoup plus fine.

Signalons encore que sur l'exine de tous les pollens examinés on trouve des gouttelettes de liant pollinique qui colle les grains les uns aux autres et qui rend la pollinisation des lavandes obligatoirement zoophile et plus précisément entomophile.

\section{Description des pollens}

Les planches I à VI viennent en illustration de la description du pollen des quatre espèces du genre Lavandula existant en France (dont une assez courante dans les jardins du midi) et de deux lavandins très cultivés.

Pour faciliter la description des pollens nous reprendrons les abréviations utilisées par VAN CAmpo (I957).

$\mathrm{P}$ - longueur de l'axe polaire

$\mathrm{E}$ - diamètre à l'équateur

EI - grand diamètre (si le pollen est de forme elliptique)

$\mathrm{E} 2$ - petit diamètre (si le pollen est de forme elliptique)

$\varepsilon-$ largeut du sillon germinal à l'équateur

$t$ - distance séparant les extrémités de đeux sillons consécutifs. 
Afin d'adapter cette méthode au cas particulier des pollens des lavandes, nous utiliserons les abréviations complémentaires suivantes :

$b \mathrm{I}$ - largeur des bandes d'exine au niveau de l'équateur

b2 - largeur des bandes d'exine les plus larges, dans le cas où ces bandes sont de largeur irrégulière

t2 - distance minimum séparant deux sillons opposés, dans le cas où la plage polaire est de forme elliptique

t3 - distance maximum séparant deux sillons opposés, dans le cas où la plage polaire est de forme elliptique.

L'examen des pollens, présentés dans les planches I à VI, montre que les différences des formes et celles des ornementations de l'exine sont suffisantes pour permettre l'identification des espèces de Lavandula.

En ce qui concerne les lavandins, le taux des pollens anormaux est assez élevé pour caractériser leur origine hybride.

Par ailleurs les particularités des pollens de ces différentes plantes montrent encore qu'il est possible de définir l'origine botanique des miels récoltés sur les lavandins ou sur les différentes lavandes.

L'examen des pollens permet encore de confirmer l'étroite parenté entre Lavandula latifolia VILL et Lavandula vera D. C. définie par ChAYToR, citée par GatTEFosse (I939), alors que celle existant entre Lavandula Stoechas L et Lavandula dentata $\mathrm{L}$. apparaît moins nette vue la forme générale des grains et l'étendue de la plage polaire.

\section{B. - Lavandes et Lavandins}

Si la détermination des espèces du genre Lavandula de la flore française est relativement aisée, il n'en est pas de même lorsque le sujet est un lavandin, tant sont grandes les affinités de ces plantes avec Lavandula vera D. C.

\section{I. - RESSEMBL,ANCES}

GIRAUd (I927) et GA'TTEFOSSE (I927) ont signalé que les lavandins ressemblaient les uns à la lavande vraie, les autres à 1'Aspic et que toutes les formes de transition existaient.

De son côté, FONDARD (I922) a montré que l'analogie des lavandins est surtout marquée avec Lavandula vera D. C. L,es observations que l'on peut faire dans les cultures conduisent à la même remarque, mais cela est peut-être dù à ce que le choix fait parmi les lavandins pour leur multiplication a surtout porté sur les formes se rapprochant du type lavande vraie.

Quoi qu'il en soit, on retrouve chez les lavandins cultivés, les mêmes variations qui ont été relevées chez Lavandula vera $\mathrm{D}$. C. et aussi chez Lavandula latifolia VILL.

C'est ainsi qu'on peut noter les formes extrêmes suivantes :

Epi : pointu chez "Abrial » - court chez "Maïme " — très long chez "Blanc ». Calice: Bleu chez "Abrial " - verdâtre chez "Super $Z$ ").

Hampe florale : courte et solide chez " Maïme " - longue et flexible chez "Super Z ". 
Le spécialiste saura certainement reconnaître les quelques "variétés " dont la culture a été très développée car il connaît leur personnalité, mais devant un type nouveau, il sera obligé de se livrer à un examen détaillé et de faire appel à des caractères distinctifs généralement assez discrets.

\section{2. - DIFFÉRENCES}

Les caractères distinctifs permettant de déterminer si un individu est un lavandin ou une lavande de l'espèce vera sont assez variés; ils se rapportent à la hampe florale (tige, épi), au pollen et aux essences.

\section{a) La hampe florale}

Les divers organes constituant la hampe florale sont les mêmes chez la lavande vraie ou chez les lavandins mais différent par les détails suivants.

Io) La tige.

La tige elle même est plus développée chez les lavandins et c'est le grand développement de ceux-ci qui a fait qu'ils furent remarqués, au milieu des lavandes, par les coupeurs et les distillateurs; tous les auteurs qui se sont intéressés à ces plantes n'ont pas manqué d'insister sur ce caractère.

Dans une plantation faite à Nice avec des lavandins de la "variété " "Super $Z$ " nous avons relevé que les plants âgés de six ans, portaient jusqu'à I 300 hampes florales et que le diamètre moyen des touffes, mesuré après la coupe, atteignait 80 centimètres.

Mais cette vigueur particulière aux hybrides et qui se retrouve de quelque façon que l'on examine la végétation, n'apparaît pleinement qu'en comparaison avec celle des lavandes vraies poussant dans les mêmes conditions, comme il ressort de 1'examen des tableaux I et 2 .

TABI,EAU I

Longueur des hampes, des épis et nombre de calices par épi. Nice 1959

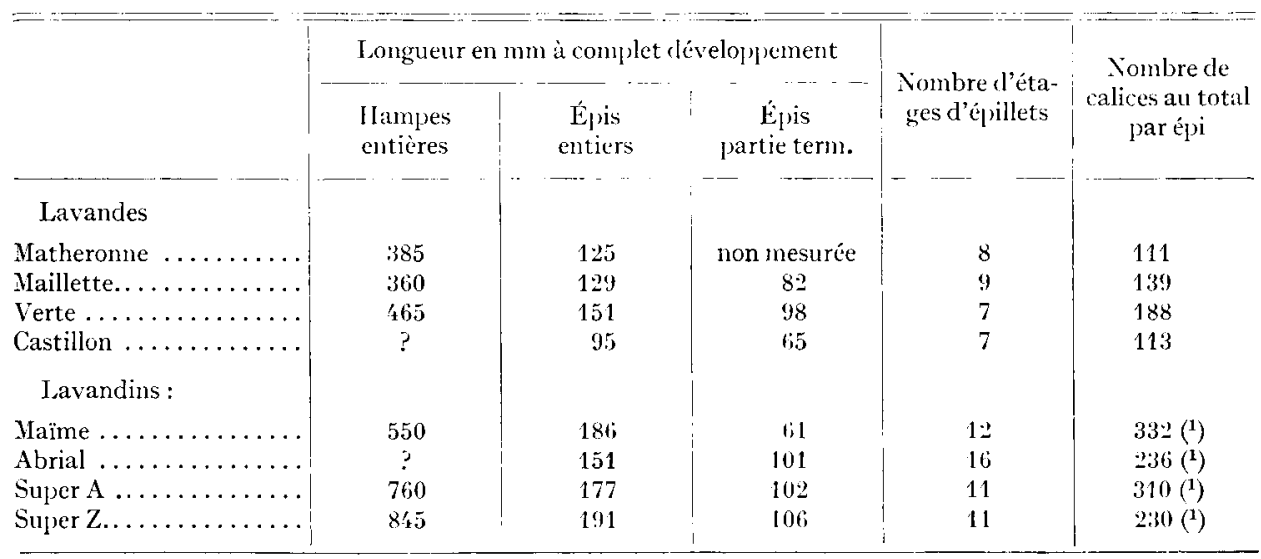

(1) Sur l'épi principal seulement. 
a) Longueur des hampes et des épis. - Dans cette série de relevés, les mesures ont été effectuées en I959 sur des plantes cultivées en collection à Nice.

Les chiffres portés au tableau I sont des moyennes établies, pour chaque "variété ", sur Io hampes et sur Io épis. La longueur est calculée à partir de la première paire de feuilles de printemps jusqu'à l'extrémité de l'épi, pour des hampes ayant atteint leur complet développement (voir également les figures 3 et 4). En ce qui concerne la longueur des épis, celle-ci est portée pour l'épi entier et pour sa partie compacte. En effet, l'épi de lavande ou de lavandin comprend une partie terminale où les épillets sont relativement serrés les uns sur les autres et, à une certaine distance de la base, il existe une paire d'épillets, en général très fournis en calices (voir aussi tableat1 3).

3) Poids des hampes. - Les pesées portées au tableau 2 ont été faites en 1958 sur des plants en culture dans les Basses-Alpes. Les terrains étaient assez semblables mais les plantations, bien qu'étant en pleine production, n'étaient pas d'âge connu. Aussi, comme il n'était pas possible de comparer les récoltes faites sur des plants entiers dont la production varie avec l'âge, nous avons préféré procéder de la façon suivante : sur un certain nombre de plants (en général 50 ) 200 à 400 épis étaient récoltés un à un en les coupant au niveau de la première paire de feuilles de printemps et les poids obtenus sont rapportés dans le tableau pour Ioo hampes. (La coupe à la faucille telle qu'elle est pratiquée normalement, laisse subsister sur la souche une certaine longueur de hampe mais les différences auraient été tout aussi nettes.)

Dans le tableau 2, on peut constater que les hampes des lavandins sont beaucoup plus lourdes que celles des lavandes (environ 3 fois plus).

Parallèlement à l'avancement de la saison, on voit la richesse en matière sèche augmenter régulièrement, sauf pour le "Super $Z$ " qui est cultivé en terrain plus frais.

TABLEAU 2

Poids de 100 hampes florales de diverses vari'tés cultivées de lavandes et lavantins (Basses-Alpes, 1958)

\begin{tabular}{|c|c|c|c|c|c|c|}
\hline \multirow{3}{*}{ Plante } & \multirow{3}{*}{$\begin{array}{l}\text { Date } \\
\text { de la coupe }\end{array}$} & \multicolumn{3}{|c|}{ Hampes enticres } & \multicolumn{2}{|c|}{ Calices } \\
\hline & & \multicolumn{2}{|c|}{ l'oids eng } & \multirow{2}{*}{$\begin{array}{c}\text { Mat. siche } \\
\%\end{array}$} & \multirow{2}{*}{$\begin{array}{l}\text { Poids en } y \\
\text { en sec }\end{array}$} & \multirow{2}{*}{$\begin{array}{c}\text { Calices/MS } \\
(\%)\end{array}$} \\
\hline & & en vert & en sec & & & \\
\hline \multicolumn{7}{|l|}{ Iavandes: } \\
\hline Maillette ......... & $17 / 7$ & 128 & 46,8 & 36,6 & 25,1 & 53,6 \\
\hline Matheronne........ & $17 / 7$ & 108 & 38,7 & 35,9 & 19,6 & 50,7 \\
\hline \multicolumn{7}{|l|}{ Lavandins: } \\
\hline Super A.......... & $31 / 7$ & 300 & $1: 27,5$ & 40,5 & 55,0 & 43,2 \\
\hline Super Z ........... & $14 / 8$ & 321 & 133,0 & $+1,5$ & 56,0 & 42,0 \\
\hline Maïme..$\ldots \ldots \ldots$ & $7 / 8$ & 272,5 & 121,0 & 45,6 & 70,5 & 56,8 \\
\hline Abrial .......... & $14 / 8$ & 282,5 & 137,5 & 48,6 & 78,7 & 57,2 \\
\hline
\end{tabular}

A la lecture des tableaux ci-dessus, que ce soit par la longueur des hampes ou par le poids de la matière organique élaborée, la végétation des lavandins apparaît comme particulièrement luxuriante. 
2o) L'épi.

L'épi également, bien qu'il soit semblable chez les lavandes vraies et chez les lavandins, présente des particularités dues à la différence de vigueur de ces plantes.

a) Nombre d'étages d'épillets. - On constatera au tableau I que les lavandins ont un plus grand nombre d'étages d'épillets, mais la différence entre lavandes vraies et lavandins apparaît plus nettement si on considère le nombre des calices portés par un épi (tableau I).

ß) Épillets secondaires. - Nous avons vu que l'épi de Lavandula vera D. C. est simple, alors que celui de Lavandula latifolia VILL présente, à la base, des épillets secondaires dont le nombre est en général de 2, mais qui atteint parfois jusqu'à 6 (échantillons récoltés au mont Chauve, Alpes-Maritimes).

$\gamma$ Calices. - Les calices des lavandins sont en tous points comparables à ceux des lavandes vraies mais ils sont plus nombreux et leur poids est plus important.

I. - Nombre - conséquence d'un plus grand nombre d'étages d'épillets plus fournis, le nombre de calices portés par un épi est très sensiblement plus élevé chez les lavandins (voir tableau I et 3).

2 - Poids en sec. Le poids des calices ne peut être déterminé sans opération compliquée que pour des calices secs.

A cet effet les hampes provenant des coupes faites en 1959 dans les Basses-Alpes (voir tableau 2) sont froissées légèrement entre la paume des mains; les pédoncules devenus fragiles par la dessiccation se brisent et il suffit, après tamisage, de peser séparément les calices.

Ici encore, la très grande production des lavandins apparaît nettement et on constate qu'une hampe de lavandin porte un poids de calices près de trois fois plus élevé que celui porté par une hampe de lavande vraie, il convient de tenir compte encore du fait que les calices de lavande vraie contiennent des graines qui, n'étant pas encore arrivées à maturité, restent dans le calice, et dont le poids n'est pas négligeable.

Or sachant que les cellules productrices d'essences sont presque uniquement localisées sur les calices on comprendra pourquoi les lavandins ont des rendements si élevés.

$\left.3^{\circ}\right)$ Importance relative de chaque partie de la hampe florale.

$\mathrm{Si}$ on considère le rapport entre le poids des calices seuls et celui des hampes florales entières sèches, on remarquera que malgré une production très élevée de calices, ceux-ci, chez certains lavandins comme "Super A » et "Super Z », ne représentent qu'une faible proportion de la hampe. Cela est dû au très grand développement de la tige comme il ressort au tableau I ; de même pour les lavandes "Maillette " et "Matheronne ", la proportion des calices est élevée, en rapport direct avec le faible développement des tiges et aussi la présence de graines immatures dans les calices.

Mais la vigueur de cette végétation peut être illustrée encore par l'observation suivante que tous les praticiens ont pu faire.

Sur le plateau de Valensole par exemple, la culture ancienne associait sur le même terrain amandiers et blé ; à l'entrée de la période sèche, le blé ayant terminé son cycle végétatif, les quelques réserves d'eau du sol restaient à la disposition des amandiers; mais l'introduction de la culture des lavandins a détruit l'équilibre 


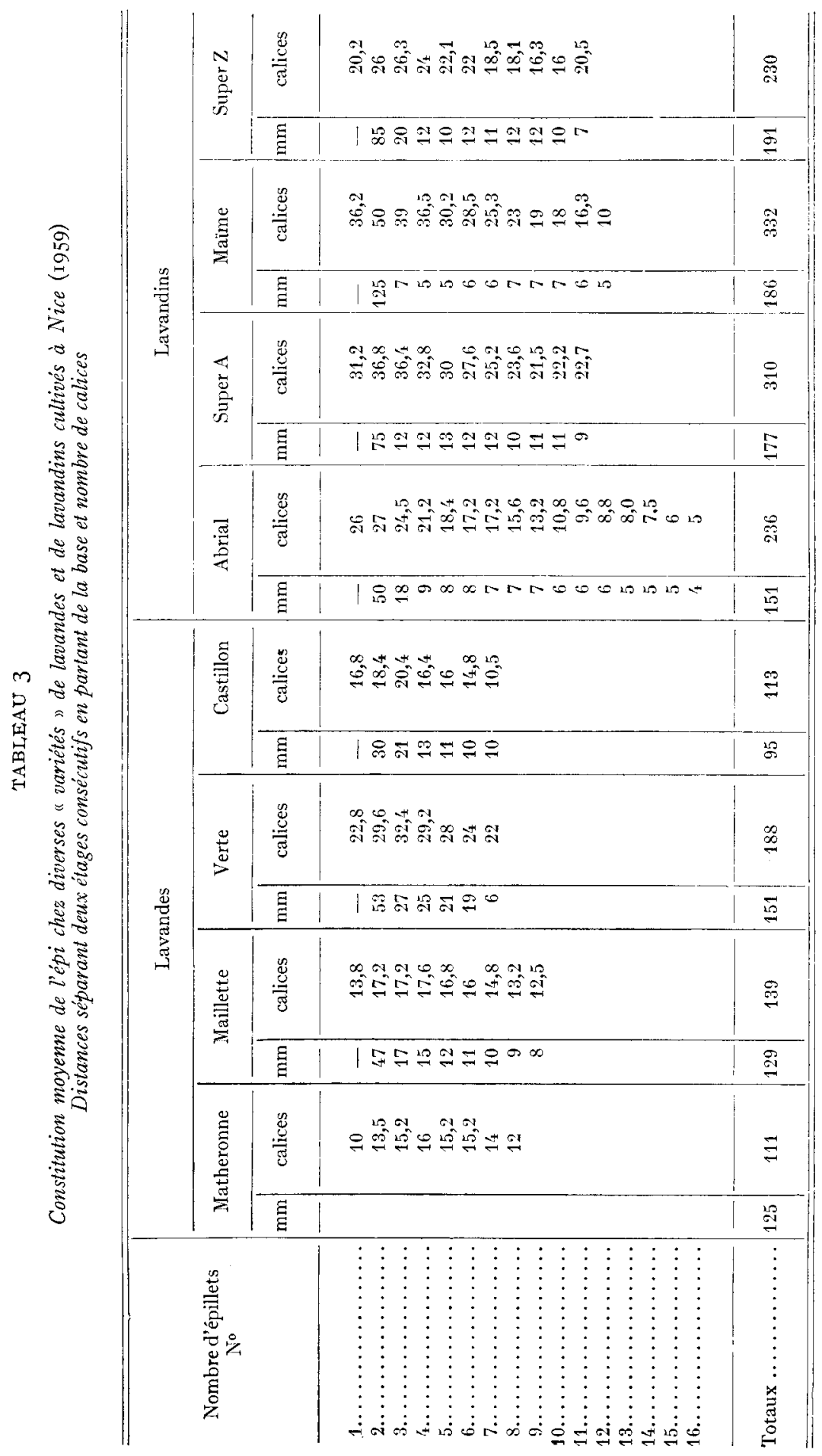




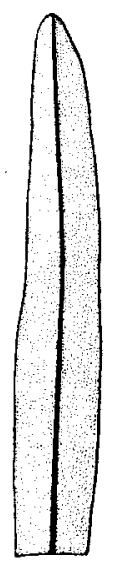

Echantillon Mont Chauve Nice

Lavandula latifolia Vill.
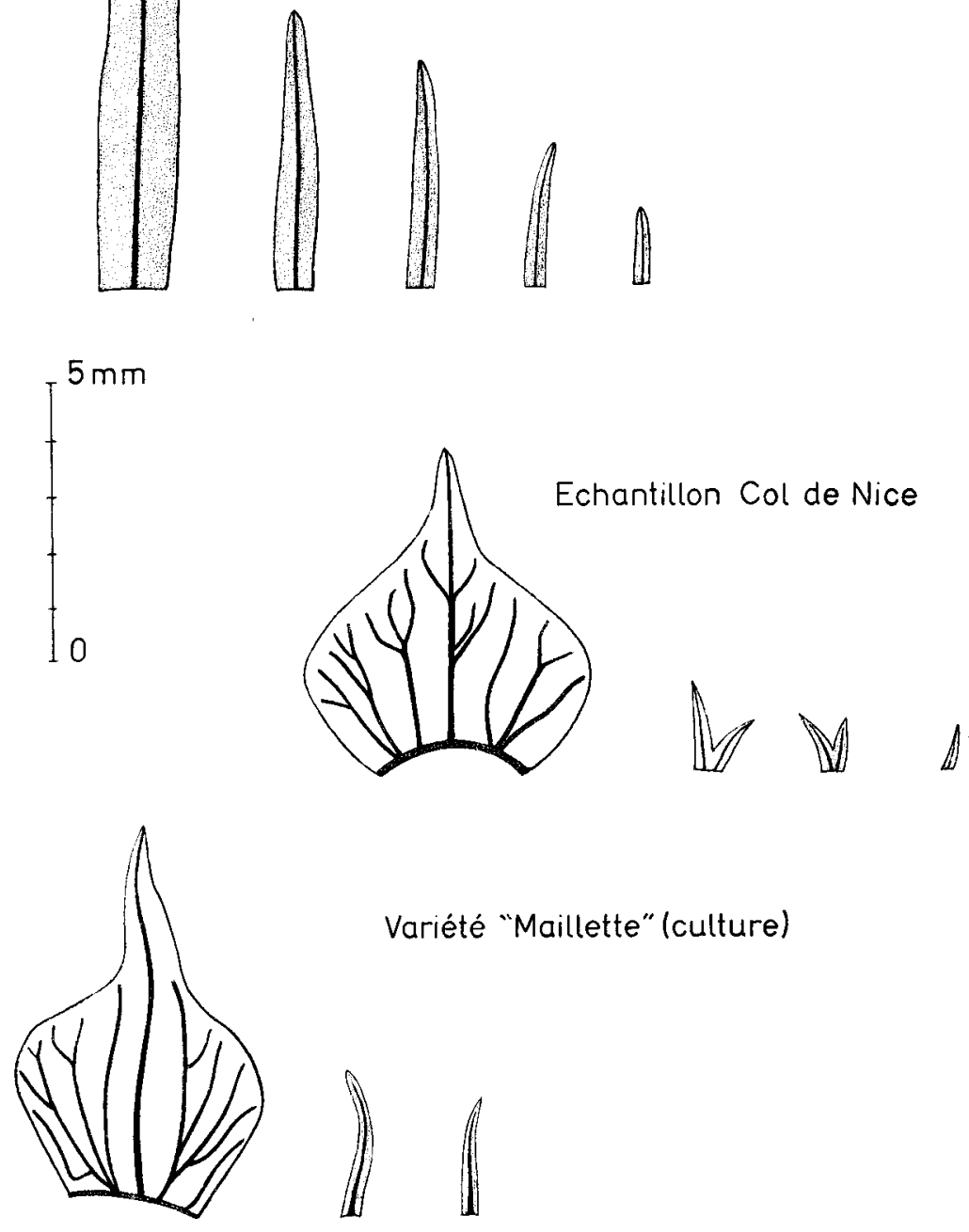

Variété "Maillette" (culture)
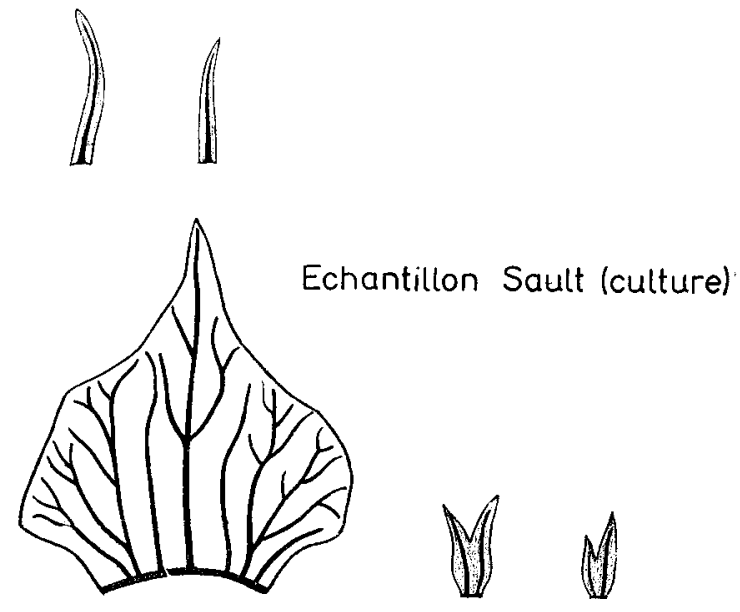

Lavandula vera DC

FIG. I. - Bractées et bractéoles chez diverses lavandes Lavandula vera $\mathrm{D}$. C et L. latifolia VILL 
existant. Le cycle végétatif du lavandin impose à celui-ci la recherche de l'eau pendant la pleine période de chaleur et de sécheresse ; la compétition entre lavandins et amandiers s'engage et, malgré sa grande rusticité, c'est 1'amandier qui disparaît.

\section{b) Bractées et bractéoles}

Déjà HuMBER'T, cité par FondARD (I922), attribue une grande importance à la forme des bractées et des bractéoles. FONDARD (I922), tout en confirmant les
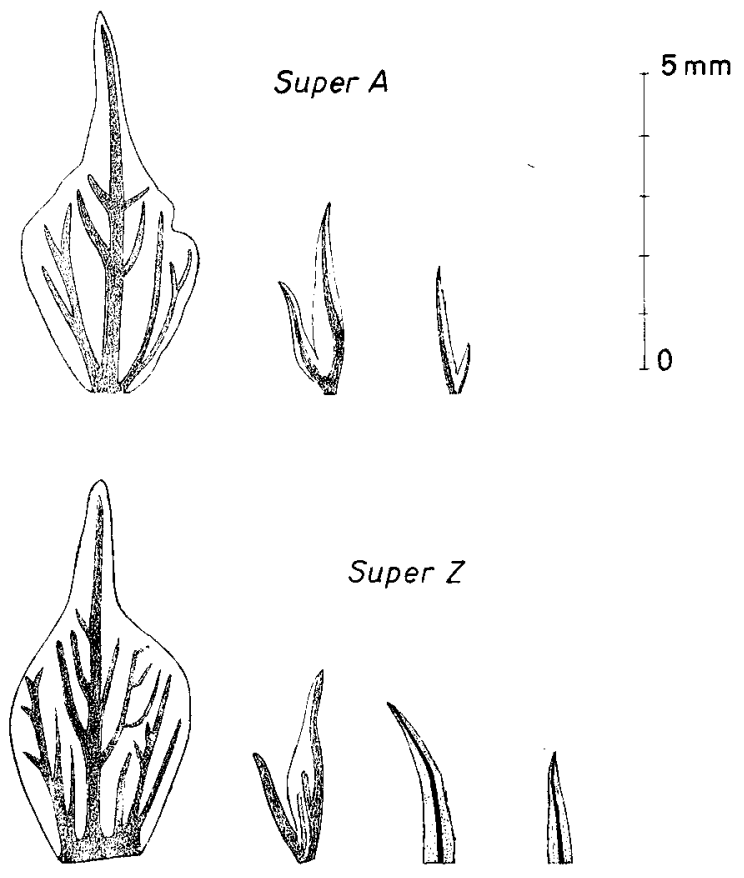

Super $Z$
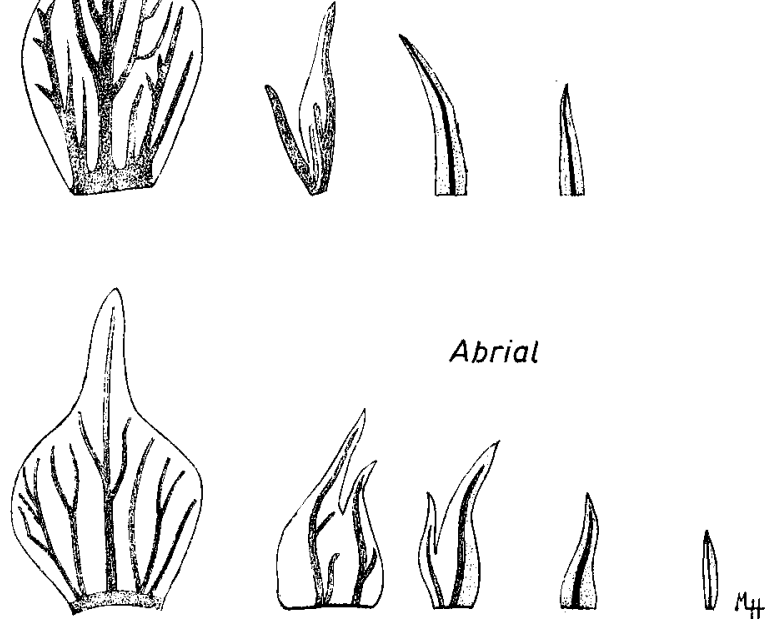

\section{Lavandins}

FIr. 2. - Bractées et bractéoles chez divers laiandins

remarques de Humberst donne sa préférence à l'odeur de l'essence pour différencier les lavandes des lavandins.

Au cours de nos observations nous avons pu remarquer que : 
Io) Chez Lavandula latifolia viı.L. - Les bractées situées à la base des épillets sont assez semblables aux feuilles. Elles sont épaisses, n'ont qu'une nervure et sont accompagnées de bractéoles qui prennent naissance à la base de chaque pédoncule.

La forme de ces bractéoles est semblable à celle des bractées - (voir figure I).

Dans un épillet, la première bractéole atteint environ la moitié de la longueur de la bractée mais les autres bractéoles sont de plus en plus petites.

Bractées et bractéoles sont couvertes de poils ramifiés et portent aussi des cellules à essence.

2) Chez Lavandula vera D. C. Au contraire, les bractées sont toujours larges, enveloppantes, en forme de coquille, leur partie supérieure est arrondie et se termine par une pointe plus o1 moins allongée. Ces bractées sont minces, membraneuses, leur couleur varie du jaune paille au brun foncé, elles portent $5 \grave{a} 7$ nervures irrégulièrement ramifiées et de couleur plus foncée.

Les bractéoles sont toujours présentes, mais souvent petites. Comme chez l'espèce précédente, la taille des bractéoles du centre de l'épillet est réduite mais toujours, de part et d'autre de la nervure centrale, la bractéole est membraneuse.

Bractées et bractéoles ne portent que peu de poils ramifiés et les cellules à essence, très rares sur les bractées, sont absentes sur les bractéoles.

Chez la plupart des échantillons récoltés en diverses localités du sud-est de la France, les bractéoles présentent deux pointes ayant chacune leur nervure, réunies par la partie membraneuse.

\section{TABLEAU 4}

Rapport longueurllargeur des bractées forales chez Lavandula vera 1). c., Javandula latifolia viLL et Lavandins

\begin{tabular}{|c|c|}
\hline Espèce-Lieu de récolte-"Variété" & Rapport moyen $\mathrm{I} / \mathrm{l}$ \\
\hline \multicolumn{2}{|l|}{$\begin{array}{l}\text { Lavandula la'ifola Vill : } \\
\text { Échantillon récolté à : }\end{array}$} \\
\hline Echantillon récolté à : & \\
\hline Mont Ventoux (Vaucluse) .... & 6,7 \\
\hline Mont Chauve (A.-M.) ........ & 6,28 \\
\hline Montmeyan (Var)........... & 5,80 \\
\hline \multirow{2}{*}{\multicolumn{2}{|c|}{ 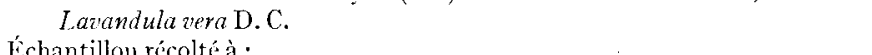 }} \\
\hline & \\
\hline Col de Njce $(\Lambda .-M.) \ldots \ldots \ldots$ & 1,08 \\
\hline Col de Gorbio $(\Lambda .-11.) \ldots \ldots$ & 1,36 \\
\hline Rives (lu Loup) (A.-M) ....... & 1,17 \\
\hline 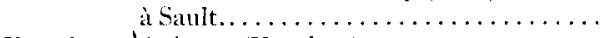 & 1,06 \\
\hline En culture 'Avignon (Vaucluse) $\ldots \ldots \ldots \ldots \ldots$ & 1,10 \\
\hline 'Bures (S.-et-O.) $\ldots \ldots \ldots \ldots \ldots \ldots$ & 1,25 \\
\hline 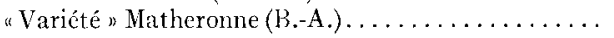 & 1,37 \\
\hline Maillette (B.-A.)............... & 1,10 \\
\hline Verte $($ A.-M. $) \ldots \ldots \ldots \ldots \ldots$ & 1,00 \\
\hline Lavandins & \\
\hline "Variété " Abrial. . & $1,9 \mathbf{r}^{\prime}$ \\
\hline Super $A \ldots \ldots \ldots \ldots \ldots \ldots \ldots$ & 2,14 \\
\hline Super $Z \ldots \ldots \ldots \ldots \ldots \ldots \ldots$ & 2,17 \\
\hline
\end{tabular}

Exceptionnellement, les deux pointes sont indépendantes. Dans ce cas la bractéole est double ; cette particularité se trouve dans la variété " Maillette " mais de part et d'autre de chaque nervure on distingue la partie membraneuse (voir figure I). 
3) Chez les lavandins examinés, les bractées ont une forme générale voisine de celle des bractées de Lavandula vera I). C. 'Toutefois ces bractées sont plus longues et le rapport longueur sur largeur est toujours plus grand que chez Lavandula vera D. C., sans toutefois atteindre le rapport relevé chez Lavandula latifolia ViL. (voir tableau 4 et figure 2).

On remarquera encore que le raccordement entre la pointe et la partie large de la bractée se fait selon un angle très ouvert, alors que chez Lavandula vera D. C. l'angle de raccordement tend vers l'angle droit.

Signalons aussi que la forme des bractées n'est pas constante dans un même épi. Iin effet le rapport longueur/largeur augmente progressivement des verticilles inférieurs aux verticilles terminaux.

Les bractéoles, comme chez la lavande vraie, sont bifides et on retrouve aussi la même structure membraneuse de part et d'autre des deux nervures mais chez les lavandins leur taille est nettement plus importante que chez Lavandula vera $\mathrm{D}$. C.

'Tout comme chez les parents, les bractéoles du centre de l'épillet sont plus petites que celles voisines des bractées, les dernières pouvant même être simples.

Comme on peut le remarquer par l'examen des caractères anatomiques de leurs bractées et bractéoles, les lavandins cultivés sont des individus intermédiaires entre les parents, mais ils sont beaucoup plus voisins de Lavandula vera D. C. que Lavandula latifolia vir.L.

\section{c) Les pollens}

Nous avons vu que les pollens des lavandins sont voisins de ceux de Lavandula vera $\mathbf{D}$. C. par le détail des ornementations de l'exine, mais ils sont en grande partie anormaux et réduits à leurs enveloppes.

TABLEAU 5

Examen des pollens de divers lavandins et Lavandula

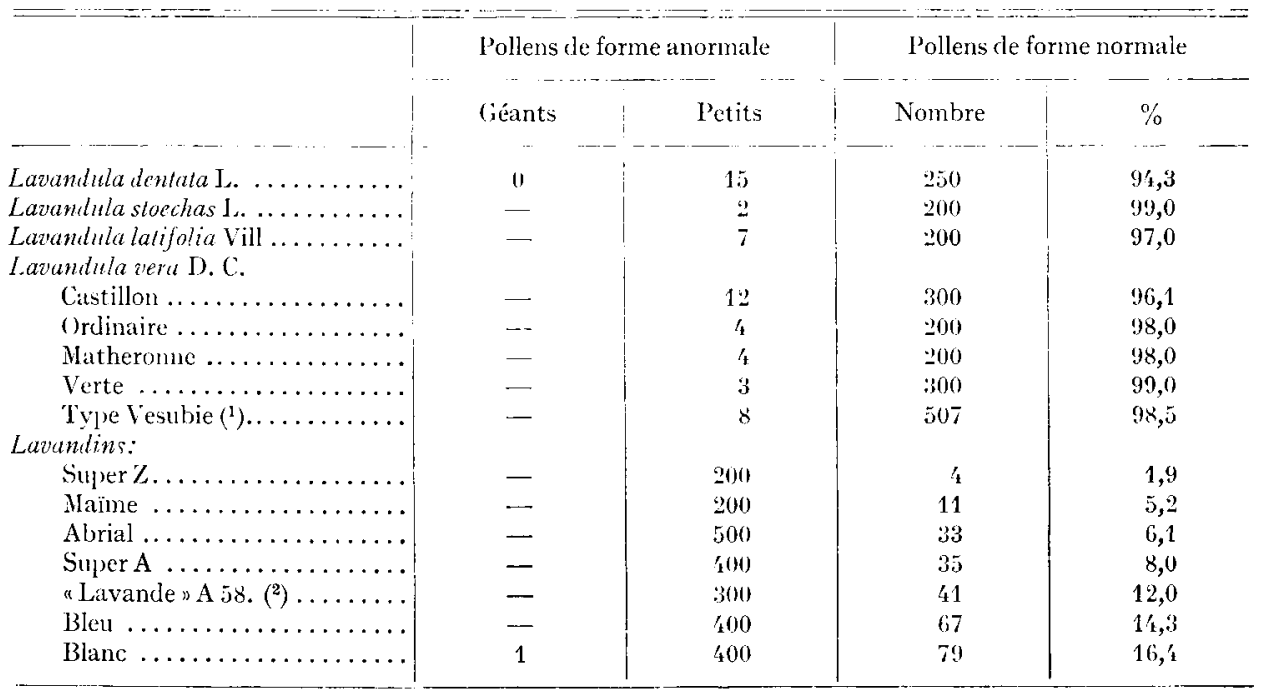

(1) Lavande récoltée au Col de Corbio $927 \mathrm{~m}$ (A.--H1.).

${ }^{2}$ ) Malgrí l'appellation de Lavande, il s'aģit bien d'un lavandin. 
I) Nombre de grains de pollen par étamine.

FONDARD (I922) signale que chez les lavandins les pollens sont présents, mais que leurs dimensions sont variables selon les individus. IGOLEN (I944) indique que les pollens sont très peu abondants et souvent inexistants.

Mais il faut reconnaître que l'examen des pollens exige une certaine habitude et que 1'application des techniques de coloration facilite beaucoup les observations. Dans ces conditions on peut constater que dans l'étamine, qu'elle soit de lavande vraie ou de lavandin, le nombre de grains de pollen est sensiblement le même et voisine goo.

Toutefois, chez les lavandins, les pollens sont pour la plupart avortés et ne sortent pratiquement pas des sacs polliniques.

2) Taux des pollens normaux.

Cet avortement du pollen fournirait un argument de grande valeur, s'il était encore nécessaire de démontrer l'origine hybride des lavandins.

Déjà GAGNEPAIN (I9OI) avait observé que l'avortement d'un fort pourcentage de pollen permettait de soupçonner l'origine hybride d'une plante.

DiLI.EMAxx (I954) dans une importante revue de l'hybridologie remarque que, sans être un critère d'une fidélité absolue, la mauvaise conformation du pollen peut être considérée comme une preuve de l'hybridité pour la très grande majorité des hybrides.

Aussi nous a-t-il paru intéressant d'examiner les pollens fournis par divers individus appartenant aux espèces françaises du genre Lavandula, à diverses sélections de lavande vraie et aux lavandins.

La lecture de ce tableau permet de constater que dans le genre Lavandula les différentes espèces possèdent un taux de pollens normaux très élevé et homogène (94 à 99 p. roo), alors que pour les lavandins ce taux est très bas et assez variable (2 à I6,4 p. IOo).

Les pollens anormaux sont de taille réduite; leur diamètre ne dépasse pas $27 \mu$, le protoplasme est absent et de ce fait ils sont sans valeur alimentaire pour les abeilles qui ne les récoltent pas.

Très exceptionnellement nous avons rencontré chez le lavandin "Blanc » un pollen de forme normale mais dont le diamètre mesurait $48 \mu$.

Cette forme géante a été signalée par Dillemann et DE Poucques (I954) pour une plante considérée comme étant un hybride : Sorbus latifolia PERs.

\section{3) Stérilité des lavandins.}

La plupart des auteurs signalent comme caractère distinctif des lavandins que ces plantes ne produisent pas de graines et qu'ils sont stériles. FondarD (I922), tout en reconnaissant que la stérilité est très courante, décrit un plant qu'il considère comme un lavandin et qui aurait fourni des graines. Mais IGOLEN (I944) pense qu'il a pu y avoir confusion avec une lavande vraie très vigoureuse.

Au cours de nos nombreux prélèvements réalisés sur la plupart des "variétés " cultivées de lavandin, nous n'avons jamais trouvé de graines, malgré la préparation particulière que les échantillons subissaient.

Après dessiccation à l'étuve, les calices étaient séparés des hampes, puis sou- 
mis à une série de criblages. Au cours de ces opérations les graines mûres se détachent facilement des calices et sont recueillies sur le dernier tamis. Or si les graines sont très abondantes pour les lavandes, chez qui elles représentent jusqu'à Io p. Ioo du poids total des hampes sèches, elles sont complètement absentes chez les lavandins.

Parfois le tamis retenait exceptionnellement quelques ovaires plus ou moins développés, mais l'aspect des téguments extérieurs et l'absence d'albumine montrent bien qu'il s'agissait d'ovaires et non de graines.

Les Établissements CHIRIS (I926) signalent aussi la présence de très rares "graines " trouvées chez les lavandins, mais qui, mal conformées, ont été incapables de germer. De même la tentative de pollinisation de lavandins par le pollen des deux parents n'a conduit qu'à des échecs.

Ainsi malgré la présence de quelques pollens de forme normale, ce qui n'implique pas qu'ils soient féconds, et d'ovaires pouvant atteindre un certain développement, il semble bien que la stérilité des lavandins soit constante et qu'elle constitue un important caractère distinctif.

\section{d) Les essences}

On peut encore diffétencier les lavandes des lavandins par leurs essences.

\section{x) Production.}

Il est bien connu que la production des lavandins en essence, et c'est d'ailleurs cette particularité qui a attiré l'attention sur eux, est plus élevée que celle des lavandes.

A cet égard nous avons rassemblé au tableau 6 des productions moyennes de quelques "variétés 》 de lavande et de lavandin relevées parmi les séries étudiées par ailleurs (BARBIER, I962), productions choisies au cours de la végétation au moment ou elles sont à leur maximum.

TABLEAU 6

Production et rendements en essence de quelques " variétc's " cultivées

\begin{tabular}{|c|c|c|c|c|c|}
\hline \multirow{2}{*}{ Variété } & \multirow{2}{*}{$\begin{array}{l}\text { Poids de la } \\
\text { récolte en sec: } \\
\text { (en g) }\end{array}$} & \multirow{2}{*}{$\begin{array}{c}\text { Essence (en ml) } \\
\text { produite par } \\
\text { un plant }\end{array}$} & \multicolumn{2}{|c|}{$\begin{array}{c}\text { Rendements en } \mathrm{ml} \text { p pour } \\
100 \mathrm{~g} \mathrm{secs}\end{array}$} & \multirow{2}{*}{$\begin{array}{c}\text { Rapyort } \\
\text { (alices/hampes } \\
\text { (en \% } \\
\text { sans les wraines }\end{array}$} \\
\hline & & & $\begin{array}{l}\text { de hampes } \\
\text { florales } \\
\text { completes }\end{array}$ & de calices & \\
\hline Lavande & & & & & \\
\hline Maillette............. & 355 & 8,6 & 2,4 & 6,10 & 12 \\
\hline $\begin{array}{l}\text { Matheronne } \ldots \ldots \ldots \ldots \\
\text { Lavandin }\end{array}$ & 800 & 7,2 & 2,4 & 6 & 40 \\
\hline $\begin{array}{l}\text { Abrial } \ldots \ldots \ldots \ldots \ldots \ldots \\
\text { Super } Z \ldots \ldots \ldots \ldots \ldots\end{array}$ & $\begin{array}{l}500 \\
800\end{array}$ & $\begin{array}{l}21,2 \\
23\end{array}$ & $\begin{array}{l}4,2 \\
2,9\end{array}$ & $\begin{array}{l}8,5 \\
8\end{array}$ & $\begin{array}{l}50 \\
36\end{array}$ \\
\hline
\end{tabular}

On remarquera la forte production des lavandins aussi bien en hampes florales qu'en essence. 
2) Rendements.

Les rendements eux-mêmes, calculés sur l'ensemble de la récolte sèche ou sur les calices seuls et sans graines pour les lavandes vraies, indiquent encore une nette différence en faveur des lavandins.

\section{3) Évolution des rendements.}

C'est sans conteste dans l'évolution des rendements en essence qu'une différence fondamentale peut être relevée entre les lavandins et les lavandes. En effet chez les lavandins le rendement en essence, calculé sur le poids des calices secs seuls, après avoir atteint un certain maximum variable selon la "variété " envisagée, se maintient à ce maximum sans fléchir.

Par contre chez les lavandes vraies, la courbe des rendements, toujours calculée sur les seuls calices secs diminue très rapidement après avoir atteint un certain maximum (BARBIER, Ig62).

\section{4) Odeur et composition.}

L'examen des indices physico-chimiques pernet encore de différencier les lavandes des lavandins. IGOI,EN (I944), MAUREL (I959) ont indiqué que, selon l'origine botanique des essences, leurs indices ou certains rapports établis entre ces indices, sont assez nettement différents.

De son côté Naves (I958) a prouvé, par chromatographie de partage en phase gazeuse, que deux constituants de l'essence de lavandin " Abrial ", le camphre et le bornéol, sont absents des essences de lavande vraie.

Toutefois le seul examen de la composition chimique d'une essence ne peut permettre à lui seul de définir la nature de la plante qui l'a produite. C'est ainsi que CRABAloxa et Gili. (I958), après analyse d'une essence de "Matheronne " et constatant une certaine proportion de bornéol, de cinéol et de camphre, concluent que cette essence " devrait être désignée par le terme de lavandin ".

Or la " Natheronne " est une "variété " qui doit incontestablement être considérée comme étant une lavande vraie. İ́n effet :

- elle présente un très fort pourcentage de pollens normaux (98 p. Ioo);

- elle produit des graines en abondance;

- elle possède des bractées et des bractéoles du type lavande vraie ;

- son épi floral ne possède pas d'épillets secondaires caractéristiques des lavandins.

Si l'essence de la " Matheronne " a une composition chimique différente de celle des essences courantes de lavande, c'est que cette "variété " est un exemple de ce que Rovestr (I955) appelle un chémotype.

La " Matheronne " n'est pas le seul chémotype de lavande. En réalité, chaque " variété " cultivée, "Matheronne ", "Maillette " ou "Verte ", ainsi que chaque individu au sein d'une population, représente autant de chémotypes différents, comme il représente également autant de types morphologiques différents.

Dans un milieu donné, un ou plusieurs types morphologiques ou chimiques vont être abondants et marquent l'aspect des populations (par exemple : couleur des calices ou qualité de l'essence) ; citons, pour le parfum, les essences de BarremE de Thorame, etc. et pour la solubilité, les essences de Mevouirion qui étant 
insolubles ont conduit les lavandiculteurs à s'orienter vers la commercialisation des calices en sachets pour parfumer le linge.

Par ailleurs l'existence de ces très nombreux chémotypes et types morphologiques différents dans les populations naturelles de Lavandula vera D. C. et de Lavandula latifolia vir.., explique les grandes différences morphologiques des divers lavandins, ainsi que celles que nous avons trouvées pour la composition et le parfum des essences produites par ces plantes.

L'origine hybride des lavandins peut également provoquer par hétérosis une plus grande aptitude à synthétiser divers composés organiques (BERNINGER, I960). Il en résulte, plus encore que pour les lavandes, que chaque lavandin aura sa propre personnalité et produira une essence particulière. Toutefois les lavandins se reconnaîtront par leurs essences grâce à la note fraîche qui leur est communiquée par une certaine proportion de camphre. 
CHAPITRE II

\section{BIOLOGIE DES LAVANDES ET DES LAVANDINS}

\section{A. - Développement végétatif}

La récolte des Lavandes et des Lavandins laisse subsister sur la souche une certaine longueur de tige de l'année; selon la coupe, il reste ainsi 5 à $8 \mathrm{~cm}$ de jeune bois aoûté sur lequel on peut compter 3 à 5 paires de feuilles.

Aussitôt la coupe, on voit se développer, à la base des 2 ou 3 dernières paires de feutlles, des jeunes tiges dont la longueur ne dépassera pas quelques centimètres avant le début de la période hivernale. Sur ces tiges, les feuilles sont petites, étroites roulées sur les bords; leurs faces sont couvertes de très nombreux poils ramifiés dont l'abondance donne à la feuille et à la plante entière une couleur grisâtre.

Cette couleur, jointe à la forme en boule que prend naturellement la plante et que la coupe ne fait qu'accentuer, donne en hiver à la Lavande aussi bien qu'au Lavandin 1'aspect d'un hérisson; c'est dans cet état qu'elle va affronter le dur climat hivernal des Alpes de Provence. Notons qu'à Nice on assiste à la formation du même revêtement pileux.

Au printemps, dès le mois de mars à Nice et plus tardivement dans les BassesAlpes, la végétation se réveille; les jeunes pousses d'automne vont reprendre leur développement et émettre de nouvelles feuilles mais celles-ci ne portent qu'un rare duvet pileux et paraissent glabres.

Lentement d'abord, puis de plus en plus vite, la plante entière va prendre une teinte d'un vert plus ou moins foncé, au fur et à mesure du développement de la végétation. Mais celle-ci évolue avec une telle rapidité qu'il nous a semblé utile de suivre en détail les diverses phases de la végétation, ainsi que les réactions de la plante à quelques facteurs écologiques, et de comparer entre elles plusieurs "variétés " de lavande vraie et de lavandin. suivante.

Cet aspect de l'évolution végétative a été examinée à l'aide de la technique

$$
\text { I. - TECHNIQUE }
$$

A Nice en fin mars, alors que la végétation des Lavandes vient à peine de s'éveiller, dix pousses réparties sur 3 ou 4 plants, pour chacune des variétés à étudier, sont marquées à l'aide d'une étiquette, laquelle est fixée à la hauteur de la dernière paire de feuilles d'automne. 
A ce moment la pousse de printemps ne mesure qu'une dizaine de millimètres de long et se réduit à un bourgeon entouré de deux feuilles.

Par la suite, à partir du moment où la végétation devient de plus en plus active, les mesures sont répétées tous les 2 à 3 jours et on peut suivre sur les figures I et 2 l'évolution végétative des lavandes et des lavandins et comparer les variétés entre elles.

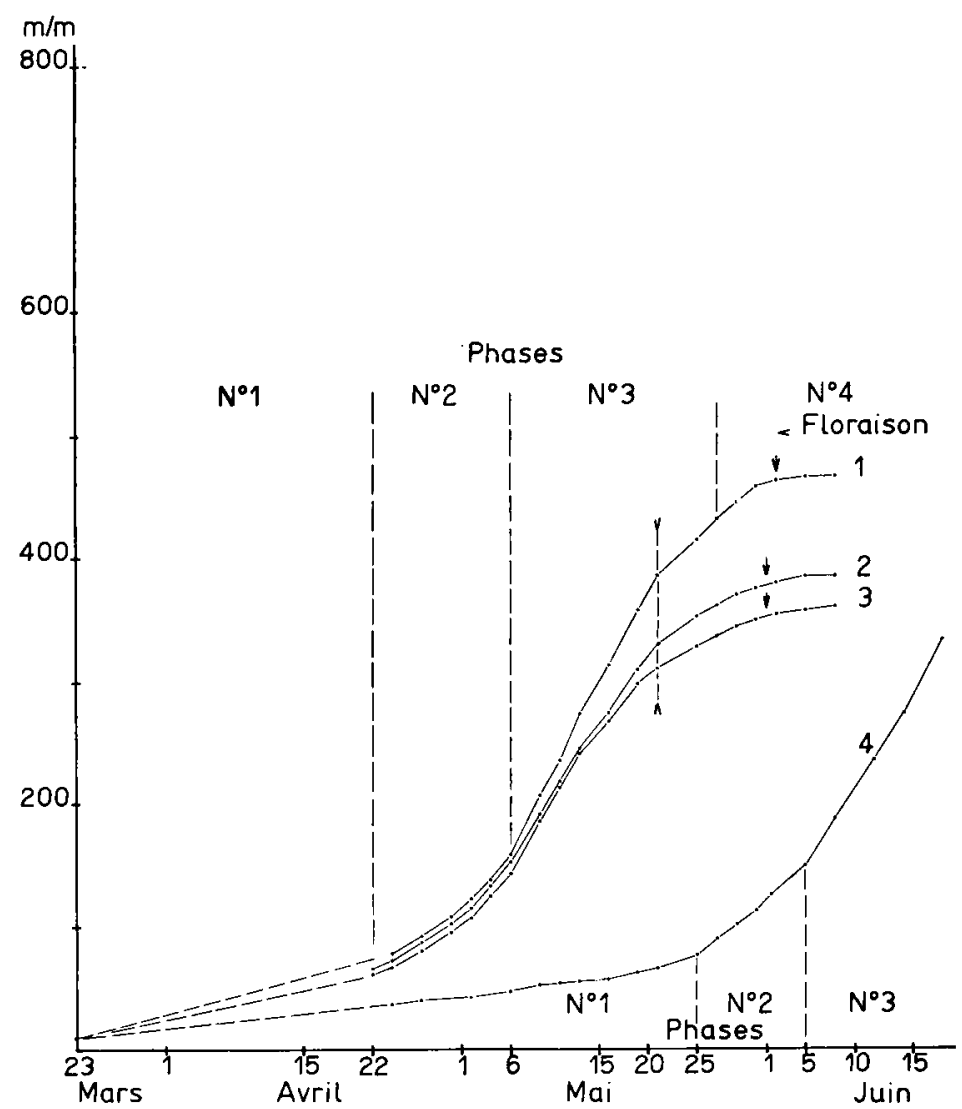

Fig. 3. - Allongement des hampes forales ches les lavandes araies (Nice 1959) I - Lavandula vera D. C - - Verte

2... Lavandula vera D). ( - .- Matheronne.

3 - Lavandulí vera D. C - Maillette.

4 -. Lavandula latifolia vis. - varićté tomentosa.

Noler le ralentissentent d'allongemént des hampes aut $2 \mathrm{I}$ mai, ainst que le grand retard de la végétation chez Lavandula latifolia YILI.

\section{2. - ArLONGEMENT DES HAMPES}

La technique exposée ci-dessus a été appliquée en I959 à diverses "variétés " cultivées côte à côte, en collection à Nice.

Sur la figure 3 sont groupés les résultats obtenus pour Lavandula vera $\mathrm{D}$. C. avec les trois "variétés " cultivées suivantes : "Matheronne " - Maillette ""Verte" - et pour Lavandula latifoliq VII, I. avec une série de plantes obtenues 
par multiplication végétative d'un plant récolté aux environs de Grasse et correspondant à la variété tomentosa (1).

L'examen des courbes permet de diviser la poussée des hampes en quatre phases bien distinctes. :

a) pendant la première phase qui s'étend du 23 mars au 22 avril, 1'allongement est très lent puisque de ro mm environ, les hampes ne mesurent en fin de cette période que 60 à $80 \mathrm{~mm}$ selon la "variété ";

b) la deuxième phase, du 22 avril au 6 mai, correspond au démarrage de la végétation active et 1'allongement journalier devient de plus en plus rapide ;

c) la troisième phase, d'une durée de 2 I jours (du 6 au 27 mai), est celle de la très grande activité ; entre le II et le I3, l'allongement atteint I $8 \mathrm{~mm}$ par jour pour la "variété " "Verte ". Pendant toute cette période le bouton floral ne se développe que très peu.

d) par contre au cours de la quatrième phase, au fur et à mesure que l'allongement devient de moins en moins rapide, on assiste au développement de l'épi, à la formation des calices et à la consolidation de la hampe qui devient plus rigide. Cette phase s'étend sur une douzaine de jours et prend fin vers le 5 juin, alors que les premières fleurs apparaissent dès le I er juin.

Il est à remarquer combien les évolutions de ces "variétés " sont identiques, bien que chacune atteigne un développement qui lui est particulier ; on note $465 \mathrm{~mm}$ pour la "variété » "Verte », $385 \mathrm{~mm}$ pour la "Matheronne " et $360 \mathrm{~mm}$ pour la "Maillette".

En ce qui concerne Lavandula latifolia VILL, on peut relever un important retard de végétation qui prolonge d'un mois environ la première phase.

La deuxième phase, ou phase de démarrage, débute au 25 mai et ne đure qu'une dizaine de jours. La troisième période débute le 5 juin, mais n'a pu être suivie audelà du Ig juin.

On peut toutefois constater la parfaite analogie de la végétation de cette lavande avec celle de l'espèce précédente.

Ajoutons que la longueur maximale atteinte par les hampes de Lavandula latifolia VIL $\mathrm{L}_{\text {, }}$ se situe entre 500 et $550 \mathrm{~mm}$ c'est-à-dire que les hampes dans cette espèce sont nettement plus longues que celles de Lavandula vera $\mathrm{D}$. C.

Sur la figure 4 sont groupés les lavandins de diverses " variétés »: " Super $Z$ »—, "Super A "- "Maïne " (ou tête carrée) et " Blanc ".

Dans l'ensemble, la végétation des lavandins est semblable à celle des lavandes vraies et débute sensiblement au même moment, mais la phase de démarrage est plus courte : du 22 avril au 2 mai, soit ro jours, et la phase de végétation très active légèrement plus longue : du 4 au 3I mai ; pendant cette dernière période également, l'allongement maximum journalier, enregistré sur la " variété » "Super $Z$ 》 atteint entre le II et le I3 mai, $28 \mathrm{~mm}$ soit plus de I mm par heure. Aussi n'est-il pas étonnant que les lavandins possèdent des hampes nettement plus longues que celles

(1) Dans la figure 3

$\mathrm{I}=$ Lavandula vera $D . C$. "Verte "

$2=$ Lavandula vera $D . C$. "Matheronne "

3 = Lavandula vera D. C. "Maillette"

$4=$ Lavandula latifolia viLL variété Tomentosa. 
des lavandes. On note pour les "variétés " " Maïme ": $550 \mathrm{~mm}$, "Blanc »: $750 \mathrm{~mm}$, “Super A " : $760 \mathrm{~mm}$ et "Super $Z$ » $=845 \mathrm{~mm}$, en fin de végétation (I).

La phase de ralentissement d'une durée de I5 jours ( ${ }^{\text {er }}$ au I5 juin) voit appa-

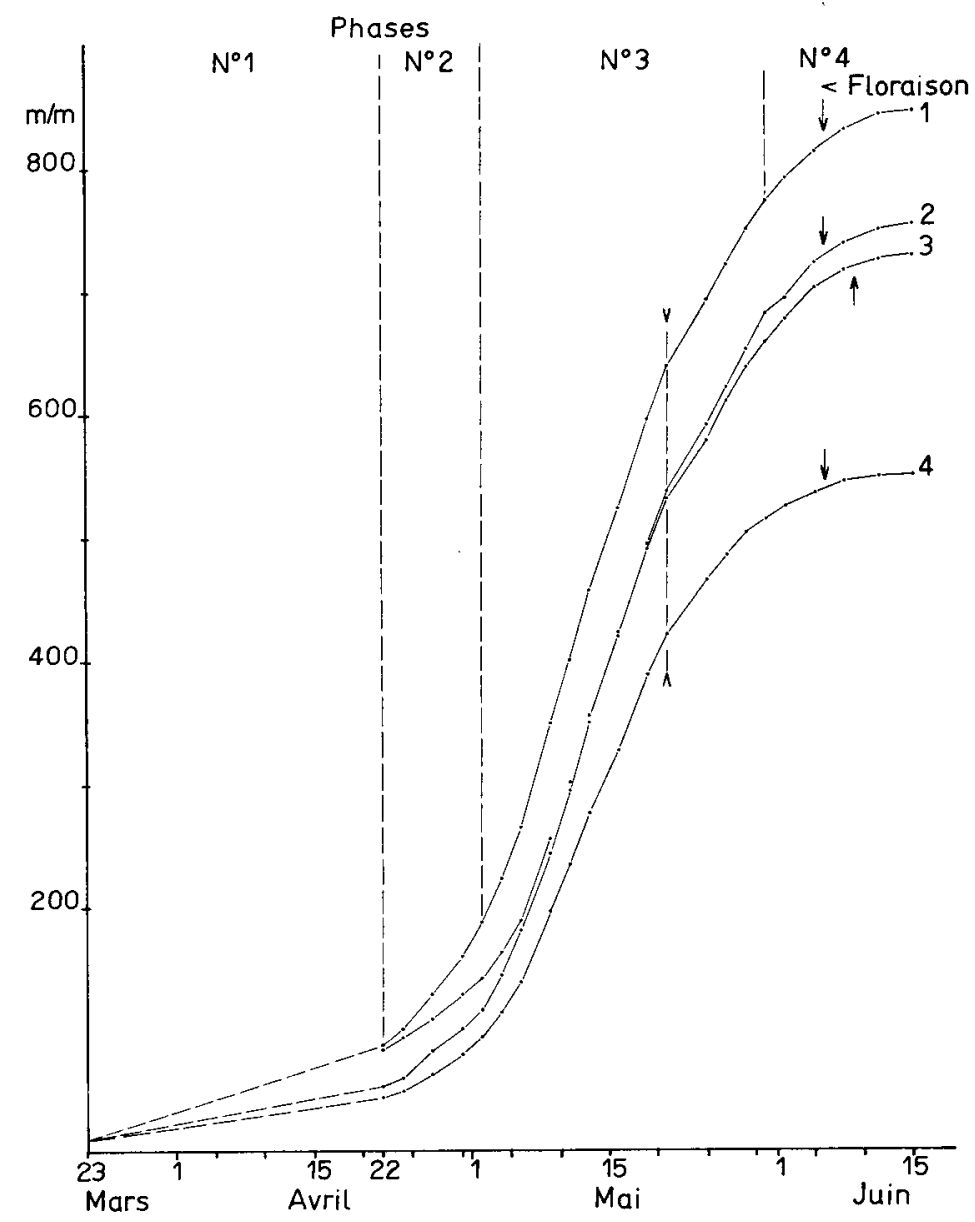

FIG. 4. - Allongement des hampes florales ches les lavandins (Nice I959)

$$
\begin{aligned}
& \text { I - Lavandin Super Z } \\
& 2 \text { - Lavandin Super A } \\
& 3 \text { - Lavandin Blanc } \\
& 4 \text { - Lavandin Maïme }
\end{aligned}
$$

Noter pour le $2 \mathbf{I}$ mai un ralentissement de l'allongement des hampes dî̀ à une chule de tempéralure.

raître les premières fleurs vers le 6 juin, soit avec un retard de moins d'une semaine sur la floraison des lavandes.

Ici encore, pour un même sol et dans les mêmes conditions climatiques, chaque " variété " garde sa personnalité. 


\section{Influence du climat}

Possédant pour le lavandin "Super $Z$ » des relevés effectués en I958 sur les mêmes plants qu'en I959 et selon le même protocole, il était intéressant de comparer le développement de ce lavandin et de rechercher l'influence possible des divers facteurs du climat sur chaque phase de la végétation.

Les relevés météorologiques publiés par la Météorologie nationale pour le poste de Nice et résumés dans le tableau 7 font apparaître précisément entre ces deux années des différences importantes.

TABLEAU 7

Le climat de Nice en $195^{8}$ et 1959

\begin{tabular}{|c|c|c|c|c|c|c|}
\hline & \multicolumn{2}{|r|}{1958} & \multicolumn{2}{|c|}{$\begin{array}{l}\text { Différence }: 1959 \\
\text { par rapport à } 1958\end{array}$} & \multicolumn{2}{|c|}{1959} \\
\hline & $\begin{array}{l}\text { Pluie } \\
\text { en mm }\end{array}$ & $\begin{array}{c}\text { Insolation en } \\
\text { heures et en } \\
\text { dixième d'heure }\end{array}$ & $\begin{array}{l}\text { Pluie } \\
\text { en mm }\end{array}$ & $\begin{array}{c}\text { Insolation en } \\
\text { heures et en } \\
\text { dixième d'heure }\end{array}$ & $\begin{array}{l}\text { Pluie } \\
\text { en mm }\end{array}$ & $\begin{array}{c}\text { Insolation en } \\
\text { heures et en } \\
\text { dixième d'heure }\end{array}$ \\
\hline \multicolumn{7}{|l|}{ Mars } \\
\hline 1 au $10 \ldots$. & 1,6 & 90,7 & & & 30,9 & 43,3 \\
\hline 11 au $20 \ldots$ & 38,8 & 53,4 & & & 1,1 & 80,8 \\
\hline 20 au $31 \ldots \ldots \ldots$ & 60 & 36,9 & & & 46,8 & 62,7 \\
\hline pour le mois ........ & 100,4 & 181,0 & $-21,6$ & $+5,8$ & 78,8 & 186,8 \\
\hline \multicolumn{7}{|l|}{ Avril } \\
\hline 1 au $10 \ldots \ldots \ldots$ & 43,7 & 61,6 & & & 4,2 & 99,2 \\
\hline 11 au $20 \ldots \ldots \ldots$ & 75 & 59,4 & & & 86,1 & 80,9 \\
\hline 21 au $30 \ldots \ldots \ldots$ & 0 & 103,4 & & & 29,6 & 63,2 \\
\hline pour le mois ........ & 118,7 & 224,4 & $+1,2$ & $+19,0$ & 119,9 & 243,4 \\
\hline \multicolumn{7}{|l|}{ Mai } \\
\hline 1 au $10 \ldots \ldots \ldots$ & 0 & 76,1 & & & 0,2 & 90,2 \\
\hline 11 au 20 & 9,1 & 117,3 & & & 2,1 & 103,9 \\
\hline 21 au 31 & 3,6 & 94,7 & & & 85,6 & 73,9 \\
\hline pour le mois ...... & 19,7 & 288,1 & $+75,2$ & $--20,1$ & 87,9 & 268,0 \\
\hline \multicolumn{7}{|l|}{ Juin } \\
\hline 1 au $10 \ldots \ldots \ldots$ & 0,7 & 103,1 & & & 0 & 125,9 \\
\hline 11 au 20 & 7,5 & 91,3 & & & 4,5 & 106,1 \\
\hline 21 au 30 & 35,8 & 101,4 & & & 3,9 & 97,5 \\
\hline pour le mois . & $44^{4}, 0$ & 296,7 & $-35,6$ & $+32,7$ & 8,4 & 329,5 \\
\hline
\end{tabular}

Sur le graphique 5 , on peut constater que si les courbes tracées ont une allure générale très voisine, des différences importantes n'en existent pas moins.

- A11 22 avril, les jeunes poussent mesurent $6 \mathrm{I} \mathrm{mm}$ en 1958 contre $87 \mathrm{~mm}$ en 1959 .

- La phase de démarrage de la végétation est nettement plus précoce et plus rapide en 1959 , l'avance étant de $\mathrm{I} 4$ jours.

- En I958 les hampes sont plus courtes qu'en I959; $735 \mathrm{~mm}$ contre $845 \mathrm{~mm}$, la différence étant de IIO $\mathrm{mm}$ soit I3 p. Ioo de la longueur de I959.

- En I959 les fleurs apparaissent avec 6 jours d'avance sur I958. 
- Par contre la longueur maximale des hampes est atteinte pour les deux années à la même date : le I 8 juin.

Si nous examinons ces différences en rapport avec les relevés météorologiques

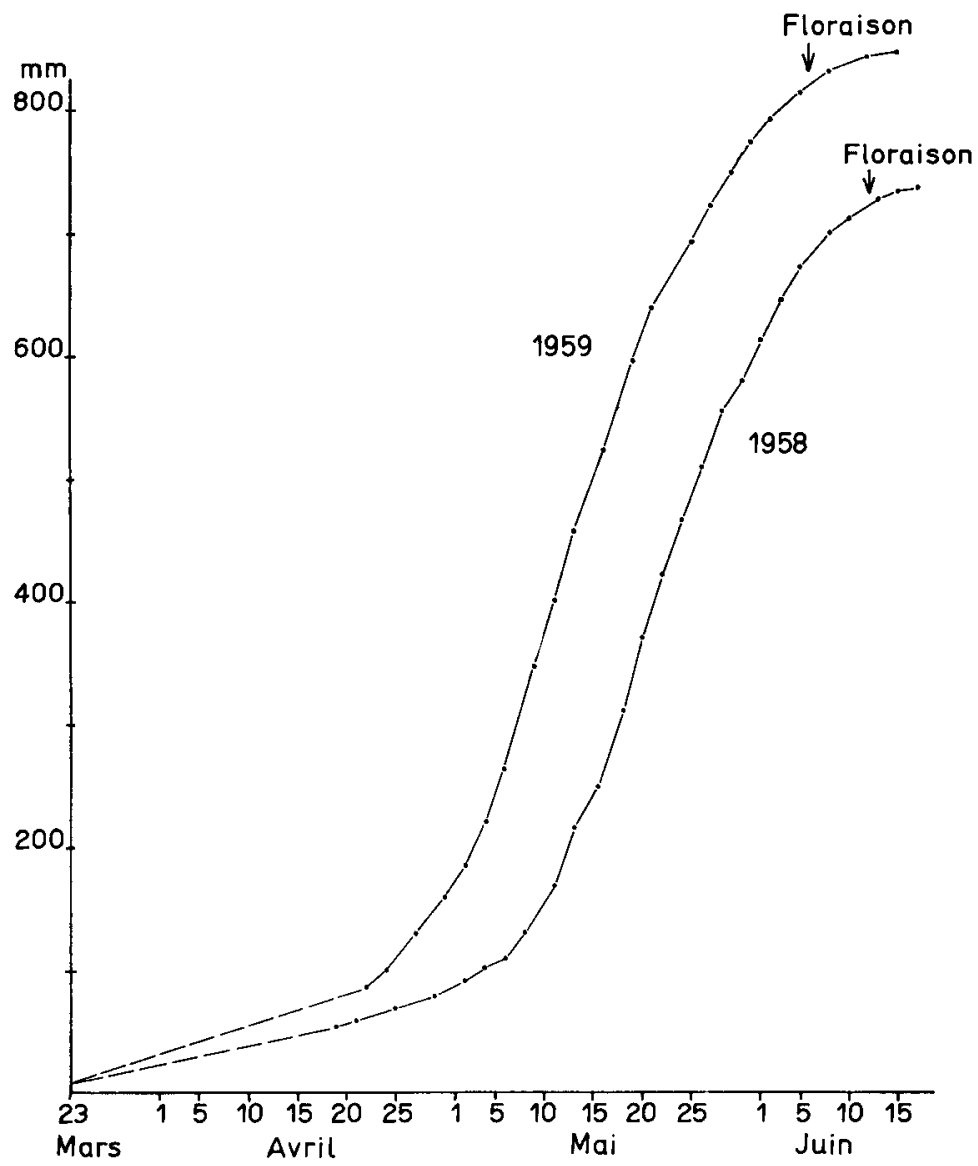

Frg. 5. - Allongement des hampes ches le lavandin Super $Z$ (Nice 1958 et 1959)

En I959, la végétation a été plus précoce et les hampes forales on eu un plus grand développement, mais leur longueur maximum a été alteinte en 1958 et en $\mathrm{I} 959$, à la même date.

(tableau 7 et figure 6) nous pouvons en dégager l'influence de divers facteurs du climat sur la végétation.

Le mois de mars, qui précède le réveil de la végétation présente en 1958 et 1959 des hauteurs de pluie voisines, mais les températures moyennes sont nettement plus élevées en I959.

Le mois d'avril, qui correspond à peu près au réveil de la végétation sous le climat de Nice, a reçu la même quantité d'eau pour les deux années, mais la répartition des pluies a été bien différente; en I958, les II $9 \mathrm{~mm}$ de pluie sont tombés d'une façon à peu près régulière pendant les $\mathrm{I} 6$ premiers jours du mois alors qu'en I959 sur les I20 mm, 79 sont tombés entre le I 7 et le I9 et entre le 28 et le 30 .

Toutefois, à ce moment de la végétation, les besoins en eau de la plante sont assez réduits, et les réserves du sol sont suffisamment importantes. 
I) Influence de la température.

Ein I959, pendant les deux premières décades du mois d'avril et malgré un déficit de pluviométrie, on constate qu'au 22 avril les hampes sont plus longues qu'en 1958 .

En mai l'action de la température est plus nette; c'est ainsi que les allongements suivants ont pu être observés en r959 entre deux mesures.

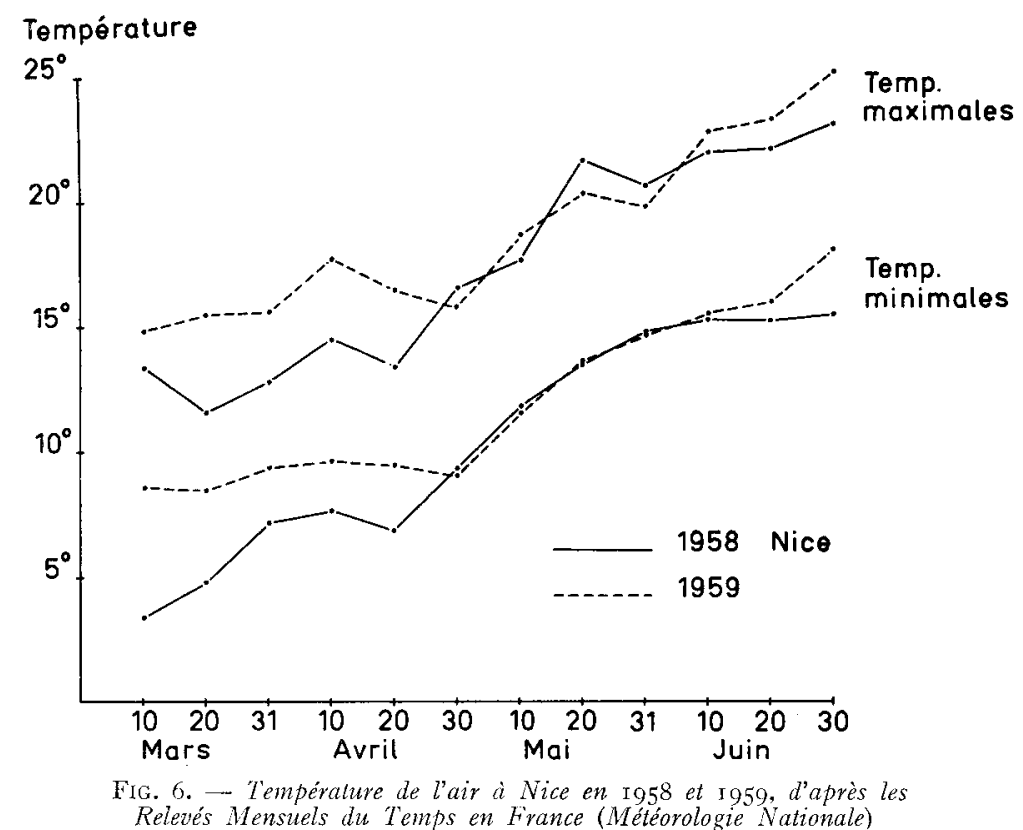

Du io mars au 30 avril les températures maximales et minimales ont élé nettement plus élevées en 1959 , ce qui explique l'ariance de la végétation pour celte année par rapport à 1958.

du I6 au I9 - 24, I mm - moyenne des températures diurnes $\left({ }^{1}\right) 22^{\circ}$

du Ig au $2 \mathrm{I}-2 \mathrm{I}, 5 \mathrm{~mm}$ - moyenne des températures diurnes $2 \mathrm{I}^{\circ}$

du $2 \mathrm{I}$ au $25-\mathrm{I} 3,5 \mathrm{~mm}$ - moyenne des températures diurnes $\mathrm{I} 7^{\circ}$.

Ce brusque ralentissement de la végétation se retrouve sur les courbes d'allongement des hampes des lavandins et des lavandes (voir les figures 3 , 4, et 5 ).

A l'inverse, une température élevée favorise un allongement journalier important. En I 958 en effet, à une élévation brusque de la température au cours des journées du Ig et 20 mai, correspond une poussée plus rapide.

2) Influence de la pluviométrie.

La température n'est pas le seul facteur intervenant dans l'allongement des hampes.

En effet, si nous considérons pour les deux années la période pendant laquelle

(1) Nous entendons par moyenne des températures diurnes la moyenne des températures des heures chaudes de la journée. Sous le climat méditérranéen ces températures sont nettement et brusquement très différentes de celles des heures nocturnes. 
TABLEAU 8

Variations de l'allongement d'une hampe sous l'influence de la température (mai 1958 Nice)

\begin{tabular}{|c|c|c|c|}
\hline \multirow{2}{*}{ Période } & \multirow{2}{*}{$\begin{array}{l}\text { Allongement en } \\
2 L_{\mathrm{t}} \text { heures }(9 \mathrm{~h} \text { à } 9 \mathrm{~h}) \\
(\mathrm{en} \mathrm{mm})\end{array}$} & \multicolumn{2}{|c|}{ Températures moyennes } \\
\hline & & diurnes & nocturnes \\
\hline 16 au 19 & 20,8 & 19,5 & 13,2 \\
\hline 19 au $21 \ldots$ & 29,4 & 23,0 & 16,4 \\
\hline 21 au $23 \ldots \ldots$ & 25,5 & 20,8 & 15,1 \\
\hline
\end{tabular}

les hampes ont eu un allongement maximum : i6 au ig mai 1958 et 6 au ig mai en I959 (voir figure 5), et si nous comparons les températures diurnes et nocturnes, nous constatons (tableau 9) qu'en 1958 cette période a été nettement plus chaude qu'en I959 et pourtant 1'allongement journalier moyen a été moins grand en I $95^{8}$.

\section{TABLEAU 9}

Températures moyennes et allongement journalier pendant la période d'allongement maximum des hampes en 1958 et 1959

\begin{tabular}{|c|c|c|c|}
\hline \multirow{2}{*}{ Période } & \multicolumn{2}{|c|}{ Températures moyennes } & \multirow{2}{*}{$\begin{array}{l}\text { Allongement journalier } \\
\text { moyen en mm }\end{array}$} \\
\hline & diurnes & noctumes & \\
\hline $\begin{array}{l}1958: 16 \text { au } 29 / 5 \ldots \\
1959: 6 \text { au } 19 / 5 \ldots\end{array}$ & $\begin{array}{l}21,03 \\
20,23\end{array}$ & $\begin{array}{l}14,69 \\
13,51\end{array}$ & $\begin{array}{l}23,20 \\
25,4^{\prime} t\end{array}$ \\
\hline
\end{tabular}

Or pour ces deux années, la pluviométrie a été toute différente.

En I958 : la période d'allongement intensif des hampes débute après 32 jours de sécheresse et le jour même d'une pluie de $9 \mathrm{~mm}$ qui sera la seule pendant cette période de végétation.

En I959: aucune période de sécheresse pendant les mêmes 32 jours; $120 \mathrm{~mm}$ d'eau, à peu près bien répartis ont permis la constitution d'importantes réserves dans le sol, réserves dans lesquelles la plante va pouvoir puiser tout à íoisir.

L'influence de l'humidité du sol sur le développement des hampes peut nous être encore confirmée par l'exemple suivant.

En I959, le I7 juin, une coupe très précoce sur la lavande " Matheronne " cultivée dans les Basses-Alpes, a permis le développement de nouvelles hampes qui furent récoltées le $\mathrm{I} 8$ août au moment de l'apparition des premières fleurs. Or ces hampes poussées pendant la période sèche étaient minces et courtes; elles avaient pris 1'allure " fragrans " alors que celles qui s'étaient développées au printemps étaient longues et puissantes et avaient nettement 1'allure "delphinensis ».

Mais l'allongement des hampes semble encore être freiné par le développement de l'épi et la formation des calices. 
En effet, pour les deux années I958 et I959, l'avance de végétation qui était de $I_{4}$ jours au début et pendant toute la période d'allongement intensif des hampes, n'est plus que de 8 jours pour l'apparition des premières fleurs, et l'allongement maximum des hampes survient à la même date, le I 8 juin.

Un tel synchronisme ne peut s'expliquer par le simple jeu des facteurs climatiques (température et humidité) dont l'importance était pourtant si grande dans les phases végétatives précédentes.

CHOUARD (I958) a montré qu'en soumettant Scabiosa ukranica à un éclairement prolongé on provoquait la formation de l'inflorescence, ce phénomène étant dî̀ à la présence d'une hormone élaborée par le végétal soumis à un tel éclairement.

Dans le cas qui nous intéresse, il est fort probable que le ralentissement, puis l'arrêt de l'allongement, ainsi que le développement de l'épi et des calices, soient provoqués par l'accumulation d'une hormone (ou de plusieurs) dont la formation dépendrait de la durée du jour.

\section{3. - ÉVOlution DU POIDS DES HAMPES FI.ORAI,ES}

Cette évolution a été examinée sur le Lavandin "Super Z " en culture à Nice en 1958 .

\section{a) Pesées}

Entre le 9 mai et le 9 juillet après chaque mesure de la longueur des hampes marquées, on recherchait 20 hampes ayant sensiblement la même longueur que la longueur moyenne déterminée.

Ces hampes étaient coupées à la hauteur de la dernière paire de feuilles d'automne puis immédiatement pesées en vert. Après séparation des différentes parties de la hampe (tige, feuilles et éventuellement épis et calices) elles étaient mises à sécher à l'étuve ventilée réglée à $60^{\circ}$ et, après dessiccation, pesées en sec.

A partir đu 9 juillet cette séparation des différentes parties de la hampe ne fut plus faite; les pesées furent effectuées pour les hampes entières en vert, puis en sec, avec seulement pesée des calices seuls.

\section{b) Evolution du poids des hampes}

et de la richesse en matière sèche (fig. 7)

I) Poids en vert :

Au 9 mai $195^{8}$, les hampes mesurent I20 $\mathrm{mm}$ et pèsent chacune I,54 g. 'I'rès rapidement leur poids augmente pour arriver au maximum de $4 \mathrm{~g}$ entre le I4 et le 23 juin. Par la suite on assiste à une lente diminution de ce poids qui redescend à 3,4 I g au I I septembre.

Des variations assez sensibles du poids en vert peuvent être remarquées sur le graphique. Elles sont dues aux conditions météorologiques qui font varier la transpiration de la plante.

2) Poids en sec :

L'évolution du poids en sec est par contre beaucoup plus régulière. Au 9 mai une hampe pèse $0,32 \mathrm{~g}$ et son poids atteint $\mathrm{I}, 4 \mathrm{~g}$ au 8 juillet. Par la suite ce poids progresse lentement jusqu'à I,53 g au 9 septembre. 


\section{3) Richesse en matière sèche:}

Cette courbe présente la particularité de subir une dépression très sensible entre le 9 et le 29 mai c'est-à-dire pendant toute la période au cours de laquelle 1'allongement des hampes est intensif. Pendant toute cette période les hampes sont minces, herbacées, molles et gorgées d'eau.

A partir du 29 mai et jusqu'au 8 juillet, la proportion de matière sèche augmente régulièrement sous l'action combinée d'influences diverses liées à la biologie de la plante.

a) du 29 mai au I9 juin, l'augmentation de la richesse en matière sèche est due à un certain ralentissement dans l'augmentation du poids en vert alors que le poids de la matière sèche progresse régulièrement; pendant ce temps les calices se forment, les hampes se renforcent et deviennent de plus en plus rigides.

b) du Ig juin au 8 juillet, la progression de la proportion de matière sèche qui atteint $38 \mathrm{p}$. Ioo est due à une diminution du poids en vert. Pendant cette période, on assiste à la formation de la plus grande partie des calices.

c) par la suite, la richesse en matière sèche augmente encore, mais plus lentement, sous l'influence d'une déshydratation progressive des hampes, alors que le poids de la matière sèche elle-même ne subit qu'une faible augmentation. Au moment de la disparition des dernières fleurs, le taux de matière sèche atteint ainsi $45 \mathrm{p}$. Ioo.

Il est à noter que, pour les Basses-Alpes, des pesées aussi complètes n'ont pu être réalisées, mais que les coupes faites à la faucille ont permis, après pesée en vert sur place et en sec à la sortie de l'étuve, de calculer la richesse en matière sèche. Les valeurs obtenues suivent la même progression que celle observée à Nice mais sont en général plus élevées.

Dès la période de pleine floraison, on relève de 45 à $50 \mathrm{p}$. Ioo de matière sèche, mais le sol et l'air sont constamment plus secs que sur le littoral et il y règne des vents, souvent violents, qui aggravent encore la sécheresse.

I a comparaison des figures 7 et 8 permet de constater que, parallèlement au ralentissement de l'allongement des hampes, correspond un ralentissement de l'augmentation du poids en vert et que, lorsque la longueur maximale est atteinte, le poids en vert subit une diminution assez sensible; pendant ce temps le poids en sec continue à progresser encore légèrement. Ceci confirme encore l'importance de l'eau pendant la période d'allongement intensif des hampes, comme cela vient d'être mis en évidence par la comparaison des années I958 et I959.

\section{c) Variations des proportions des différentes parties de la hampe florale (figure 8)}

L'étude de ces variations a été faite après dessiccation à l'étuve des hampes qui viennent d'être examinées ci-dessus.

Jusqu'au 9 mai la hampe s'est peu développée et la plante a surtout formé des feuiilies ; aussi, à cette date, ce sont elles qui constituent la plus grande partie de la masse végétale soit $86 \mathrm{p}$. Ioo.

Mais à partir du 9 mai, la plante ne forme plus de feuilles et le poids des hampes ne varie pratiquement pas. Par contre toute l'activité végétale se porte sur l'allon- 


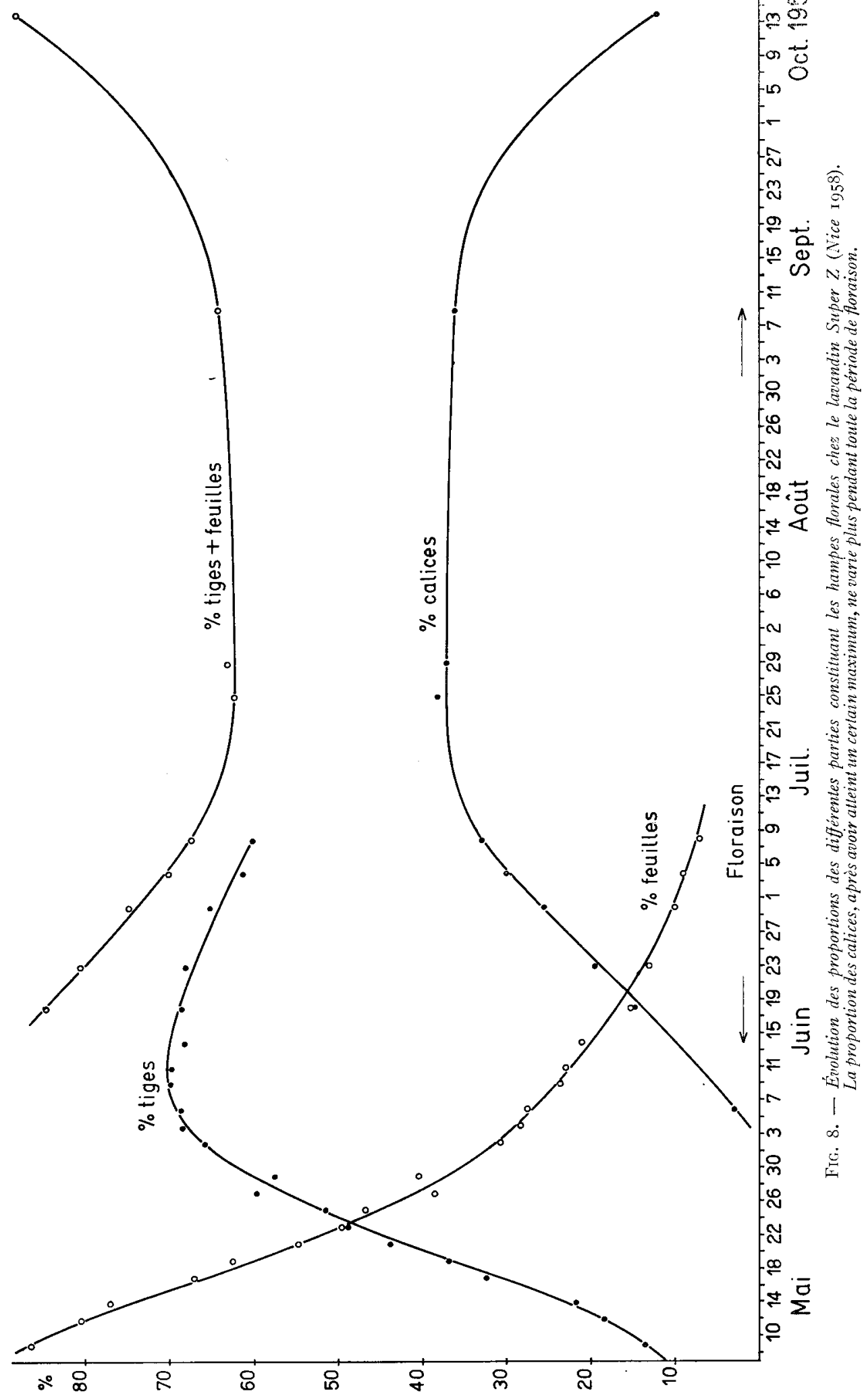


gement de la hampe dont le poids atigmente avec une grande rapidité. En conséquence les proportions des feuilles et de la tige s'inversent et au 6 juin la tige représente près de $70 \mathrm{p}$. Ioo du poids total.

Après le 6 juin, 1'allongement de la hampe entre dans une phase de ralentissement marqué et s'arrête bientôt ; son poids progresse encore un peu, mais les calices font leur apparition. Ceux-ci rares encore au 6 juin vont se former régulièrement jusque vers le $\mathrm{I} 7$ juillet. Parallèlement, leur proportion augmente en même temps que celle des feuilles et des hampes diminue.

Au-delà du 8 juillet où il n'était plus possible de continuer cette série, nous disposons de relevés faits sur des coupes plus importantes destinées à suivre l'évolution des rendements en essence.

Sur ces coupes, seuls les poids des calices et du reste des hampes (tiges + feuilles) ont été déterminés; aussi entre le $\mathrm{I} 8$ juin et le 8 juillet, la proportion de la partie herbacée a-t-elle été portée sur la figure de façon à pouvoir suivre son évolution ultérieure.

On peut constater ainsi que pendant toute la période où la plante porte des fleurs, c'est-à-dire pendant que la plante garde une certaine activité végétative, les proportions de calices et de matière herbacée varient peu.

Jusqu'au 25 juillet, la formation des calices se poursuit, mais après cette date, par suite de la chute de quelques-uns, leur proportion baisse très légèrement de $3^{8}$ à 36 p. Ioo.

Par contre, après la disparition des dernières fleurs, toute vie quitte la hampe ; celle-ci se dessèche et les calices tombent facilement sous l'influence du vent ou de la pluie. C'est ainsi qu'une coupe faite le I4 octobre ne fournit plus que i2 p. Ioo de calices malgré les précautions qui avaient été prises pour éviter leur chute au moment de la récolte.

I)ans les conditions normales de la récolte, une coupe faite à cette date aurait provoqué une chute importante des calices et fourni surtout des pailles, dont le rendement en essence aurait été extrêmement bas puisque ce sont les calices qui fournissent l'essence.

Dans les régions de culture où le climat est plus sec, cette chute des calices surviendra à une date d'autant plus précoce que les réserves en eau du sol seront moins grandes comme il ressort de l'observation suivante.

Lans une jeune plantation d'oliviers réalisée en coteau, dans le Vaucluse, une culture de lavandin avait été faite dans les interlignes. Au cours de l'été de la première récolte, toutes les plantes d'une bande de terrain, en travers du champ, se desséchèrent rapidement alors que le reste de la culture était encore en pleine végétation et couverte de fleurs. Les rendements en essence obtenus avec ces hampes furent inférieurs à ceux des plantes ayant eu une vie active plus longue.

Or, les lavandins à végétation écourtée poussaient sur un sol peu profond recouvrant un affleurement rocheux et le manque de réserve d'eau était cause de cette dessiccation précoce dont la conséquence fut l'arrêt de la formation des calices qui entraîna une diminution du rendement, et la chute d'un grand nombre de ceux-ci. C'est également à cette chute des calices que 1'on doit attribuer les baisses de rendements dues à des pluies violentes ou à la chute de grêle $\left({ }^{1}\right)$.

(1) Nous n'envisagreons ici que lés rendements calculés sur le poids sec ou rapportés par pieds ou à l'hectare, et non pas les rendements calculés sur le poids vert, dont les variations continuelles sont sous la dépendance d'une pluie ou d'un vent sec. 
Les praticiens avaient bien constaté que certaines distillations de lavandes avaient un très faible rendement en essence et ils prétendaient que les plants étaient " estoufées ". Dans le cas des lavandes, la chute des calices peut être évoquée mais nous verrons que cette diminution de rendement peut être provoquée par un phénomène biologique particulier à la lavande.

I'observation de la courbe de proportion des calices tracée à la figure 8 montre bien que tant que les hampes gardent une certaine activité végétative, ce qui se
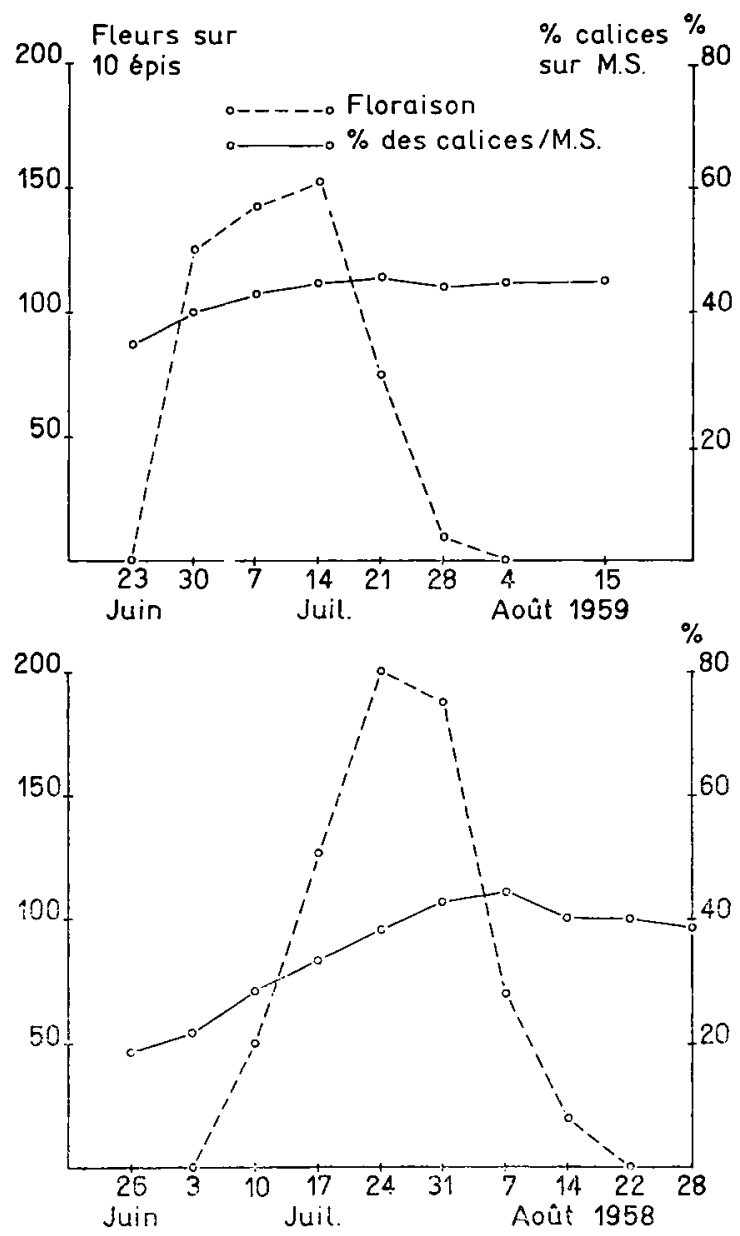

Lisi. o. Intensité de la Rartison et proportion des culices

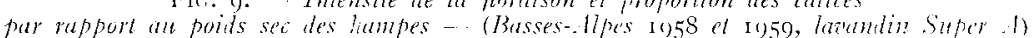
Pourles deux années, le maximum de calices est constaté en fin de fluraison.

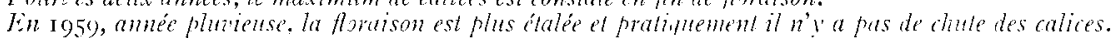

matérialise par la persistance de la floraison, la chute des calices n'est pas à craindre. Aussi n'y a-t-il aucun intérêt à procéder à une coupe précoce de la "variété " de Lavandin "Super $Z$ " d'autant plus que le rendement en essence et la qualité de celleci ne cessent de s'améliorer (BARBIER, I950; MAUREI, et BARBIER, I958). 
Pour les autres "variétés " de lavandins, nous ne possédons que les relevés hebdomadaires effectués dans les Basses-Alpes et destinés à suivre 1'évolution des rendements en essence.

Sans doute, sur la figure 9 constate-t-on pour I958 une certaine baisse de la proportion des calices qui survient avant que la floraison ne soit complètement achevée ; mais cette année a été assez pluvieuse pour que le sol constitue des réserves d'eau suffisantes; il n'y a pratiquement pas de chute de calices tout comme cela avait été constaté à Nice sur la "variété " "Super $Z$ ".

Cette chute des calices semble due en définitive à un état physiologique de la plante et le producteur aura donc toujours intérêt à suivre la végétation de la culture avant de décider de l'époque de la coupe. Celle-ci, en année humide, devra toujours être effectuée après la disparition des fleurs mais en année sèche il sera bon de couper un peu plus tôt. En aucun cas il n'y a intérêt à couper en pleine floraison, comme cela se fait trop souvent.

Par ailleurs, les exemples des années I958 et I959 montrent bien que l'époque de coupe n'a rien à voir avec le calendrier, mais qu'elle doit être fixée par l'état de la végétation des plantes.

En ce qui concerne les Lavandes vraies, le problème est beaucoup plus complexe car, à la chute normale des calices, s'ajoute une disparition plus ou moins rapide de l'essence contenue dans les cellules. Ce phénomène particulier à la lavande est lié à l'activité biologique de la plante.

\section{B. - Evolution Morale}

En dehors de la parure que revêtent les lavandes et les lavandins pendant la floraison, celle-ci mérite d'être examinée avec attention car elle constitue un repère phénologique pour déterminer le moment de la coupe.

Malgré l'importance que présente la floraison, la littérature ne fournit que bien peu de renseignements utiles, en dehors de l'existence d'un certain décalage entre les floraisons de la lavande vraie, du lavandin et de l'aspic (GAtTefosse, I927 : Etablissement CHIRIS, I926 ; IGOLEN, I944).

\section{I - APPARITION DES FItEURS SUR I'ÉPI}

FONDARD (I948) indique : "L'épi de lavande commence sa floraison par le bas et la continue progressivement vers le sommet, si bien que, lorsque les fleurs du haut de l'épi sont en plein épanouissement celles du bas portent des graines déjà avancées. "

Mais de très nombreux comptages de fleurs, répétés sur diverses variétés de lavandes et aussi de lavandins nous permettent d'affirmer que la floraison de l'épi n'est pas aussi simple.

S'il est exact que la floraison débute par les épillets du bas, il n'en est pas moins vrai que, dans les quelques jours qui suivent, tous les épillets portent des fleurs et que celles-ci apparaissent pendant toute la période de pleine floraison sur les épillets inférieurs alors que ceux du sommet portent, avec des fleurs épanouies, des fleurs fanées depuis longtemps. 
Chez les Lavandins, au moment où la hampe termine son allongement, le nombre des épillets a atteint son maximum, mais le développement de ces épillets est loin d'être achevé. Sur les figures 7 et 8 nous voyons que l'allongement des hampes est terminé depuis le I4 juin alors que l'importance des calices continue à augmenter jusque vers le 25 juillet. Il est à noter que la proportion des calices continue à augmenter sans que le poids de la hampe augmente sensiblement.

Ainsi, sans considération de la position de l'épillet sur l'épi, les corolles s'épanouissent dès que chaque fleur a terminé son développement et cela aussi bien chez les lavandes que chez les lavandins.

En dehors de ces observations, le rythme de l'épanouissement des corolles subit des variations importantes qui vont être examinées ici, et grâce auxquelles nous allons essayer de dégager l'influence de divers facteurs de climat.

\section{2 - RYTHME JOURNALIER DE LA FLORAISON}

La floraison journalière a été étudiée à Nice en juin I 960 sur deux «variétés » de lavande vraie : la "Maillette » et la "Matheronne », cultivées côte-à-côte.

Les plants sont âgés respectivement de 3 à 5 ans; ils sont bien développés et leur floraison située juste au déclin de la pleine floraison est encore abondante.

\section{a) Technique}

Pour chaque variété on repère à l'aide d'étiquettes 30 hampes florales réparties sur 3 plants. Les résultats obtenus seront exprimés sur le tableau et les graphiques pour Ioo hampes.

Le I4 juin à I $8 \mathrm{~h}$, toutes les corolles présentes sur les épis sont arrachées et les jours suivants les corolles épanouies sont dénombrées 4 fois par jour : $9 \mathrm{~h}$ II h $30-I_{4}$ h et $\mathrm{I} 8 \mathrm{~h}$. Au cours du dernier comptage toutes les corolles ouvertes pendant les 24 heures précédentes sont arrachées. Notons qu'elles sont apparues à tous les étages de l'épi.

Par ailleurs au début de chaque dénombrement des fleurs, les relevés météorologiques suivants sont effectués : insolation, nébulosité, vitesse du vent selon l'échelle préconisée par ANGOT (I93I) ainsi que température, humidité et pouvoir évaporant de l'air.

A cet effet un abri type anglais, installé à proximité immédiate des plants de culture, contient un thermomètre-hygromètre enregistreur, un psychromètre destiné à contrôler la marche de l'appareil et un évaporomètre du type PICHE, dont le tube étroit permet de mesurer une évaporation apparente 4 fois plus importante que celle du Piche ordinaire, ce qui facilite la lecture (la pénétration régulière de l'air qui aurait pu être gênée est assurée par une fine perforation au centre du disque évaporateur).

Sur le tableau Io, les relevés météorologiques sont exprimés sous forme de moyennes horaires pour la période considérée et le pouvoir évaporant de l'air, également exprimé en moyennes horaires, est calculé sur une évaporation convertie, telle qu'elle aurait été fournie par un Piche ordinaire. 
I,AVANDES ET APICUITURE

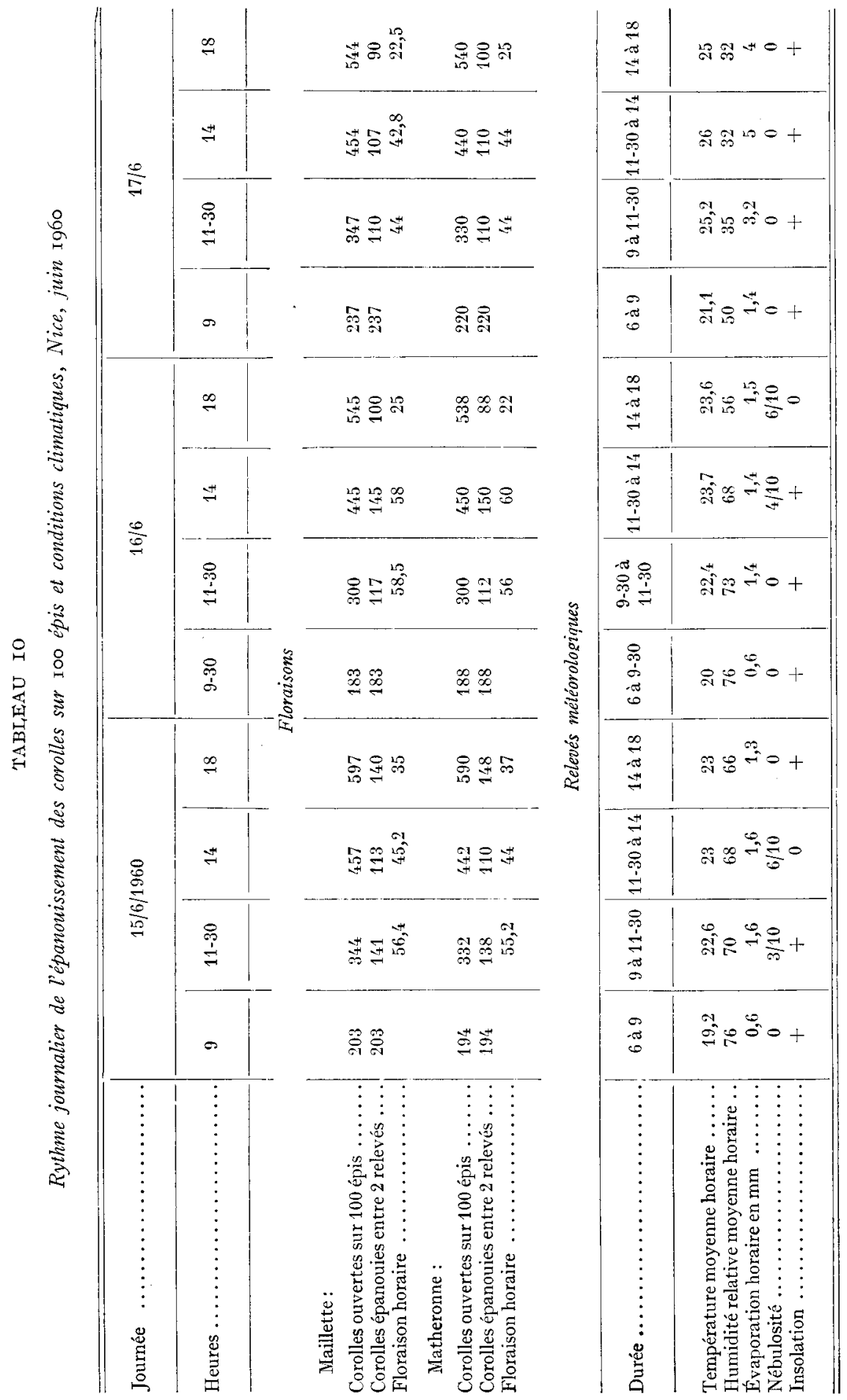


L'examen de ce tableau permet de constater combien les floraisons des deux variétés sont voisines et combien sont identiques leurs variations au cours de la journée. Sans conteste ces variations sont dues aux facteurs du climat parmi lesquels la température, 1'humidité et l'ensoleillement jouent un grand rôle.

\section{b) Action de la température}

Si nous considérons les floraisons relevées à 9 h les $I_{5}$ et $\mathrm{I}_{7}$ juin, on remarque qu'à une augmentation assez sensible des températures moyennes calculées entre $o$ et 6 heures et entre 6 et $9 h$, correspond une certaine augmentation du nombre des corolles, ainsi qu'un pourcentage de cette floraison plus élevé par rapport à la floraison journalière.

TABLEAU II

Floraison matinale et température moyenne

\begin{tabular}{|c|c|c|c|c|}
\hline Date & \multicolumn{2}{|c|}{$15 \cdot 6 \cdot 1960$} & \multicolumn{2}{|c|}{$17 / 6 / 60$} \\
\hline $\begin{array}{c}\text { Température moyenne de : } \\
\text { o hà } 6 \mathrm{~h} \quad \ldots \ldots \ldots \ldots \ldots \\
6 \text { hà } 9 \mathrm{~h} . \ldots \ldots \ldots \ldots \ldots\end{array}$ & 17 & & & \\
\hline Floraison & $\begin{array}{l}\text { nombre de corolles } \\
\text { épanouies à } 9 \mathrm{~h}\end{array}$ & $\begin{array}{l}\% \text { par rapport à la } \\
\text { floraison de la } \\
\text { journée }\end{array}$ & $\begin{array}{l}\text { nombre de corolles } \\
\text { épanouies à } 9 \mathrm{~h}\end{array}$ & $\begin{array}{c}\text { \% par rapport à la } \\
\text { floraison }\end{array}$ \\
\hline $\begin{array}{l}\text { Variété Maillette .......... } \\
\text { Variété Matheronne ...... }\end{array}$ & $\begin{array}{l}203 \\
19 t_{4}\end{array}$ & $\begin{array}{l}34 \\
32,8\end{array}$ & $\begin{array}{l}237 \\
220\end{array}$ & $\begin{array}{l}43,5 \\
40,7\end{array}$ \\
\hline
\end{tabular}

L'influence de la température qui avait été étudiée par PFEFFER en I873 puis plus récemment par GLAESER (cités par JAEGER, I959) apparaît ici comme un facteur très important pour la floraison de la lavande; mais ce facteur n'est pas seul à contrôler l'épanouissement des fleurs.

\section{c) Action de l'ensoleillement}

Alors que pour les I6 et I7 juin le rythme des éclosions se maintient sensiblement à la même intensité jusqu'à $\mathrm{I} 4$ heures, on peut constater une diminution très sensible de la floraison le $\mathrm{I}_{5}$, entre II $\mathrm{h} 30$ et $\mathrm{I} 4 \mathrm{~h}$, en même temps que le ciel devient nuageux et que le soleil reste caché.

Bien que la température de l'air n'ait pas baissé pendant cette période, il est difficile de préciser comment l'ensoleillement intervient. Quoi qu'il en soit, dès que les nuages ont disparu, juste après le comptage, l'intensité de la floraison, au lieu de diminuer dans les mêmes proportions que les jours suivants, se maintient à un rythme relativement élevé (figure Io).

\section{d) Action de l'humidité de l'air}

On connaît sur Carlina acaulis L., ou sur la rose de Jéricho, 1'influence considérable de l'humidité de l'air sur les mouvements de l'involucre qui réagit simplement comme un hygromètre. Mais dans le cas de la lavande, l'humidité atmosphérique 
a une influence directe sur un phénomène biologique : l'épanouissement même des corolles.

Ainsi, dans la journée du I7 où l'air a été particulièrement sec et malgré une température plus élevée, l'intensité de la floraison a été nettement plus basse, entre $9 \mathrm{~h}$ et $\mathrm{I} 4 \mathrm{~h}$, que celle qui a été enregistrée pendant les mêmes périodes pour les journées du $\mathrm{I} 5$ et $\mathrm{I} 6$.

\section{e) Action de la pluie}

Au cours des opérations préliminaires à ces essais, nous avons pu constater incidemment l'action d'une pluie artificielle.

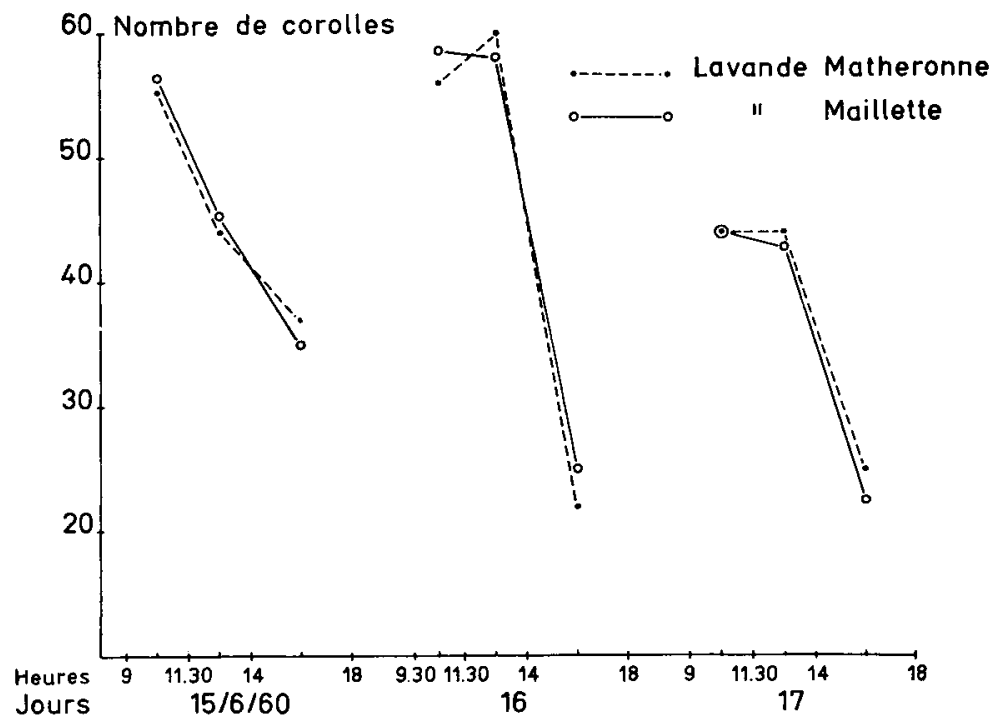

FIG. Io. - Rythme journalier de l'éclosion des corolles chez deux lavandes (Nice 1960) Les éclosions sont exprimées en nombre de corolles épanouies à l'heure sur roo épis.

Le 1.5 - entre I I $h 30$ el 4 h, le ralentissement des éclosions est dî̀ la l'absence d'ensoleillement, - entre 14 h et $\mathrm{I} 8 \mathrm{~h}$. le talux élevé des éclosions est dû̀ à une humidité relative de l'air assez élevée.

Les $\mathrm{I} 6$ et $\mathrm{I} 7$ - entre $\mathrm{I}+$ et $\mathrm{i} 8 \mathrm{~h}$, et le $\mathrm{I} 7$ de $9 \mathrm{~h}$ à $\mathrm{I} 4 \mathrm{~h}$, les éclosions sont peu nombreuses, en relation avec la faible humidité de l'air.

Un des plants de la variété Matheronne sur lequel les corolles portées par Io hampes avaient été arrachées, comme sur les autres, s'était trouvé arrosé par l'un des jets d'une rampe d'arrosage installée sur du gazon voisin. L'aspersion dura jusqu'au soir où, au moment du comptage, les hampes ne portaient pas de fleurs ; mais le lendemain matin on pouvait dénombrer sur ces hampes environ $5^{\circ} \mathrm{p}$. roo de fleurs en plus que sur les hampes des plants non arrosés.

Ainsi le rythme de l'éclosion des fleurs des Lavandes et très certainement aussi des Lavandins, est sous la dépendance de plusieurs facteurs parmi lesquels la température, 1'humidité et l'ensoleillement jouent un rôle très important. Aussi n'est-i1 pas étonnant qu'après une période de pluie pendant laquelle la floraison a été freinée par l'absence de soleil et aussi par la pluie elle-même, puis favorisée par l'humidité de l'air des jours suivants, les champs offrent à la vue une intense coloration bleue.

De l'action des divers facteurs on peut conclure que pendant les heures nocturnes, 
l'épanouissement des corolles, si toutefois il n'est pas totalement interrompu, doit être extrêmement faible. En effet le grand nombre de fleurs trouvées le matin semble dû̀ à la longue période qui précède le comptage de 9 heures (à Nice, à cette époque, le soleil se lève à $4 \mathrm{~h} 30$, heure civile) et aussi à l'accumulation de l'eau dans le végétal au cours de la nuit qui est la conséquence de la forte humidité nocturne, du faible pouvoir évaporant de l'air et de la très faible transpiration de la plante.

Pendant cette période matinale, la température joue un rôle important; puis, lorsque la plante a perdu une forte proportion de l'eau en réserve, le rythme de la floraison baisse et semble s'équilibrer avec les entrées et les sorties d'eau.

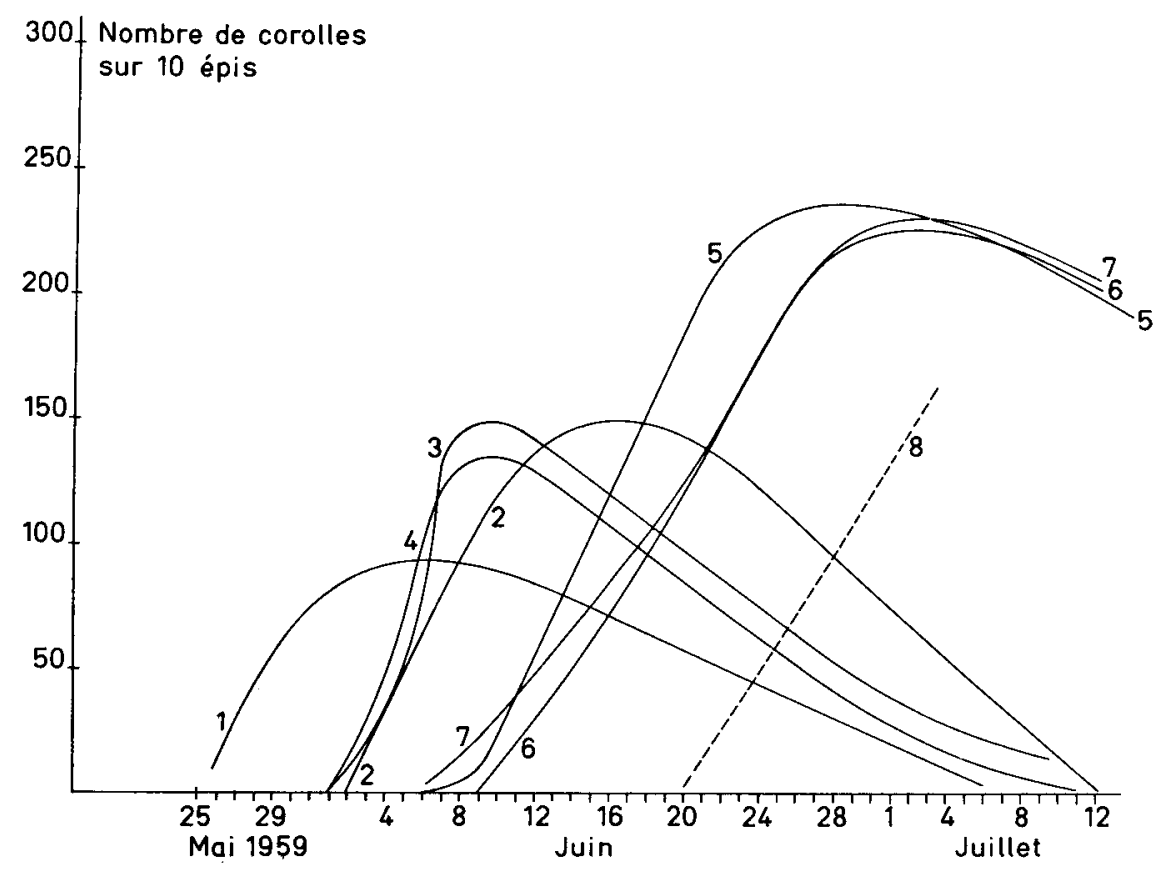

FIG. II. - Nombre de corolles épanoties sur ro épis de lavandes et de lavandins.

(Nice 1959. Plusieurs relevés hebdömadaires)

I - Lavande Ordinaire
2 - Lavande Verte
3 - Lavande Maillette
4 - Lavande Vatheronne
5 - Lavandin Super Z. (sur épi principal)
6 - Lavandin Blanc
7 - Lavandin Super A
8 - Lavandin Abrial

Les lavandes sont plus précoces que les lavandins ; parmi ces derniers, la variété Abrial est nettement tardive.

\section{3 - ÉPOQUE ET INTENSTTÉ DE TA FLORAISON}

Si nous considérons la floraison au cours des jours successifs, nous constatons que la floraison évolue d'une façon assez constante ; après un départ rapide, le nombre des corolles passe par un certain maximum puis diminue assez rapidement au début mais se maintient plus ou moins avant de s'interrompre définitivement.

A Nice en I959, dès l'apparition des premières fleurs, dix hampes réparties 
sur 3 ou 4 plantes pour chacune des variétés cultivées en collection sont numérotées ; tous les 2 à 3 jours les corolles ouvertes sont dénombrées entre ro et II $h$.

Les courbes tracées à la figure II font abstraction des fluctuations dues aux facteurs climatiques et représentent la floraison moyenne de chaque variété. L'examen de ces relevés permet de faire plusieurs constatations.

Io) Les lavandes sont plus précoces que les lavandins. L'apparition des premières fleurs chez les lavandes se situe avec une avance de 6 à 7 jours par rapport aux lavandins. Mais au moment de la floraison maximale les lavandins accusent un retard d'une vingtaine de jours.

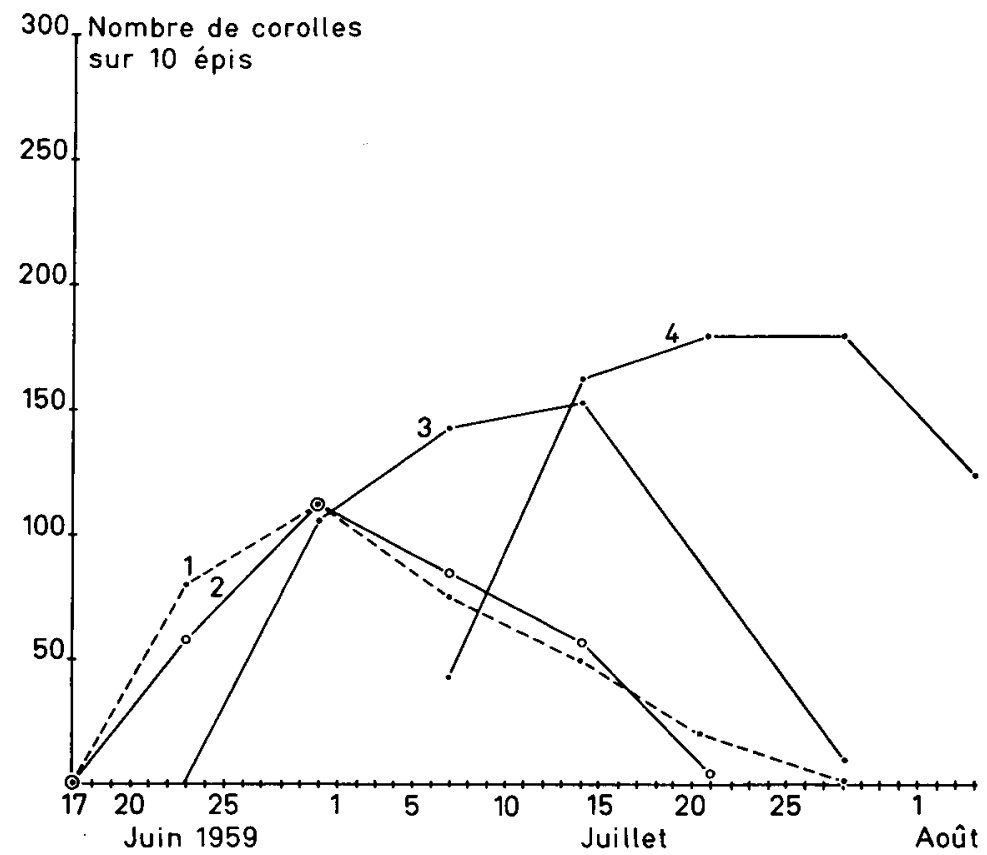

FIG. 12. - Nombre de corolles épanouies sur 10 épis de lanande et de lavandin (Basses Alpes 1959. Releztés hebdomadaires).

I - Lavande Matheronne.

2 -.. I avande Jaillette.

3 - Iavandin Super i (sur epi principal).

4 - Iavandin Abrial.

$\left.2^{0}\right)$ La période de pleine floraison chez les lavandins est notoirement plus longue que chez les lavandes. (figure II)

$\left.3^{\circ}\right)$ Pour chaque groupe de plantes, il existe aussi des types dont la floraison est particulière comme la lavande "ordinaire " qui est nettement précoce, le lavandin "Abrial " qui est très tardif ou encore la lavande "verte " dont la floraison est assez étalée.

$\left.4^{\circ}\right)$ L'intensité de la floraison est nettement plus élevée chez les lavandins comme le laissait prévoir le décompte des fleurs portées par les épis (voir tableau 3).

Pour le lavandin "Super Z ", nous disposons de relevés de floraison effectués au cours de plusieurs années. Selon les conditions météorologiques, on constate une différence de précocité qui peut atteindre 8 à Io jours pour l'apparition des premières fleurs et allant jusqu'à I 5 jours pour la pleine floraison. Pendant cette 
période on constate des variations assez importantes dans le nombre des fleurs épanouies qui sont en relation avec le climat, mais l'allure générale ne varie pas sensiblement. Toutefois cette période de pleine floraison se trouve interrompue plus ou moins rapidement selon la rigueur de la sécheresse.

En ce qui concerne la région des Basses-Alpes, les très nombreux relevés effectués chaque année de semaine en semaine pour suivre l'évolution des essences permettent de constater un certain retard de végétation entre le littoral méditerranéen et les régions situées en altitude. Selon les années ce retard varie entre 15 et 20 jours.

Pour I959 il est de I7 jours et les écarts entre les diverses variétés en culture près de Puimoisson à $700 \mathrm{~m}$ d'altitude sont les mêmes que ceux relevés à Nice. On note seulement entre les deux stations une intensité de floraison moins forte pour les Basses-Alpes, différence due sans doute à une moins grande richesse du sol et aussi à une plus grande sécheresse (figures I I et 12 ).

\section{4) DURÉE DE VIE DE LA COROLILE}

Dans les conditions normales c'est-à-dire en plein air, alors que les insectes butinent activement, la corolle passe par les phases suivantes.

Au moment où l'opercule qui obture le calice se soulève pour laisser passer la corolle, celle-ci se présente sous forme d'un tube fermé à son extrémité et sa couleur est bleu pâle. Après s'être allongé pendant quelques heures, ce tube s'ouvre; les deux lobes supérieurs se redressent, bientôt imités par les trois lobes inférieurs et tous ensemble vont se développer jusqu'à donner à la corolle sa physionomie particulière.

La couleur bleue pâle persiste ainsi pendant 36 à 48 heures. Pendant ce temps, les insectes et particulièrement les abeilles au cours de leurs multiples visites, ont prélevé pollen et nectar. Mais bientôt la couleur vire au bleu foncé et très rapidement la corolle perd sa turgescence elle prend une couleur de plus en plus grise et se flétrit; les lobes se rapprochent et 48 à 60 heures après 1'ouverture des lobes la corolle fanée a terminé sa vie éphémère.

C'est cette durée de vie, qui porte sur 2 jours à 2 jours et demi, qui fait que lors des comptages de floraison, le nombre de fleurs présentes sur les hampes est toujours plus élevé que celui de la floraison journalière (voir Matheronne et Maillette pour les journées du I5 au I7 juin).

Quant aux fleurs protégées des abeilles, leur durée de vie atteint Io à $\mathbf{2} 2$ jours. 


\section{VALEUR APICOLE, PRINCIPALEMENT DES LAVANDINS}

L'extraordinaire développement des cultures de lavande et principalement de lavandin a permis, ces plantes étant très mellifères, un accroissement important de l'apiculture dans les départements où sont cultivées ces plantes et dans les départements limitrophes.

Comme sur un très grand nombre de plantes mellifères, l'abeille peut récolter sur les lavandes du pollen et du nectar, alors que les lavandins ne lui offrent pratiquement que du nectar. Cette particularité propre aux lavandins a des conséquences très importantes pour l'équilibre biologique de la colonie et la pratique apicole, ainsi que pour la composition pollinique des miels.

\section{A. - Le nectar}

\section{I - ÉTUDE DE LA SÉCRÉTION NECTARIFÈrRE}

C'est surtout pour leur production nectarifère que les lavandes et surtout les lavandins sont connus en tant que plantes apicoles, aussi bien par les producteurs que par les consommateurs.

Le nectar de lavande a été étudié par BonNIER (I878) et plus récemment par MaUrizio (I959). Mais nos travaux ont porté sur le nectar des lavandins "Super Z " sous le climat de Nice (A.-M.) et "Grande Bleue " à Allemagne-en-Provence (B.-A.)

\section{a) Prélèvement à la pipette}

Sur un plant protégé des abeilles, environ 200 fleurs de même âge sont marquées avec des étiquettes numérotées, collées sur les calices.

L'âge des fleurs est déterminé par le moment où les lobes de la corolle se sont soulevés entre deux observations effectuées le matin à 9 h et à to $h 30$.

A la fin de l'opération de marquage des fleurs, et par la suite chaque jour à 9 heures et I7 heures, Io fleurs sont récoltées en sectionnant le pédoncule et transportées au laboratoire pour procéder au prélèvement du nectar.

Afin d'éviter une concentration du nectar pendant la récolte et le transport ( 3 à 4 minutes seulement) les fleurs sont introduites dans une boîte dès leur récolte pour les protéger du soleil et du vent. 
Au laboratoire, le calice est ouvert de façon à mettre le tube de la corolle à nu et rendre ainsi visible par transparence, le nectar rassemblé au fond du tube.

On introduit alors l'extrémité effilée d'une petite ampoule dans le tube de la corolle, et, à l'aide d'un tuyau souple s'adaptant à l'autre extrémité de l'ampoule, le nectar est aspiré.

Les ampoules sont faites avec du tube de verre de $5 \mathrm{~mm}$ de diamètre intérieur, étiré aux extrémités; l'une d'elle, très effilée, mesure environ 20 à $25 \mathrm{~mm}$ de long, alors que l'autre, coupée très court, facilite l'adaptation du tube de caoutchouc. Le corps de l'ampoule mesure également $20 \mathrm{~mm}$ de longueur et la capacité totale voisine $0,3 \mathrm{ml}$.

L'ampoule seule, préalablement tarée, est alors portée sur une balance sensible et pesée à $x$ /ro de $\mathrm{mg}$ près ; ce poids est relevé et la double opération de prélèvement et de pesée est répétée successivement avec la même ampoule pour les ro fleurs du lot. Cette façon d'opérer permet de contrôler la régularité des sécrétions et le cas échéant d'éliminer dans les calculs la ou les fleurs qui pourraient avoir une sécrétion anormale. Si plus de 2 fleurs sont dans ce cas, la série est éliminée.

Aussitôt cette opération terminée, on introduit dans le fond du tube de la corolle, toujours à l'aide de la pointe d'une ampoule, 2 à 3 millimètres cubes d'eau distillée pour faire un rinçage. Environ I minute après, cette eau est prélevée avec une troisième ampoule tarée, son poids et sa richesse en sucre sont déterminés et éventuellement la quantité du sucre contenue dans cette eau de rinçage, sera ajoutée au sucre contenu dans le nectar.

Mais il convient de signaler que ces eaux, si le prélèvement du nectar a été bien fait, ne contiennent que très peu de sucre, même lorsque la concentration du nectar est élevée, comme le montre le tableau suivant où sont portés les chiffres obtenus avec la série 73 .

Il n'en serait pas de même si l'anatomie interne de la fleur se trouvait compliquée par la présence d'étamines prenant naissance au voisinage du nectaire, ce qui provoquerait forcément des retenues de nectar.

TABLEAU I 2

Quantités de sucre contenu dans le nectar et dans les eaux de rinçage de Io fleurs de lavandin (juillet 1954 Nice)

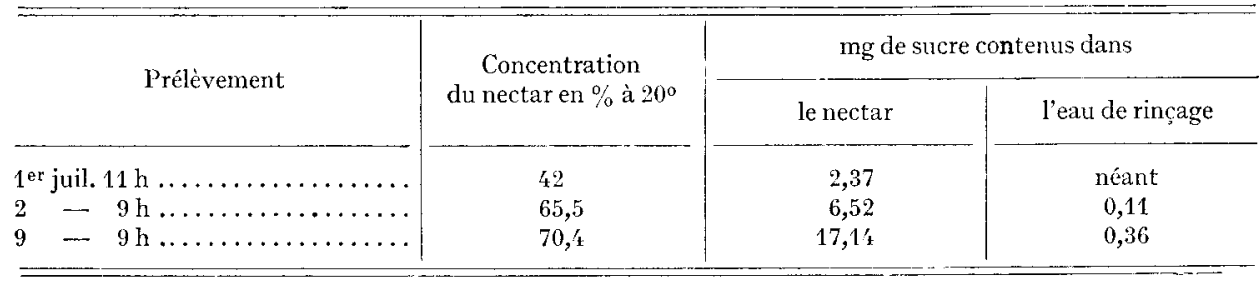

A la fin de l'opération de prélèvement du nectar 1'ampoule contient la totalité du nectar produit par Io fleurs du lot et la pesée en est faite.

Ce nectar est alors déposé entre les prismes d'un réfractomètre après homogéisation par quelques aspirations et refoulements successifs. Sa concentration est alors déterminée en tenant compte de la température. 
Par examen du nectar extrait des lots de fleurs récoltées successivement il est possible de suivre la production de nectar et de sucre pendant toute la période où ces fleurs restent ouvertes.

\section{b) Observations sur la sécrétion nectarifère}

I) Présence du nectar avant l'ouverture de la fleur

Chez la lavande, Bonnier (I878) a signalé la présence de nectar dans la fleur avant l'épanouissement de la corolle. Chez le lavandin la même observation peut être faite, mais nous avons remarqué que la concentration de ce nectar est la plupart du temps assez élevée et, sauf changement important du climat, toujours supérieure à celle du nectar s'écoulant par la suite.

TABLEAU $I_{3}$

Nectar et sucre contenus dans io feurs au moment de l'ouverture des corolles

\begin{tabular}{|c|c|c|c|c|}
\hline Serie & J)ate & mgrectar & $\%$ sucres & mg sucre \\
\hline $72 \ldots \ldots \ldots$ & $22: 6 / 5 / 5$ & 13,3 & 25,2 & 3,37 \\
\hline $73 \ldots \ldots \ldots \ldots \ldots \ldots$ & $1 / 7 / 5^{\prime}$ & $5, i$ & 42,4 & 2,37 \\
\hline $81 \ldots \ldots \ldots \ldots \ldots \ldots$ & $18 / 7 / 56$ & 7,6 & 50,5 & 4,60 \\
\hline
\end{tabular}

La période pendant laquelle le nectar s'est écoulé ne peut être connue, mais il est infiniment probable que la quantité et la concentration de ce nectar sont déterminées :

a) par les conditions climatologiques du moment et dont nous avons pu relever l'influence sur la sécrétion nectarifère des Eucalyptus (BARBIER, I95I et I952).

b) par l'abondance des réserves sucrées contenues dans les nectaires.

Notons que sur la concentration du nectar le pouvoir évaporant de l'air n'a pu avoir aucune action directe puisque le nectar était protégé par la corolle encore fermée.

2) Concentration du nectar sous l'action du pouvoir évaporant de l'air.

Le climat méditerranéen est connu pour sa sécheresse, tout au moins aux heures chaudes de la journée, et il était intéressant de rechercher les modifications subies par le nectar contenu dans les corolles et dues au pouvoir évaporant de l'air.

Cette expérience a porté sur des fleurs de même âge, marquées au moment de l'épanouissement de la corolle, et abandonnées au butinage des abeilles pour que toute trace de nectar soit enlevée. Au moment de l'essai, les fleurs sont protégées des abeilles par une cage. Wans le même temps, le tube de la corolle de certaines autres fleurs est fermé avec une très petite pince, 24 heures après le nectar fourni par les deux lots est examiné.

3) Variations de la sécrétion nectarifère au cours de la vie de la fleur.

Pour étudier ces variations en dehors de toute action des facteurs du climat, l'expérience suivante a été réalisée. 
TABLEAU I4

Concentration du nectar due au pouvoir ézaporant de l'air

\begin{tabular}{|c|c|c|c|}
\hline & Poids du nectar en mg & Richesse en sucre & Poids du sucre en mg \\
\hline \multicolumn{4}{|l|}{ Nice du 10 an 11 juin 56} \\
\hline $\begin{array}{l}10 \text { fleurs ouvertes } \ldots \ldots \ldots \ldots \ldots \\
10 \text { fleurs avec pinces } \ldots \ldots \ldots \ldots \ldots\end{array}$ & $\begin{array}{l}15,0 \\
27,2\end{array}$ & $\begin{array}{l}62,2 \\
36,8\end{array}$ & $\begin{array}{r}9,33 \\
10,00\end{array}$ \\
\hline Basses-Alpes 10 au 20 juil. 56 & & & \\
\hline 10 fleurs onvertes $\ldots \ldots \ldots \ldots \ldots$. & $?$ & 63,4 & $?$ \\
\hline 10 fleurs avec pinces.$\ldots \ldots \ldots \ldots$ & $?$ & 46,8 & $?$ \\
\hline
\end{tabular}

Sur un plant normalement butiné par les abeilles, chaque jour à 9 heures, Io fleurs sont marquées au moment où les lobes sont entrouverts.

$$
\begin{aligned}
& \text { lot } n^{0} \text { I : fleurs I à ro marquées le } 15 / 7 / \text { r956 à } 9 \mathrm{~h} \\
& \text { lot } \mathrm{n}^{\circ} 2 \text { : fleurs II à } 20 \text { marquées le I6/7/1956 à } 9 \mathrm{~h} \\
& \text { lot } n^{\circ} 3 \text { : fleurs } 2 \mathrm{I} \text { à } 30 \text { marquées le } \mathrm{I} 7 / 7 / \mathrm{I} 956 \text { à } 9 \mathrm{~h} \\
& \text { lot } n^{\circ} 4 \text { : fleurs } 3 \mathrm{I} \text { à } 40 \text { marquées le } 18 / 7 / 1956 \text { à } 9 \mathrm{~h} \text {. }
\end{aligned}
$$

A ce moment les abeilles ont prélevé le nectar produit avant l'ouverture de la corolle bien mieux que nous ne pourrions le faire nous-même.

Le I7 à 9 heures, la plante est protégée de la visite des abeilles, et celles qui pourraient être restées sur la plante sont soigneusement chassées.

Dans ces conditions, le r 8 juillet à 9 heures, les fleurs des lots I, 2 et 3 contiendront le nectar sécrété pendant la même période de 24 heures c'est-à-dire du 17 à 9 heures au I 8 à 9 heures, et celles du lot no 4 marquées de la même façon le $\mathrm{I} S$ à 9 heures contiendront le nectar sécrété pendant une période indéterminée précédant l'ouverture des corolles.

\begin{tabular}{|c|c|c|c|c|}
\hline \multicolumn{2}{|c|}{ Au moment du prélèvement } & \multicolumn{2}{|c|}{ Nectar } & \multirow{2}{*}{$\begin{array}{l}\text { I'oids du sucre } \\
\text { en meg pour ra } \\
\text { la journée }\end{array}$} \\
\hline Age des fleurs (en heures) & État des corolles & Poids en mg & $\begin{array}{c}\text { Concent ration } \\
\text { enl }\end{array}$ & \\
\hline & Les iuste ou & (n) & $\cdots$ & $-\quad, \cdots$ \\
\hline $\begin{array}{l}0 \text { (fleurs } 31 \text { a } 10) . . \\
24 \text { (fleurs } 21 \text { it } 30) . .\end{array}$ & $\begin{array}{l}\text { Lobes juste ouverts } \\
\text { Fleurs ćpanouies }\end{array}$ & $1,0,3$ & (1) & $\begin{array}{l}4,610 \\
(i, 15\end{array}$ \\
\hline 48 (fleurs 11 a 20$)$. . & Fleurs fanćes & 8,8 & $: 11,5$ & 2,77 \\
\hline \multirow[t]{2}{*}{72 (fleurs 1 à 10$)$. } & Fleurs fances & 11 & & -- \\
\hline & Totaux : & $: 31,7$ & & $13,5: 2$ \\
\hline
\end{tabular}

\section{TABI,EAU I5}

Production nectarifère pour Io feurs d'àgz différent en 24 heures du 17 juillet $9 \mathrm{~h}$ au 18 juillet $19569 \mathrm{~h}$. Nice Série 84

On remarquera dans ce tableat, en dehors de toute action du climat, puisque la sécrétion porte sur la même période de 24 heures:

a) que la concentration du nectar en sucre diminue avec l'âge des fleurs, 
b) que ce sont les fleurs âgées de 24 heures au moment du prélèvement qui ont produit le plus de nectar.

c) qu'au moment de l'ouverture de la corolle, la sécrétion nectarifère de la fleur a déjà commencé depuis un certain temps,

d) qu'en même temps que survient le flétrissement des corolles provoqué par 1a pollinisation, la sécrétion nectarifère s'interrompt, alors que chez les fleurs non pollinisées la sécrétion nectarifère se poursuit encore pendant 6 à 7 jours mais avec un nectar de moins en moins riche.

Cet arrêt de sécrétion sous l'action du butinage des abeilles est dîu, chez la lavande vraie, à la germination du pollen et à la formation d'hormones dans le stigmate et le style, hormones dont la présence détermine la fin de la période éphémère de la floraison et la fin de ce gaspillage de matière sucrée qu'est la sécrétion nectarifère.

Chez le lavandin, les mêmes phénomènes sont constatés; ils ne peuvent toutefois pas être provoqués par le pollen puisque celui-ci est réduit à ses enveloppes. Or 1'abeille, pour constituer les pelotes de pollen, ajoute à ce dernier une importante quantité de nectar ou de miel dilué, et aussi d'autres produits provenant de sécrétions des glandes salivaires qui tuent le pollen et assurent sa conservation dans la ruche.

Des travaux actuellement en cours prouvent que ce sont ces sécrétions de l'abeille qui provoquent chez le lavandin la mort de la fleur et l'arrêt de la sécrétion. nectarifère. Nous avons remarqué en effet qu'une fleur butinée par les abeilles produit en moyenne I mg de stucre environ; par contre la même fleur, si elle n'est pas butinée, en produit le double.

Pour la plante cet arrêt de la sécrétion nectarifère correspond à une économie importante de sucre, sucre qui pourra être utilisé à la formation des essences (BARBIER, Ig62).

2) LE NICTAR RÉCOLTÉ PAR LES ABEIIIEAS

\section{a) Prélèvement du nectar}

La technique utilisée ici est inspirée de celle décrite par HAMmer (I953). Itlle est utilisée en plein champ et consiste à capturer à divers moments de la journée 5 o11 Io abeilles butinant les fleurs.

Il n'est naturellement pas possible d'installer une balance de précision en plein champ ni de peser le nectar contenu dans le jabot, mais il est facile en arrachant la tête, d'entraîner le jabot et de prélever avec la pointe d'une ampoule le nectar qu'il contient, puis d'en déterminer la richesse en sucre comme indiqué précédemment.

Cette technique a été utilisée à Nice et dans les Basses-Alpes, avec des abeilles butinant respectivement les lavandins "Super $Z$ " et "Grande Blete ". On trouvera à la figure $\mathrm{n}^{0}$ I3 les variations enregistrées dans les Basses-Alpes du I9 au 20 juillet 1956 .

\section{b) Observations sur la richesse en matière sèche}

On remarquera entre le Ig à 20 heures et le 20 au matin, et malgré une grande différence des conditions météorologiques (ht1midité relative, température et pouvoir évaporant de l'air), le peu de changement relevé dans la concentration du nectar 


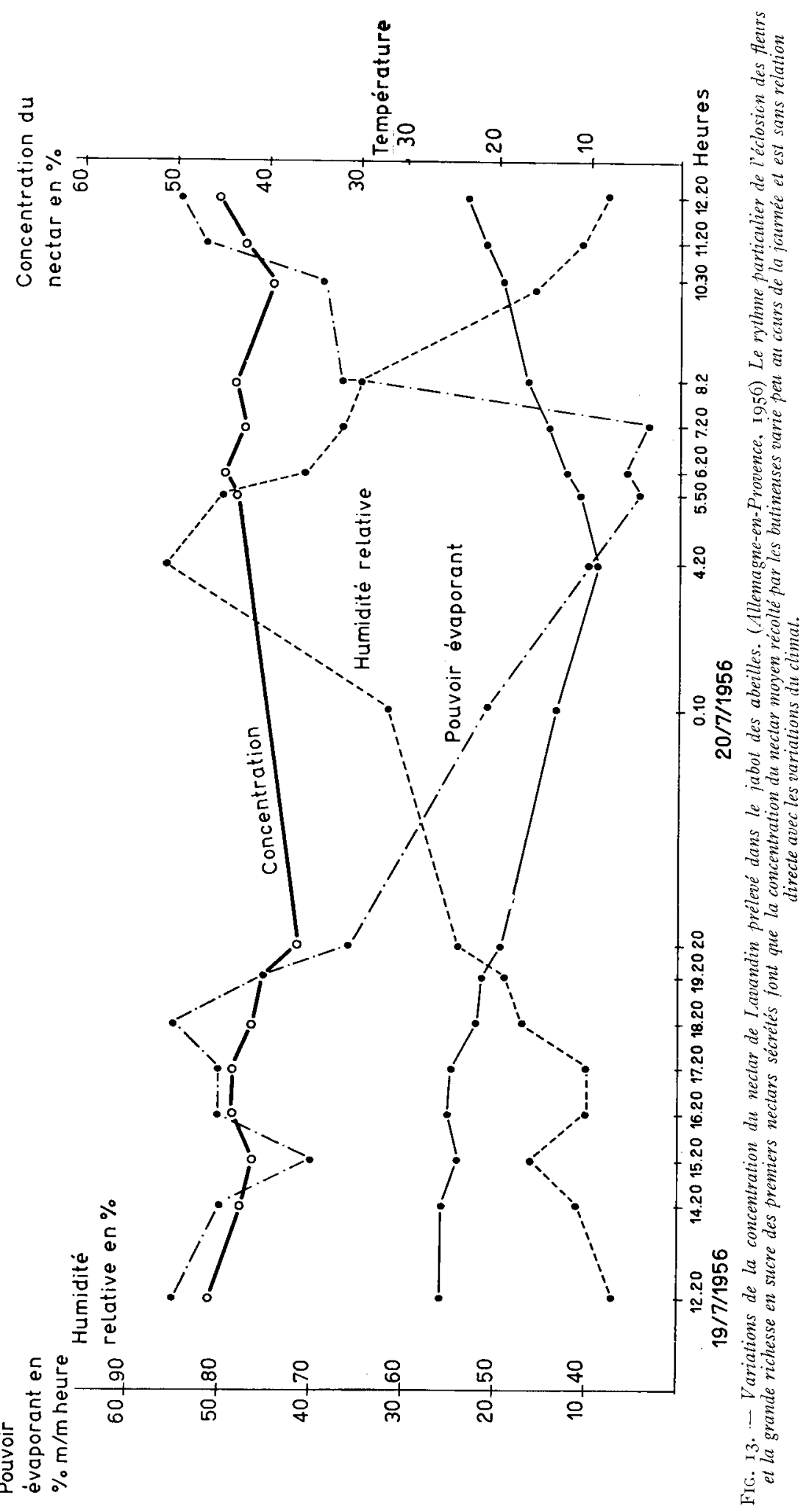


$(36,5$ contre $43,4 \mathrm{p}$. I00). Ce changement se produit d'ailleurs à l'inverse de ce qu'il devrait être car à humidité élevée devrait correspondre une concentration en sucre plus basse. Ce phénomène s'explique facilement. Nous avons vu que l'épanouissement des fleurs se produit principalement le matin (voir tableau Io) et que les fleurs en s'ouvrant contiennent un nectar plus concentré que celui qui sera sécrété par la suite (tableau I6). Les abeilles récoltent forcément un nectar moyen dans lequel la proportion de nectar provenant des jeunes fleurs sera très importante; c'est ce qui explique la forte concentration du nectar récolté le matin.

Par la suite, l'éclosion des jeunes fleurs devenant moins importante, le nectar récolté contient proportionnellement une plus grande quantité de nectar de fleurs plus âgées dont la concentration est moins élevée. Il en résulte que le nectar moyen récolté par les abeilles sera moins concentré ou d'une richesse en sucre peu différente, sans relation apparente avec les modifications des conditions météorologiques.

D’autres relevés effectués entre II et Ig heures au cours d'autres journées, soit dans les Basses-Alpes soit à Nice, nous ont constamment donné les mêmes faibles variations de concentration qui viennent d'être signalées. Mais selon les conditions météorologiques de ces journées, le niveau où évoluent ces variations est très différent. C'est ainsi que nous avons relevé les concentrations suivantes en comparaison desquelles nous avons porté l'humidité relative de l'air, sans pour cela considérer que la concentration du nectar soit en relation directe avec l'humidité de 1'air, cette humidité n'étant qu'un élément du climat.

TABL,EAU I6

\begin{tabular}{|c|c|c|}
\hline & Concentration du nectar & IIumidité relative de l'air \\
\hline Nice $11 / 7 / 1956 \ldots \ldots \ldots \ldots \ldots \ldots \ldots$ & 28 à $34 \%$ & 55 à $60 \%$ \\
\hline Basses-Alpes $12 / 7 / 56 \ldots \ldots \ldots \ldots \ldots \ldots$ & $37 \dot{\mathbf{a}} \mathbf{1} 2 \%$ & 35 à $40 \%$ \\
\hline 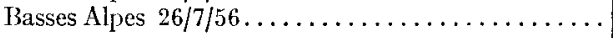 & $t_{\mathrm{r}} 9$ à $56 \%$ & $23 \mathrm{a} 30 \%$ \\
\hline
\end{tabular}

\section{3) Composition CHIMIQUE DES NECTARS}

Afin de définir la nature des sucres présents dans les nectars de lavandin, nous avons fait appel à deux méthodes d'analyse.

TABIEAU I7

Composition chimique de deux nectars de lavandin "Super $Z$ "(Nice 22 juillet 1955)

\begin{tabular}{|c|c|c|}
\hline & $\begin{array}{c}\text { Nectar du jour } \\
\text { récolté dans les jeunes fleurs }\end{array}$ & $\begin{array}{l}\text { Nectar plus ancien } \\
\text { récolté dans les fleurs âgées }\end{array}$ \\
\hline $\begin{array}{l}\text { Milligrammes de nectar } \ldots \ldots \ldots \ldots \ldots \ldots \ldots \ldots \ldots \ldots \\
\% \text { de matière sèche } \ldots \ldots \ldots \ldots \ldots \ldots \ldots \ldots\end{array}$ & $\begin{array}{l}83 \\
59,5\end{array}$ & $\begin{array}{l}325 \\
55,5\end{array}$ \\
\hline $\begin{array}{l}\% \text { de glucose } \ldots \ldots \ldots \ldots \ldots \ldots \ldots \ldots \ldots \ldots \ldots \ldots \ldots \\
\% \text { de lévulose } \ldots \ldots \ldots \ldots \ldots \ldots \ldots \ldots \ldots \\
\% \text { de saccharose (ou sucres non réducteurs) } \ldots \ldots \ldots \ldots\end{array}$ & $\begin{array}{l}18 \\
24,7 \\
57,2\end{array}$ & $\begin{array}{l}17,5 \\
27,1 \\
54,1\end{array}$ \\
\hline
\end{tabular}

Annales de l'Abeille. $\rightarrow$ I963. 


\section{a) Méthode chimique}

Plusieurs échantillons de nectar ont été prélevés à la pipette dans des fleurs protégées de la visite des abeilles. Ces nectars analysés par la microméthode de BERTRAND donnèrent les résultats suivants :

D'autres analyses faites sur des quantités plus faibles donnèrent des résultats qui confirmèrent la grande richesse en saccharose de ces nectars, richesse déjà signalée par BoNNIER (I878).

\section{b) Méthode chromatographique}

Madrizio (I959) a examiné par chromatographie le nectar de lavande vraie et a obtenu, pour un nectar frais prélevé dans les fleurs, la composition suivante (sucres principaux seulement) :

$$
\begin{aligned}
& \text { Lévulose......... 24,2 p. } 100 \\
& \text { Glucose......... I7,0 p. IOO } \\
& \text { Saccharose........ 58, 5 } \quad \text { Ioo. }
\end{aligned}
$$

On notera ici encore la proportion élevée du saccharose et la concordance des méthodes utilisées.

Malheureusement l'analyse des nectars par les méthodes chimiques nécessite des quantités assez importantes de sucres à doser et ainsi, ne permet pas de suivre la composition du nectar avec assez de précision. Aussi, dès I956, avons-nous entrepris la mise en application de l'analyse des nectars par chromatographie de partage, après une visite faite au Laboratoire de Liebefeld (Suisse) où Mlle MaURizro appliquait la méthode préconisée par DEDONDER (I952).

Sur onze nectars frais de lavandin récoltés à la pipette, dix ne contiennent que saccharose, glucose et lévulose. Seul le nectar prélevé dans les fleurs au moment de l'ouverture de la corolle contient des traces de raffinose, de mélézitose et d'un sucre voisin du maltose (fleurs 3 I à 40 du tableau I5 $_{5}$ ), alors que ces sucres ont une certaine importance dans le nectar de lavande (Maurizio, I959).

On retrouve également ces trois derniers sucres dans les nectars récoltés à la pipette 24 heures après 1'ouverture des corolles et comprenant, outre la sécrétion de ces 24 heures, celle qui existait avant l'ouverture des corolles.

\section{c) Modifications du nectar dans le jabot de l'abeille}

Les 27 nectars récoltés dans le jabot des abeilles butinant les variétés de lavandin, "Super $Z$ " ou "Grande Bleue " contiennent en quantité notable du raffinose, du mélézitose et un sucre voisin du maltose.

En mëme temps la tache de saccharose est sensiblement moins importante que lorsque le chromatogramme est fait avec le nectar prélevé à la pipette et où les sucres plus complexes n'existent pas. De même, le glucose et le lévulose paraissent plus abondants.

Cette dégradation du saccharose en glucose et lévulose dans le jabot, signalée par OER'TEL (I95I), est due incontestablement à l'action des enzymes produites par les glandes pharyngiennes de 1'abeille (Maurizio, I957 $a$, I957 $b$, I959). 
Quoi qu'il en soit on remarquera que ces enzymes agissent avec une extrême rapidité mais, que malgré leur activité, elles laissent subsister, dans le nectar contenu dans le jabot, une importante quantité de saccharose.

On remarquera encore la différence importante de composition qui existe entre les nectars de lavande et de lavandin.

\section{B. - Les miels de lavandin et leur caractérisation}

Ces miels sont d'excellente qualité, de couleur claire et à cristallisation fine ; leur parfum et leur goût en font en outre des miels très recherchés. Ils sont le plus souvent improprement appelés miels de lavande, mais ils se caractérisent à l'analyse par des particularités qui vont être examinées.

\section{I - RICHESSE EN POLLENS ET SPECTRE POLIINIQUE}

Nos connaissances sur la production nectarifère et pollénifère des lavandins, expliquent pourquoi les miels récoltés sur ces plantes sont nécessairement très pauvres en pollen et pourquoi dans leur spectre les pollens secondaires prennent une place importante.

Pour des miels très purs récoltés uniquement sur lavandin et extraits des cellules à la pipette, on trouve entre 800 et I 200 grains de pollen pout Io grammes de miel, et dans le spectre pollinique le lavandin dépasse rarement 22 à $30 \mathrm{p}$. Ioo.

Cette faible proportion des pollens de lavandin est due aux pollutions du nectar, qui se produisent dans la ruche, aux apports de pollens pour l'alimentation du couvain (LoUvEAUX, I958) et à l'utilisation du pollen mis en réserve dans les cadres (MAURIZIO, I952).

Pour les miels extraits selon les procédés classiques, les causes de pollution sont plus grandes et ils contiennent de 2500 à 3000 grains et jusqu'à $6000-8000$ grains pour Io grammes de miel. En même temps la proportion de pollen de lavandin dans le spectre est le plus souvent comprise entre ro et $\mathbf{I}_{5} \mathrm{p}$. roo et tombe parfois jusqu'à 5 p. Ioo.

Mais il arrive aussi qu'au moment de l'extraction, certains cadres contiennent, en plus du miel de lavandin, du miel récolté aux diverses étapes de transhumance. Le miel ainsi obtenu sera un mélange dont les caractéristiques et notamment la composition pollinique, seront plus ou moins modifiées selon la nature du miel récolté auparavant.

Dans ce cas, la richesse pollinique peut atteindre jusqu'à I5 ooo grains de pollen et le taux de pollen de lavande tomber à I p. Ioo. C'est aussi ce qui peut se produire dans le cas où le pollen en réserve dans les cellules est libéré par suite d'une désoperculation mal faite.

Quoi qu'il en soit, les miels de lavandin se caractérisent par une grande pauvreté en pollen et, dans leur spectre pollinique, par la présence des pollens de lavandin (LOUVEAUX, I954) dont l'identification est assez facile - (voir planches V et VI) ainsi que par les pollens d'un grand nombre d'espèces végétales constituant un véritable échantillonnage de la flore butinée en même temps que le lavandin, ou butinée au cours des différentes étapes de la transhumance printanière.

Parmi ces plantes on doit citer les espèces suivantes :

Annalas de l'Abeille. 
Dans la zone de lavandin. - Lavandin - Lavandula vera D. C. et formes "fertiles» de pollen de lavandin - Lavandula latifolia VILI. - Brachypodium phonicoïdes $\mathrm{R}$ et S - Plantago sp. - Echninops Ritro L. et E. sphaerocephalus I. - Allium sphaerocephalum L. - Thesium divaricatum JAN - Centaurea sp. (pollen du type $C$. aspera L.) et parmi les plantes cultivées Zea mays I. —Daucus carota L. - Il conviendra aussi de rechercher Medicago sativa $\mathrm{L}$. dont la culture tend à se développer.

b) Dans la zone côtière. - (Maures - Estérel) Erica arborea L. - Cistus salviaefolius I. et C. monspeliensis L. - Acacia dealbata Link et rarement Acacia Farnesiana - Eucalyptus globulus Link. - Lavandula stoechas L. - Castanea vulgaris Lam. Rosmarimus officinalis $\mathrm{L}$.

c) Dans la zone sub-littorale. - (en retrait de la zone précédente, zone de culture) Diplotaxis erucoides D. C. - Paliurus australis GAERTN - Rosmarinus officinalis L. - Dorycnium suffruticosum VIL.L. - Thymus vulgaris I. - Olea europaea L. Cistus albidus L. - Onobrychis sativa $\mathrm{L} \mathrm{MK}$.

d) Dans la zone préalpine. - (altitude moyenne de 800 à I ooo mètres environ) : Trifolium repens $\mathrm{L}_{1}$. et $T$. pratense $\mathrm{I}_{1}$. - Onobrychis sativa $\mathrm{L}_{\mathrm{MK}}$ et plantes de prairies - Epilobium spicatum LAM. et, ce qui est remarquable, Myosotis alpestris $\mathrm{scH}$.

D'autres pollens se retrouvent régulièrement dans les miels de lavandin. LouvEAUX a signalé ainsi Papaver Raeas L.

\section{2 - COULEUR}

Les miels de lavandin à l'état pur sont de couleur très claire (BARBIER et PANGAUD, I96I). Cette couleur est égale à celle d'une solution d'iode à la concentration $\mathrm{N} / 2000$ (ou 63,5 mg d'iode par litre) et peut être classée dans la catégorie Blanc III ; de plus ces miels sont très limpides (trouble $n^{\circ}$ I) (BARBIER et VAIIN, I957).

Bien entendu la présence de miels plus foncés provenant des zones de transhumance de printemps modifie plus ou moins cette couleur.

\section{3 - PeNTE DE LA COURBE DE NEUTRALISATION DES ACIDES LIBRES}

Pour les miels de lavandin très purs, la pente de cette courbe se situe entre I,9 et 2,0 (BARBIER et PANGAUD, I96I). Ici encore et à un degré plus grand que pour la couleur, la présence de miels différents modifie cette valeur. Mais c'est la présence d'un miellat récolté parfois sur les chênes qui perturbe le plus profondément la pente de neutralisation des acides des miels récoltés sur le lavandin.

\section{4 - Composition chimique}

MaURizio (I957 $a$, I957 $b$, I959) a montré les profondes modifications subies par les sucres du nectar sous l'influence des enzymes sécrétées par l'abeille.

Toutefois ces modifications, dans une ruche normalement constituée, sont activées considérablement par les nombreuses reprises que les abeilles font subir au nectar et où, chaque fois, une nouvelle quantité d'enzymes est ajoutée. 
Dans le cas d'une miellée abondante d'un nectar riche en saccharose, l'apport de saccharose est si important que les abeilles n'ont pas la possibilité de reprendre aussi souvent qu'il serait nécessaire le nectar et que celui-ci reçoit une quantité insuffisante d'enzymes.

Il en résulte que le saccharose ne sera pas entièrement transformé en glucose et lévulose, et que les miels provenant de ces nectars riches en saccharose seront également riches en saccharose.

\section{5 - Teneur EN EAU DU MieL,}

La dépopulation des ruches pendant la miellée rend plus difficile la concentration du nectar de lavandin qui contient d'après nos relevés de 44 à 72 p. Ioo d'eau. Aussi arrive-t-il trop souvent que les miels de lavandin soient d'une conservation difficile. Ils entrent parfois en fermentation dans les cellules operculées elles-mêmes ou le plus souvent au moment de la cristallisation. 


\section{PROBLÈMES POSÉS PAR LE BUTINAGE DES ABEILLES SUR LES LAVANDES ET LAVANDINS}

\section{A. - Les abeilles et la production des essences}

Rappelons que nos recherches ont été provoquées par un différent qui s'était élevé entre lavandiculteurs et apiculteurs. Elles ont été conduites en toute indépendance et les résultats obtenus, publiés en toute objectivité (BARBIER, I962).

Dans l'esprit des agriculteurs qui constataient dans leurs cultures des diminutions de production, celles-ci étaient dues aux abeilles. Des pertes de 7 à Io p. Ioo étaient avancées et, la surenchère aidant, on citait des pertes de 30 p. I00, sans qu'à notre connaissance ces valeurs aient été obtenues par des expériences régulièrement conduites.

Partant de cette hypothèse, certains agriculteurs voulurent interdire aux apiculteurs transhumants le droit de transporter leurs ruches sur les cultures de lavandin.

Pour les apiculteurs, le fait que le miel récolté sur les lavandes ou les lavandins possède un parfum très différent de celui de l'essence constitue la preuve que les abeilles ne causent aucun dommage à la production d'essence.

Cette remarque sur le parfum du miel est exacte et écarte toute action directe du butinage sur la production des essences.

Toutefois nous avions remarqué aux cours de recherches sur la production nectarifère des lavandins que les corolles des fleurs butinées restaient épanouies pendant deux à trois jours alors que celles des fleurs protégées des abeilles vivaient pendant I I à 13 jours.

Dans ces conditions, le butinage ne pouvait-il pas avoir une action indirecte sur l'accumulation des essences?

Ne pouvant trouver une réponse à cette question des recherches furent entreprises. Si une modification positive ou négative de la production des essences était constatée, n'y avait-il pas là un moyen inattendu d'approfondir nos connaissances sur cet irritant problème de physiologie végétale que constitue la présence et l'origine des essences dans les plantes, ou tout au moins chez les lavandes.

Après de nombreux essais nous pouvons préciser que chez les lavandes comme chez les lavandins les réactions de la plante sont identiques au début de la floraison puis différentes lorsque la pleine floraison est passée. 


\section{I - RÉACTIONS DES LAVANDINS AU BUTINAGE}

En utilisant des cages identiques recouvrant un même nombre de plants de même âge et en plaçant sous une cage une colonie d'abeilles ne pouvant butiner que les fleurs présentes dans la cage, on constate que :

a) aucune différence sensible ne peut être relevée entre les plantes butinées sous cage ou en plein air,

b) le nombre de fleurs épanouies sur les épis à un moment donné est trois à quatre fois plus important sur les plantes non butinées que sur les plantes visitées par les abeilles,

c) les rendements en essence, obtenus par des distillations effectuées en pleine floraison ou plus tardivement sur deux "variété ) de lavandin ("Super Z " et "Grande Bleue »), sont toujours plus élevés chez les plantes butinées. Cette différence atteint I6 à 20 p. Ioo par rapport aux rendements obtenus avec les plantes non butinées,

d) les caractéristiques des essences ainsi obtenues n'ont pas été déterminées, sauf en ce qui concerne 1'indice de réfraction pour lequel aucune différence sensible n'a été constatée.

\section{2 - RÉACtions D'UNE LAVANDE VRAIE AU BUTINAGE}

Avec une lavande vraie, la "Matheronne », des essais similaires ont été réalisés en I959, mais nous avons voulu suivre de semaine en semaine les réactions de la plante ats butinage.

Aussi, chaque semaine, trois lots étaient récoltés, pesés et distillés dans des conditions rigoureusement identiques. Le dépouillement des résultats indique que les conséquences du butinage sont les suivantes :

a) comme pour les lavandins, aucune différence sensible ne peut être relevée entre les lavandes butinées en plein air ou sous cage,

b) comme pour les lavandins, on note trois à quatre fois plus de corolles épanouies sur les plantes non butinées, que sur les plantes butinées,

c) les plantes non butinées ne produisent aucune graine, alors que chez celles qui le sont le poids des graines atteint au maximum ro p. Ioo du poids des hampes sèches,

d) rendements en essence - au début de la floraison les augmentations de rendements sont identiques.

Chez les plantes non butinées, à partir du moment où la floraison atteint son maximum, la courbe de rendement s'infléchit; elle progresse lentement jusqu'à la fin de la floraison jusque vers $4 \mathrm{p}$. Ioo du poids des calices seuls, puis se maintient à cette valeur.

Chez les plantes butinées par contre, la courbe des rendements progresse régulièrement jusque vers $4 \mathrm{p}$. Ioo, puis plus lentement jusqu'à $4,3 \mathrm{p}$. Ioo, alors qu'à ce moment les rendements des plantes non butinées atteignent seulement $4 \mathrm{p}$. Ioo.

Un peu avant la fin de la floraison, la courbe des rendements s'infléchit puis baisse très rapidement en même temps que les graines mûrissent.

Il faut signaler ici que cette chute des rendements s'est produite en I959, année humide, plus tardivement qu'elle ne se produit en année normale. 
e) les caractéristiques des essences évoluent également d'une façon différente selon que les plantes sont butinées ou protégées de la visite des abeilles.

En conséquence le butinage des lavandins par les abeilles est constamment favorable à une augmentation de la production des essences.

Chez les lavandes, par contre, on constate que le butinage des abeilles provoque pendant un certain temps une très nette augmentation des rendements.

Mais en fin de floraison (et plus tôt en année à climatologie normale), les rendements s'écroulent rapidement.

Il faut remarquer ici que pour les lavandes, l'époque à laquelle les praticiens font la récolte correspond à peut près aut moment où les plantes fournissent le maximum d'essence, alors que pour les lavandins le maximum de rendement se situe tout à fait à la fin de la floraison (BARBIER, I958).

En tout état de cause, le butinage des abeilles est loin d'avoir les conséquences qui lui avaient été attribuées puisque les plantes butinées produisent une plus grande quantité d'essence.

\section{B. - Activité des abeilles et densité des ruches}

\section{I ÉVALUATION DE IAA PRODUC'TION MELLIFÈRE D'UN LAVANDIN}

Avant d'aborder les problèmes posés par la présence même des abeilles et des ruches, il convient de rechercher pourquoi les ruches sont si nombreuses au moment de la floraison des lavandins.

Si le midi de la France jouit d'un climat relativement favorable à l'élevage des abeilles et à la constitution des colonies puissantes, il n'y existe que peu de régions favorables à la récolte du miel.

Or les lavandins couvrent, principalement sur le plateau de Valensole, de vastes surfaces faciles d'accès et offrent une floraison qui se situe justement à un moment de disette. C'est la raison pour laquelle de si nombreuses ruches sont transportées chaque année sur la riche miellée du lavandin.

A l'aide de relevés effectués sur le lavandin "Super $Z$ " sous le climat de Nice, on peut évaluer la production moyenne d'une fleur à environ I mg de sucre ou $I$, Io mg de miel (à I $8 \mathrm{p}$. Ioo d'eau) soit environ 300 grammes de miel pour un plant portant 250000 fleurs, sous réserve que la production nectarifère soit constante pendant toute la période de floraison. Dans ces conditions, un hectare de lavandin planté à $2 \mathrm{~m}$ sur I,60 $\mathrm{m}$ pourrait produire 930 kilogrammes de miel.

Mais étant donnée l'extrême variabilité de la sécrétion nectarifère, il semble plus logique d'exprimer la production pour une journée de pleine floraison. Pendant cette période on compte 25000 fleurs sur un plant, mais comme la vie d'une fleur est de 2 jours, la production de I,I mg de miel doit être réduite de moitié, soit une production journalière par plant de $1375^{\circ} \mathrm{mg}$, ou par hectare de près de 42 kilogrammes.

Notons toutefois que ces évaluations de production mellifère ne sauraient être prises à la lettre. Elles n'ont d'autre but que de montrer la grande valeur apicole du lavandin. 
Il ne nous est pas possible, vu la différence des conditions écologiques, d'évaluer la production nectarifère des lavandes, mais il est certain que ces plantes doivent être considérées comme étant de première importance.

\section{INTENSITÉ DU BUTINAGE}

Au cours de nos recherches sur la richesse en sucre du nectar contenu dans le jabot des butineuses (voir figure I3), l'activité des abeilles a été relevée d'heure en heure entre $\mathrm{I} 2 \mathrm{~h}$ et $\mathrm{I} 5 \mathrm{~h}$ du I9 au 20 juillet $\mathbf{I} 95^{6}$ sur le lavandin "Grande Bleue» à Allemagne-en-Provence.

Cette activité est considérable ; on compte couramment une centaine d'abeilles par plant de lavandin et chaque fleur reçoit un nombre de butineuses très important, nombre qui n'est certainement pas inférieur à une centaine à l'heure. Ce rythme se maintient apparemment sans modification jusque tard dans la soirée.

Dans la soirée du I9 juillet, l'activité des butineuses décline rapidement à partir de $x 9$ h 30 environ ; le dernier passage est enregistré à 20 h I5 au coucher du soleil ; la température de $1^{\prime}$ air à ce moment est de $19,2^{\circ}$.

Lans la matinée du 20, le premier passage d'abeilles est noté à $4 \mathrm{~h} 48$. Le soleil se lève à 5 h 32 au-dessus des montagnes bordant les gorges du Verdon, mais déjà à 5 h I 5 les passages d'abeilles sont plus nombreux, encore que nettement isolés les uns des autres. A 5 h 45 les premières butineuses sont observées sur les lavandins. A $5 \mathrm{~h} 50$ le bourdonnement est nettement perceptible. A ce moment la température de $1^{\prime}$ air est de I $^{\circ}$ (voir figure I $_{3}$ ).

Comme on peut s'en rendre compte, l'activité des butineuses sur les lavandins est très grande. Cela est dî, d'une part à la forte sécrétion nectarifère de ces plantes, qui sont pratiquement les seules plantes nectarifères dans l'aire d'activité des abeilles, mais aussi au fait de la forte concentration des ruches sur les zones de culture des lavandins.

Cette concentration est très importante. Elle atteint I ooo à 2000 ruches par kilomètre carré en certains points (DroMARD, I955) et certains apiculteurs n'hésitent pas à utiliser l'avion pour rechercher les emplacements où la densité des ruches est moins forte.

\section{ConcLusion}

Les lavandins présentent pour l'apiculture du midi de la France une très grande valeur par suite de l'importance des surfaces cultivées, de la grande production nectarifère de leurs très nombreuses fleurs, de la qualité du miel récolté sur cette plante, et aussi grâce aux possibilités de la transhumance.

Malheureusement l'absence de valeur alimentaire du pollen produit par les lavandins, et la rareté des pollens produits par d'autres plantes, ont pour conséquence une dépopulation très rapide des ruches, ce qui impose en automne le retour sur de nouvelles floraisons, afin de permettre aux colonies de reconstituer leur population.

Le miel récolté sur les lavandins est de très belle qualité grâce à sa couleur claire, son gồt agréable et sa fine cristallisation.

Ses défauts sont : une certaine variabilité de sa couleur, due le plus souvent aux miels récoltés aux diverses étapes de transhumance, et une teneur en eau souvent trop élevée qui peut provoquer des fermentations. 
Ses particularités sont : une assez grande richesse en saccharose due à la richesse du nectar en ce sucre; une grande pauvreté en pollen, ainsi qu'un taux très faible de pollen de lavandin. Ce taux ne dépasse jamais $30 \mathrm{p}$. Ioo pour un miel très pur, mais dans les miels courants il est le plus souvent voisin de Io à I 5 p. Ioo.

La grande valeur apicole des lavandins et les conditions générales de l'apiculture méridionale, sont favorables à la concentration d'un grand nombre de ruches dans les régions où ces plantes sont cultivées.

Cet état de fait a provoqué dernièrement des difficultés avec les cultivateurs, qui reprochaient aux abeilles d'être responsables d'une certaine diminution des rendements en essence chez les lavandins.

Par une série de travaux, nous avons démontré que ces accusations étaient non seulement sans fondement, mais que bien au contraire les abeilles, en provoquant une mort rapide des fleurs et l'arrêt de la sécrétion nectarifère, provoquaient une augmentation des rendements en essence, permanente chez les lavandins et temporaire seulement chez les lavandes vraies.

Reçu tour publication en juin 1962.

\section{SUMMARY}

LAVENDERS AND APICLLTURE IN THE SOUTII-EAST OF FRANCE

The genus Lavandula is represented in France by three species, Lavandula latifolia VilL., L. vera $\mathrm{D}$. C. and L. stoechas $\mathrm{L}$., and by one hybrid which groups together a series of individuals differing considerably one from another under the name of "Lavandins".

These lavandins are the result of cross-pollination by insects and especially by bees carrying the pollen from $L$. vera to the stigmata of $L$. latifolia.

The pollen of each species can be identified by its distinctive characteristics. In the three species the normal rate of pollen formation varies between 94 and $99 \mathrm{p}$. Ioo, while in the lavandins this amounts to from 2 to I 6 p. Ioo.

The lavandins are closely enough related to $L$. vera, but they have certain clistinguishing anatomical characters : vigorous vegetation and absence of seed. The essential oils produced from the various cultivated types are different from, and more abundant than, those extracted from the true lavenders.

Except that the lavandins have ccrtain differences of vegetation and longer stems, both they and the lavenders follow a very similar course of vegetative development.

The opening of the corollas on the spikes takes place on all the verticils at almost the same time and lasts for over a month in each cultivated "variety".

The daily flowering rhythm of the corollas is influenced by a number of different factors, among which temperature and atmospheric humidity are very important. Rain, taken as an isolated factor, has a definite effect and sunshine also exerts positive action. Blossoming is particularly abundant in the morning time.

A corolla normally sucked by the bees fades in two to two and a half days, the secretion of nectar ceasing at the same time. If it is not visited by the bee, the flower will persist for to to 12 days. In the former case the flower produces on average I $\mathrm{mg}$ of sugar as compared with $2 \mathrm{mg}$ in the latter.

The honey-gathering bees will stimulate a permanent increase in the yield from the lavandins, whereas with the true lavanders this increase is only temporary and is followed by an important drop in the amount of essential oils which can be removed by steam extraction.

Lavandin cultivation dates only from about 1925 , but today it covers larges areas in P'rovence, particularly in the Departments of the Basses-Alpes, Vaucluse and Drôme. It may even have extended into Languedoc.

Although lavandins are very important nectar-bearing plants, their pollen has no nutritive value to bees and is not gathered by them.

The older flowers produce a more concentrated nectar. The nectar contains only three sugars : glucose, laevulose and sucrose.

Sucrose reaches $54 \mathrm{p}$. 100 of the dry matter. 
The concentration of the nectar gathered by the bees varies little during the day because of the blossoming rhythm of the flowers.

Immediately after ingestion by the bee the nectar undergoes radical changes in its crop : the sucrose content drops, the glucose and laevulose fractions rise, while at the same time more complex sugars are formed.

Lavandin honeys are very poor in pollen and in the pollen spectrum which is very dispersed the proportion of lavandin pollen is never greater than $30 \mathrm{p}$. 100 .

Present-day honeys are richer in pollen and the pollen spectrum is even more dispersed owing to the presence of pollens coming from honeys or reserves of pollen gathered from other areas. In these honeys the proportion of lavandin pollen in the pollen spectrum does not rise above to to I 5 p. 1oo, and is often lower.

In consequence of the depopulation of the hives, lavandin honeys often contain too much water and are difficult to preserve at crystallization point. They are, moreover, very high in sucrose.

Honey-gathering by the bees provokes :

a) In the lavandins, a permanent increase in the yield of essential oils. This is in the order of 16 to 20 p. 100 ;

b) In the lavanders, a temporary increase followed by a heavy drop in yield, which phenomenon is linked to the ripening of the seed.

\section{RÉFÉRENCES BIBLIOGRAPHIQUES}

Barbier E. C, 1951. La sécrétion de nectar chez les Eucalyptus. Rev. Fr. Apic., 529-532, 553-559.

Barbier E. C., 1952. Sécrétion de nectar chez les Eucalyptus. (Suite.) Rev. Fr. Apic., no 77 , I39-1 45 .

Barbier E. C., Vallin J., 1957. Détermination de la couleur des miels. Ann. Fals. Fraudes, n ${ }^{\circ} 587 / 8$, 400-4II.

Barbier E. C., Maurel A. I958. Contribution à l'étude de l'essence de lavandin. C. R. Congrès Intern. Chimie Indusir., Liège.

BARbier E. C., I958. Avantages réciproques d'une association naturelle entre le lavandin et l'abeille. C. R. Acad. Agric., 623-628.

Barbier E. C., Pangaud, C. Y., ig6r. Origine botanique et caractéristiques physico-chimiques des miels. Ann. Abeille, 5I-65.

Barbier E. C., I962. Sur quelques facteurs de la productivité quantitative et qualitative des essences chez les lavandes. Thèse Fac. Sci. Paris (sous presse).

Berninger E., ig6o. Note sur quelques aspects de l'hétérosis. Ann. Amelior. Plantes, 345-350.

Bonnier G., 1878. Les Nectaires. Thèse Fac. Sci. Paris.

Van Campo-Duplan, I946. Observations sur l'emploi des graines de pollen en Phylogénie. Bull. Soc. Hist. Nat. Toulouse, 81, art. XII.

Van Campo-Duplan, I957-58. Palynologie africaine. Bull.inst. Fr. Afr. Noire, 1957, 659-78, 1958, $753^{-60 .}$

Chiris Établissements, ig26. Réalisation expérimentale de l'hybride entre l'Aspic et la lavande. Partums de France, no $44,3^{1} 9^{-32} 5$.

CirouaRd P., r958. Remarques sur l'induction de quelques capacités fonctionnelles chez les plantes ì fleurs et sur leur réversibilité. Rev. Path. gen., no 695, 289-295.

Crabalona, Gilli M, 1956. Lavandes et lavandins. Nouvelles de Grasse, nº 2.

Dedonder R., 1952. Chromatographie de partage sur papier des glucides. Bull. Soc. Chim. Fr., 874-884.

Dillemand G., Poucoues M. T., I954. Le pollen de Sorbus latifolia et son origine hybride. Bull. Soc. Bot., 239-240.

Dillemann G., 1954. L'hybridation interspécifique naturelle. Bull. Soc. Bot., 36-87.

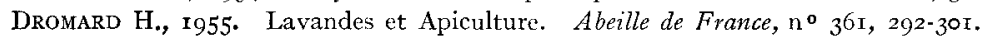

Drouineau G., Guinochet M., I944. Notes sur la végétation et le sol aux environs d'Antibes. Rev. Trav. Instit. Bot. Montpellier, I, 22-40.

FONDARD L., I922. Recherches morphologiques et biologiques sur les lavandes. Thèse Fac. Sci. Marseille.

Fondard L., igz6. Culture de la lavande. Off. Agricole Départ. des Basses-Alpes.

Fondard L., 1948. Culture de la Lavande et du Lavandin. Imp. Manivet et Fils. Marseille.

Fournier P., I946. Les quatre flores de la France. Éditions Lechevalier.

Gagneparn F., rgor. Sur le pollen des hybrides. Bull. Soc. Nat. d'Autin, 2o-29.

Gattefosse R. M., Iamotie, I.., I9I7. Culture et industrie des plantes aromatiques et des plantes médicinales de montagne. Éditions Scientifiques françaises, Paris. 
Gattefosse R. M., 1927. Le lavandin et son essence. Parfumerie Moderne, 192-I95.

Gatrefosse J., 1939. Distribution géographique des lavandes. Parfumerie Moderne, 33, 107-I18.

Giraud L., I927. Contribution à l'étude du lavandin et de son essence. Thèse Fac. Sci. Lyon.

Hammer O., 1953. Observations sur la sécrétion nectarifère chez le Romarin. Rev. Fr. Apic., no 86, 397403.

Humbert, igig. La lavande. Rapport ${ }^{\text {re }}$ mission d'études. Trav. Off. Nat. Mat. prem. vég. Not., no ${ }^{\circ}$.

Igoten G., I944. Contribution à l'étude de la composition chimique de l'essence de lavandin. Thèse Fac. Sci. Marseille.

JAEger P., I959. La vie étrange des fleurs. Editions Horizons de France, Paris.

Lamothe L., 1926. La lavande Aspic et son avenir. Parf. Mod. févr., i 7-19.

Louveaux J.. I954. P'ossibilités de caractérisation des miels de lavandin par l'analyse pollinique. Rapp. VIII ${ }^{\mathrm{e}}$ Congrès Int. Bot., Paris, Sect., 6, 282.

Louveaux J., I958. Recherches sur l'origine dans le miel du pollen de plantes entomophiles dépouivues de nectaires. Ann. Abeille, 89-92.

Louveaux J., I958. Recherches sur la récolte du pollen par les abeilles. (Apis Mellifica L.). Thése Fac. Sci. Paris.

Maire R., 1933. Étude sur la flore du Sahara central. Mem. Soc. Iitst. Nal. Nord, no 3 , Mission du Hoggar II.

Maurel A., I959. Caractères physico-chimique des essences de lavande et lavandin. Journée de la lavande, Nyons, 29-3r.

Maurizio A., 1952. Woher stammen die im IIonig enthaltenen pflanzlichen Bestandteile. Archiv für Bienenkunde, I-I.

Maurizio A., 1957. Breakdown of sugars by inverting enzymes in the pharyngeal glands and midgut of the honeybee. Bee world, 38, 14-I 7 .

MaUrizio A, 1957. Zuckerabbau unter der Einwirkung der invertie renden Fermente in Pharynxfrüse und Mitteldarm der Honigbienne. Insectes sociaux, $225-243$.

Maurizio A., I959. Breakdown of sugars by inverting enzymes in the pharyngeal glands and mitgut of the honeybee. Bee World, 40, 275-283.

Mavrizio A., 1959. Papierchromatographische untersuchungen en blütenhonigen und nektar. Annales Abeille, 4, 29I-34I.

Naves Y. R., 1958. Sur les distinctions analytiques entre essence de lavande et de lavandin. $C . R$. Acal. Sci., 9 avril.

OERTEL E., 195r. Inversion of cane sugar in the honey stomach of the bee. J. écon. Ent, 44, 487-492.

Paulet M., I96r. La garrigue et ses essences. La France et ses parlums, i68-174.

Rovestr P., 1955. Recherches sur l'origine et les variations des huiles essentielles dans les plantes. Parfumerie Moderne, $\mathrm{n}^{\circ}$ 45, 6I-72.

T. B. Dr., I926. La lavande dans l'antiquité. Parfumerie Moderne, I67-r68.

Wagenitz, 1955. Pollinmorphologie und Systematik in der Gattung. Centaurea Flora Jena, Bd I42, 2 I 3-279. 